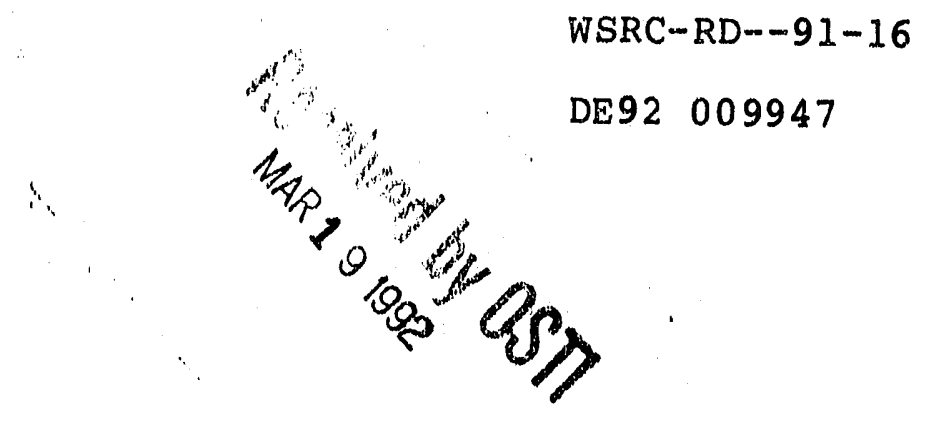

\title{
GAMMA-RAY SPECTROMETRY OF LDEF SAMPLES (U)
}

by

W. G. Winn

Westinghouse Savannah River Comrany

Savannah River Laboratory

Aiken, South Carolina 29808

\section{DISCLAIMER}

This is a DP Report

\begin{abstract}
This report was prepared as an account of work sponsored by an agency of the United States Government. Neither the United States Government nor any agency thereof, nor any of their employees, makes any warranty, express or implied, or assumes any legal liability or responsibility for the accuracy, completeness, or usefulness of any information, apparatus, product, or process disclosed, or represents that its use would not infringe privately owned rights. Reference herein to any specific commercial product, process, or service by trade name, trademark, manufacturer, or otherwise does not necessarily constitute or imply its endorsement, recommendation, or favoring by the United States Government or any agency thereof. The views and opinions of authors expressed herein do not necessarily state or reflect those of the United States Government or any agency thereof.
\end{abstract}

This paper was prepared in connection with work done under Contract No. DE-AC09-89SR18035 with the U.S. Department of Energy. By acceptance of this paper, the publisher and/or recipient acknowledges the U.S. Government's right to retain a nonexclusive, royalty-free license in and to any copyright covering this paper, along with the right to reproduce and to authorize others to reproduce all or part of the copyrighted paper. 


\author{
Willard G. Winn \\ Westinghouse savannah River Company \\ Savannah River site \\ Aiken, SC 29808
}

\begin{abstract}
SUMMARY
In January 1990, NASA retrieved the Long Duration Exposure Facility (LDEF), which had orbited the Earth since April 1984. The satellite had become slightly radioactive due to cosmic exposure, and NASA sought out low-level radiometric laboratories to provide ultra-sensitive analyses of samples from LDEF. The SRI Environmental Technology Radiometrics Group was selected by NASA as such a laboratory, and it received and analyzed LDEF samples during 1990 and early 1991.

A total of 31 samples from LDEF, including materials of aluminum, vanadium, and-steel trunnions were analyzed by ultralow-level gamma spectrometry, The study quantified particle induced activations of ${ }^{22} \mathrm{Na},{ }^{46} \mathrm{Sc},{ }^{51} \mathrm{Cr},{ }^{54} \mathrm{Mn},{ }^{56} \mathrm{Co},{ }^{57} \mathrm{Co},{ }^{58} \mathrm{Co}$, and ${ }^{60} \mathrm{Co}$. The samples of trunnion sections exhibited increasing activity toward the outer end of the trunnion and decreasing activity toward its radial center. The trunnion sections did not include end pieces, which have been reported to collect noticeable ${ }^{7} \mathrm{Be}$ on their leading surfaces. No significant ${ }^{7} \mathrm{Be}$ was detected in the samples analyzed.

The SRL Underground counting Facility was used in this work. The facility is $50 \mathrm{ft}$ underground, constructed with lowbackground shielding materials, and operated as a clean room. The most sensitive analyses were performed with a $90 \%$-efficient $\mathrm{HPGe}$ gamma-ray detector, which is enclosed in a purged active/passive shield. Each sample was counted for 1-6 days in two orientations to yield more representative average activities for the sample. The non-standard geometries of the IDEF samples prompted the development of a novel calibaration method, whereby the efficiency about the sample surfaces (measured with point sources) predicted the efficiency for the bulk sample.

The information contained in this article was developed during the course of work under Contract No. DE-AC09-89SR18035 with the U.S. Department of Energy.
\end{abstract}


SUMMARY $\ldots \ldots \ldots \ldots \ldots \ldots \ldots \ldots \ldots \ldots \ldots \ldots \ldots \ldots \ldots \ldots \ldots$

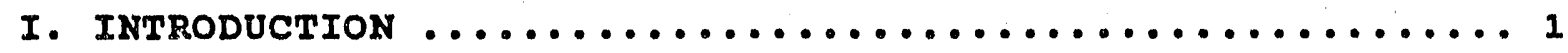

II. MEAGUREMENTS $\ldots \ldots \ldots \ldots \ldots \ldots \ldots \ldots \ldots \ldots \ldots \ldots \ldots \ldots \ldots \ldots$

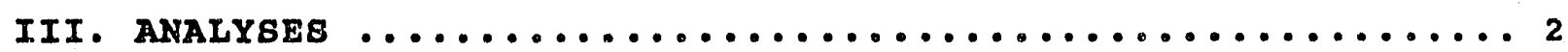

HPGe spectral Analyses ..................... 2

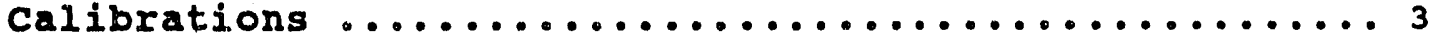

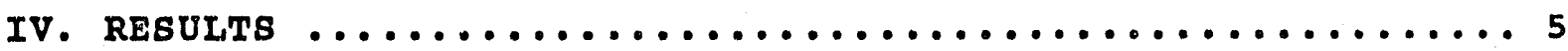

v. DIscUssion $\ldots \ldots \ldots \ldots \ldots \ldots \ldots \ldots \ldots \ldots \ldots \ldots \ldots \ldots \ldots \ldots \ldots \ldots \ldots$

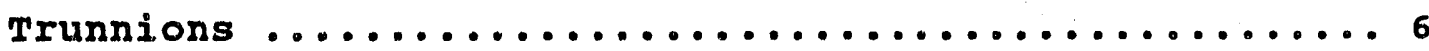

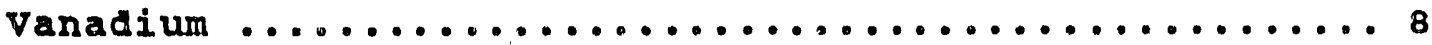

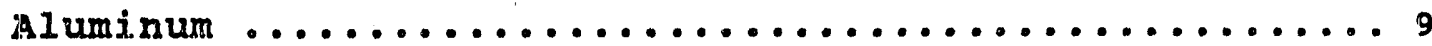

ACIRNOWLEDGEMENTS $\ldots \ldots \ldots \ldots \ldots \ldots \ldots \ldots \ldots \ldots \ldots \ldots \ldots$

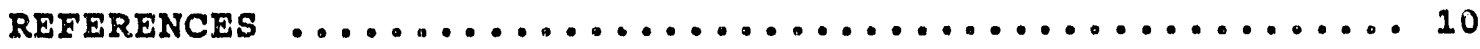

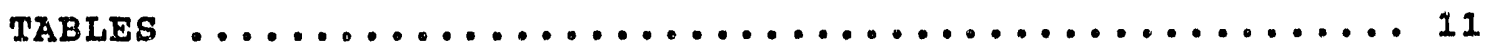

1. Trunnion Disk Results ................ 11

2. Trunnion Layer Results ............... 12

3. Vanadium and Aluminum Sample Results ........ 13

4. Cosmic Pay Interactions ................ 14 
TABLE OF con'TENTS (continued)

FIGURES $\ldots \ldots \ldots \ldots \ldots \ldots \ldots \ldots \ldots \ldots \ldots \ldots \ldots \ldots \ldots \ldots \ldots \ldots \ldots$

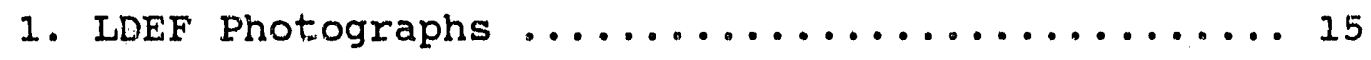

2. Background spectrum ................... 16

3. Active Shield Effects ................... 17

4. Typical spectrum Analyzed by GRABGAM ....... 18

5. Efficiency Calibration ..................... 19

6. LDEF Sample Location Scheme ............ 20

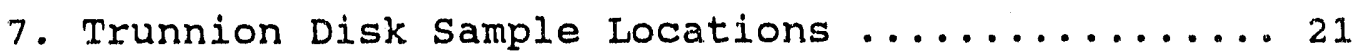

8. Trunnion Axial Dependence ............. 22

9. Trunnion Layer Locations $\ldots \ldots \ldots \ldots \ldots . \ldots \ldots$

10. Trunnion Radial Dependence .............. 24

11. Aluminum Sample Locations ................. 25

12. Average Radial profiles ............... 26

A.PRENDICIES .............................

A. Background spectrum Identifications ........ A-1

B. Detector Efficiency Calibrations ........... B-1

C. Sample Details ...................... C-1 


\section{INTRODUCTION}

The Long Duration Exposure Facility (LDEF) was placed in orbit about 250 miles above the Earth by the Challenger space shuttle in April of 1984. As implied by its name, the LDEF was geared to study long-term radiation effects in the near-Earth space'. The results would be useful in the design of a future orbital space station. NASA had originally planned to retrieve the LDEF within a year; however, major obstacles, particularly those due to the Challenger disaster in 1986, delayed retrieval until January of 1990. Following this retrieval by the columbia space shuttle, the LDEF was transported to Kennedy space center at Cape Canaveral, Florida. Photographs describing the sequence of these events are given in Figure 1.

Personnel at NASA Marshall space Center initiated a program for radiometric analysis of the LDEF samples? Due to extensive experience in ultra-low level counting of environmemtal samples at the SRL Underground counting Facility, NASA selected it as one of the laboratories for LDEF analyses. SRI received its first LDEF samples on March 7, 1990, and a total of 68 gamma spectrometry analyses were conducted on 31 samples submitted during 1990-1991. Round-robin gamma analyes of these and/or similar samples were conducted at PNL, INL, LBL, LLL, ORNL, TVA, and at NASA facilities in Houston, Texas and Huntsville, Alabama. To date, the SRS results have compared favorably with those reported at the other laboratories.

This report emphasizes the measurements of the induced radioactivity in the IDEF samples submitted to sRS. These results will be used to appraise and improye models for characterizing trapped particles and cosmic rays ${ }^{2-4}$; however, this is beyond the scope of the present report. Yet, the report does identify particle reactions for producing the observed radionuclides, and examines trends within the data. A special emphasis is also given to the methods used to develop efficiencies for these somewhat unorthodox samples.

\section{MEASUREMENTS}

The SRL Underground counting Facility ${ }^{5}$ was used to conduct gamma spectrometry on the LDEF samples. This facility is $50 \mathrm{ft}$ below ground and constructed with low-background materials. PreWWII steel comprises the 4 in walls of the counting chamber, which is shielded by 4-7 ft of specular hemitite. The total 
overburden is equivalent to $104 \mathrm{ft}$ of water shielding, which reduces the cosmic background by an order of magnitude. The facility operates as a class 10,000 clean room, whereby airborne particulates are removed by filtering. The very stable spectrometry electronics use an uninterruptable power suppy to protect against data losses during extended counting times.

HPGe detectors with standard efficiencies of $20 \%, 25 \%$, and $90 \%$ were used in this study. A low-level lead shield encloses each detector and its sample cavity, which is purged of radon with the nitrogen that evaporates from its $\mathrm{LN}_{2}$ dewar. The $90 \%$ HPGe has an inner shield of cadmium and copper to reduce $x$-ray backgrounds induced in the shielding by gammas from the sample. Figure 2 gives a typical background spectrum for this detector, as applicable in most of the present study. The background peaks are discussed further in Appendix $A$. Near the end of the study, the detector background was further reduced with an active plastic-scintillator shield, which detects cosmic background events in anticoincidence with the gamma counting to veto this background. Figure 3 gives a schematic of the $90 \%$ HPGe and iliustrates the performance of the active shield in reducing the cosmic continuum. In the present study, which used 1-6 day counting intervals, estimated detection limits ${ }^{6}$ for a ${ }^{60} \mathrm{Co}$ point source atop these detectors ranged from 0.04 to $0.4 \mathrm{pci}$.

A total of 31 LDEF samples were examined by HPGe gamma spectrometry. The samples were trunnion disks and rectangular slabs of steel, vanadium, and aluminum. The disks had 3.25 in diameter and 0.4-0.9 in thickness; the slabs had maximum dimensions of $2 \times 2 i^{2}$ area and 0.35 in thickness. Some of the slab samples were from radial layers of the trunnion disks. Detailed sample descriptions are given in Appendix C. Each sample was counted with one side facing the detector and then recounted with its other side facing the detector, so that activity distributions within the sample could be detected and averaged.

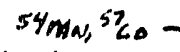

Detector efficiency calibration for the above samples used a method of mapping the point source efficiency over the sample surfaces. Point sources of ${ }^{60} \mathrm{Co},{ }^{133} \mathrm{Ba}$, and ${ }^{137} \mathrm{Cs}$ were used. A paper mapping grid was developed for sample and source positioning. Such a non-destructive calibration technique was important in this work, because NASA required that the samples be returned intact for round-robin analyses at other laboratories.

\section{ANALYSES}

\section{HPGe spectral Analyses}

The HPGe data were collected as 4000 channel gamma spectra, as illustrated in Figure 4. All spectra were in the form of ADCAM files, as developed by EG\&G ORTEC. The GRABGAM codes, which was 
developed at SRL for low-level counting, analyzed the spectra. This code uses three area trapping windows to identify prospective peaks. The narrowest window makes the first scan, so that any significant multiplet features can be identified. The middle window scans next. Finally, the largest window provides the best sensitivity for picking out peaks with low counting statistics. These candidate peaks are examined as integral probability functions $F(x)$ per channel $x$, to provide better statistics than afforded by fitting the peak to a differential. probability $f(x) d x$; such enhanced statistics are useful in characterizing the centroids and widths of low-level peaks. Following the analysis, any peak contributions from the background spectrum, such as that of Figure 2, are subtracted.

GRABGAM also permits development of calibration curves for unusual geometries. Here $\log (e f f)$ vs $\log (E)$ efficiency curves may be fitted as a hyperbola, cubic polynomial with or without crossover, and a combination of these. Calibration analyses for the LDEF samples are discussed below.

\section{Calibrations}

Trunnion Disks. The counting genmetry for a disk sample is given in Figure 5 , along with the point sources locations used for calibration. Each point source spectrum yielded an efficiency $\epsilon(r, h)$, where $r$ and $h$ are the radial and height coordinates relative to the disk. The efficiency $\epsilon$ of a disk of uniform activity is the average of $\epsilon(r, h)$ over the disk, viz.

$$
\epsilon=\frac{\int_{V} \epsilon(r, h) 2 \pi r d r d h}{\int_{V} 2 \pi r d r d h}
$$

where $V$ is the disk volume. The only measured $\epsilon(r, h)$ are the $\epsilon\left(r, h_{t}\right)^{\prime}$ and $\epsilon\left(r, h_{p}\right)$ on top and bottom surfaces of the disk; thus, a model is needed to infer the $\epsilon(r, h)$ within the disk. The model assumed in the present work was

$$
\epsilon(r, h)=g(r) e^{-u(r) h}
$$

where the $\mathrm{h}$-dependence is exponential and the $\mathrm{r}$-dependence is dictated by functions $g(r)$ and $U(r)$. An exponential is supported experimentally $y^{7-8}$, and it models both geometry and material absorption dependences of the efficiency, as discussed in Appendix $B$. 
Substituting Equation 2 into Equation 1 yields

$$
\epsilon=\frac{\int_{A} \epsilon(r) 2 \pi r d r}{\int_{A} 2 \pi r d r},
$$

where $\epsilon(r)$, resulting from integrals over $h$, is given by

$$
\epsilon(r)=g(r) \frac{e^{-U(r) h t}-e^{-U(r) h b}}{-U(r)\left[h_{t}-h_{b}\right]}=\frac{\epsilon\left(r, h_{t}\right)-\epsilon\left(r, h_{b}\right)}{\ln \left[\epsilon\left(r, h_{t}\right) / \epsilon\left(r, h_{b}\right)\right]}
$$

Note that $\epsilon(r)$ is an exponential average along $h$ within the sample volume, but it depends only values $\epsilon\left(r, h_{t}\right)$ and $\epsilon\left(r, h_{b}\right)$ measured on the surface outside the volume.

Individual $\epsilon(r)$ were determined using Equation 4 with experimental measurements, and these values were fitted to a function

$$
\epsilon(r)=A-B r^{p},
$$

where $A, B$, and $p$ are positive constants, and $p$ is approximately equal to 2. Integrating this expression for $\epsilon(r)$ in Equation 3 yields

$$
\epsilon=A-[2 /(2+p)] B\left[r_{d}\right]^{p} \text {, }
$$

where $r=r_{d}$ is the radius of the trunnion disk. Values of $\epsilon$ were determined as a function of energy, using the $\epsilon\left(r, h_{t}\right)$ and $\epsilon\left(r, h_{b}\right)$ point source measurements at different energies. The analysis details, given in Appendix $B$, indicate that the resulting $\epsilon$ are accurate within $5 \%$.

Metal Slabs. Efficiencies for the rectangular metal slabs were determined using techniques similar to those for the trunnion disks. However, because the slabs were smaller in area and thickness, an effectively constant $U(x)=U$ was assumed, as consistent with experimental results ${ }^{7,8}$, so that Equation 2 could be expressed with separable variables in $r$ and $h$, viz.

$$
\epsilon(r, h)=\epsilon\left(r, h_{b}\right) e^{-u(h-h b)}
$$

When inserted in Equation 1, this $\epsilon(x, h)$ yields

$$
\epsilon=\frac{\int \epsilon\left(r, h_{b}\right) 2 \pi r d r}{\int 2 \pi r d r} \times \frac{1-e^{-U(h t-h b)}}{U\left(h_{t}-h_{b}\right)},
$$


where the first term is numerically integrated over the rectangular bottom surface and the second term has already been integrated over $h$. The point source mappings on the detector surface are used to determine the first term. The second term requires a knowledge of $U$, which may be expressed as

$$
\mathrm{U}=\mathrm{C}+\mu \mathrm{f},
$$

where $c$ models the geometry dependence and $\mu f$ models the material absorption. Here, the material attenuation coefficient $\mu$ is increased by a factor of $f$ to correct for the average attenuation path, which is somewhat greater than h. The entire energydependence of $U$ is contained in $\mu$, as $c$ and $f$ are purely geometrical parameters. Thus, just two experimental measurements of $U$ for different $\mu$, which are known from tabulations, yield a $c$ and $f$ that can predict $U$ for any other $\mu$. The present study determined $c$ and $f$ using $\mu$ corresponding to experimental measurements with $661 \mathrm{keV}$ and $1332 \mathrm{keV}$ gammas. Appendix B provides further details on the slab calibrations, including a relatively large summing correction that needed to be developed for ${ }^{22} \mathrm{Na}$ produced in the aluminum slabs.

\section{RESULTS}

The respective results for trunnion disks, trunnion radial layers, vanadium slabs, and aluminum slabs are summarized in Tables 1, 2, and 3. Figure 6 gives the location of the samples on the LDEF. Additional details are given below and in Appendix $C$.

Trunnion disk sample results are summarized in Table 1 and correspond to data locations in Figure $7{ }_{58}$ Specific activities are given for ${ }^{7} \mathrm{Be},{ }^{46} \mathrm{SC},{ }^{51} \mathrm{Cr},{ }^{54} \mathrm{Mn},{ }^{56} \mathrm{Mn},{ }^{57} \mathrm{Co},{ }^{58} \mathrm{Co}$, and ${ }^{60} \mathrm{Co}$, where ${ }^{54} \mathrm{Mn}$ is dominant and ${ }^{7} \mathrm{Be}$ is only marginally detected at best. Here the results from counting both sides of the disk have been averaged to yield the values presented. A $\left(1 / \sigma^{2}\right)$-weighted average was used, as the values with either side of the disk facing the detector generally agreed to within the counting errors. An exception was for sample LHB, where a $7.5 \%$ difference in ${ }^{54} \mathrm{Mn}$ was noted; but an even-weighted average for this case was the same as the $\left(1 / \sigma^{2}\right)$-weighted average because the errors were identical. Figure 8 plots the disk results for ${ }^{54} \mathrm{Mn}$ and ${ }^{57} \mathrm{Co}$ as a function of axial position along the trunnion, showning that these activities decrease as the position nears the LDEF end of the "runnion from the space end.

Trunnion radial layer activities.are given in Table 2 and their sample locations are identified in Figure 9. The only significant radionuclides detected in these relatively small samples were ${ }^{54} \mathrm{Mn}$ and ${ }^{57} \mathrm{Co}$. The results given are the average from counting both sides of the sample. An even-weighted average was 
used as the activities for the two sides often differed significantly. Figure 10 plots the layer results, showing that the activities increase with increasing radial position of the trunnion. The data also suggest that the radial profiles on the space side of the trunnion differ from those on the Earth side.

Vanadium and aluminum sample activities are presented in Table 3. Detailed aluminum locations are given in Figure 11. Only ${ }^{46} \mathrm{Sc}$ was detected in the vanadium and only ${ }^{22} \mathrm{Na}$ was detected in the aluminum. Even-weighted averages of the results for each sample side are given, as these properly address differences between the two sides.

\section{v. DISCUSSION}

The LDEF samples examined in the present work implied cosmic activations induced by protons and neutrons, as summarized in Table 4. Also listed is the production of ${ }^{7} \mathrm{Be}$; however, little if any ${ }^{7} \mathrm{Be}$ was observed. Noticeable ${ }^{7} \mathrm{Be}$ had been reported on samples with leading surfaces that can collect particles in the LDEF path ${ }^{10}$, but none of the samples analyzed at SRS had such surfaces.

\section{Trunions}

The trunnion samples were sufficient in number to provide trend data. Figures 7 and 9 show activity trends of ${ }^{54} \mathrm{Mn}$ and ${ }^{57} \mathrm{Co}$ along the axial ( $z$ ) and radial ( $r$ ) coordinates. The activities decrease as the $z$-position becomes closer to the LDEF body. The activities also decrease as the r-position decreases. Both decreasing trends are consistent with increased cosmic-ray shielding. In addition, the $L H$ or westward-facing trunnion was activated somewhat more than the RH or eastward-facing trunnion, and this is a signature of the trapped proton anisotropy in the South Atlantic Anomaly region ${ }^{3}$. This anisotropy is caused by the Earth's magnetic field. The results are further supported by independent measurements on trunnions ${ }^{8}$, which are consistent for predictions for trapped and galectic protons ${ }^{4}$.

The data of Figures 8 and 10 also provide a self-consistency test between the modelled gamma efficiencies for the layer and disk samples. The two radial profiles (earth side and space side) for ${ }^{54} \mathrm{Mn}$ were combined to yield their average radial profile in Figure 12, where it is shown that the activity $A(r)$ is represented by

$$
A(r)=B+C e^{D r}
$$


The average $A(r)=A_{a v}$ over the trunnion range of $r=0$ to $r_{d}$ is then given as

$$
A_{a v}=\frac{\int A(r) 2 \pi r d x}{\int 2 \pi r d r}=B+2 C / D r_{d}\left[e^{D r d}+\left(1-e^{D r d}\right) / D r_{d}\right]
$$

Using the parameters for ${ }^{54} \mathrm{Mn}$ in Figure $11, \mathrm{~A}_{\mathrm{BV}}=79.8 \mathrm{pCi} / \mathrm{Kg}$ for the RHG trunnion, which is consistent with the RH-trunnion trend in Figure 8 ; for comparison, the adjacent RHF trunnion disk value was $78.98 \pm 1.34 \mathrm{pCi} / \mathrm{Kg}$. Althoul the the ${ }^{57} \mathrm{Co}$ radial profile is consistent with that of the $5 /, n$, the imprecise data allow rather different profiles as wel1. However, no reasonable ${ }^{57} \mathrm{Co}$ profile yielded an $A_{a v}$ that agreed well with that for the corresponding trunnion disk. Specifically, the reasonable ${ }^{57}$ Co profiles predicted $A_{\text {gy }}$ in the range of $10.5-13.7 \mathrm{pCi} / \mathrm{Kg}$, while the adjacent RHF trunnion disk measurement was $7.00 \pm 0.59 \mathrm{pCi} / \mathrm{Kg}$.

The above comparison neglects the impact of the radial activity profile on the detetection efficiency of the disk. Addressing this profile $p(r)$, which is directly proportional to $A(r)$, the corresponding efficiency $\epsilon_{p}$ is given as

$$
\epsilon_{p}=\frac{\int_{A} p(r) \epsilon(r) 2 \pi r d r}{\int_{A} p(r) 2 \pi r d r}
$$

The tabulated disk values should be corrected by a factor of $\epsilon / \epsilon_{p}$. Using the profile of Equation 10 for the RHG layers and the $\epsilon(r)$ measured for the adjacent RHF disk, an $\epsilon / \epsilon_{\mathrm{p}}=1.022$ was calculated for ${ }^{54} \mathrm{Mn}$. Applying this correction to the ${ }^{54} \mathrm{Mn}$ of $\mathrm{RHF}$ disk yields $80.73 \pm 1.37 \mathrm{pCi} / \mathrm{Kg}$ compared with the $79.8 \mathrm{pCi} / \mathrm{Kg}$ determined from layers of the adjacent RHG disk. A similar treatment using the same $p(r)$ with the ${ }^{57} \mathrm{Co} \epsilon(r)$ also yields a small correction, which does not resolve the above difference between the ${ }^{57} \mathrm{Co}$ layer and disk results. Apparently, a different $p(r)$ applies for ${ }^{57} \mathrm{Co}$. Using a $p(r)=\mathrm{kr}^{2}$ profile, which corresponds to the lowest reasonable $A_{a v}=10.5 \mathrm{pCi} / \mathrm{Kg}$ for $\mathrm{RHG}$, the resulting $\epsilon / \epsilon^{\mathrm{P}}=1.269$ for $\mathrm{RHF}$ yields $8.88 \pm 0.75 \mathrm{pCi} / \mathrm{Kg}$. This illustrates that the ${ }^{5} \mathrm{Co}$ layer and disk results may become more consistent depending on the detailed nature of $p(r)$.

The trunnion disk results of Table 1 are all based on the assumption of uniform sample activities. Because appropriate $\epsilon / \epsilon^{p}$ corrections are not generally available for these samples, such corrections were not applied. At the same time, a single available example for correcting ${ }^{54} \mathrm{Mn}$ illustrated a small correction in this case, implying that ${ }^{54} \mathrm{Mn}$ values in Table 1 are reasonably accurate. Values for other radio-isotopes of Table 1 can also be cnisidered accurate if their corresponding $p(r)$ are 
in reasonable agreement with that for ${ }^{54} \mathrm{Mn}$. However, caution should be exercised here, as the $\epsilon / \epsilon^{\mathfrak{p}}$ examination for ${ }^{57}$ Co implied a quite different $p(r)$, suggesting that the ${ }^{57} \mathrm{Co}$ of Table $1 \mathrm{might}$ need to be increased by a factor of 1.6 10.3 . Finally, these observations suggest scrutiny in comparing round-robin results from the different participating laboratories, because the the $\epsilon$ determined for the various detectors will need to be corrected by their different $\epsilon / \epsilon$ before precise agreement can be expected. Unfortunately, current experimental data appear insufficient for determining these $\epsilon / \epsilon_{p}$; however model predictions based on particle fluxes may be possible $e^{3,4}$.

\section{Vanadium}

The ${ }^{46} \mathrm{Sc}$ activated in vanadium indicated some trends; however, the photographs suggest that some of the samples may have been shielded so that only signatures of these trends are evident. The corresponding data of Table 3 are discussed below for signatures of anisotropic radiation received by the space/Earth ends and east/west sides of LDEF.

The ${ }^{46} \mathrm{SC}$ density of two samples (I-HI2-VA and I-H12-VB) on the space end of IDEF was about $30 \%$ larger than that of a single sample (G12-A2-FNV) on the Earth end; however, the error for the comparison is also about 30\%. Because the photographs imply that the space end samples were probably more shielded, the observation implies that the radiation received from the space side is greater, which is consistent with the Earth acting as a cosmic shield for irradiation aimed at the Earth end of LDEF.

The ${ }^{46} \mathrm{SC}$ density of a sample (I-F2-V) on the west side of IDEF is only about 5\% larger than that of a sample (I-C9-V) on the east side, and the error for the comparison exceeds $5 \%$. However, the photographs imply that the sample on the west side is more shielded, suggesting that the radiation from the west is higher than that from the east. Such anisotropy for trapped protons is well known and called the South Atlantic Anomaly ${ }^{4}$.

\section{Aluminum}

The ${ }^{22} \mathrm{Na}$ activated in aluminum supports the anisotropic trends more dramatically than the vanadium results. In logical order of development, the evidence for east/west and space/Earth anisotropies are discussed below, using data of Table 3 and the location information of Figures 6 and 11.

Two aluminum samples of the keel plate are on opposite sides of the keel and tend to be shielded from each other by the keel. Consequently, one sample $(\mathrm{KP}-3)$ received radiation preferentially from the west and the other $(\mathrm{KP}-10)$ from the east. The ${ }^{22} \mathrm{Na}$ 
density of the west side sample was $48 \pm 6 \%$ higher than that of the east side sample, showning an unmistakable signature for the east/west anisotropy.

The keel itself is midway between the space and Earth ends, so that the aluminum samples (KP-3 and $\mathrm{KP}-10)$ of the keel plate are closer to the space end than are the two samples (ESR-1 and ESR-2) of the retainer ring on the Earth end. The ${ }^{22} \mathrm{Na}$ densities of the two samples from the retainer ring essentially agree, having a difference of $1.2 \pm 4.2 \%$, as these samples were both unshielded and exposed to the same radiation. Both keel plate samples were shielded, so that a hypothetical unshielded sample at this location would have ${ }^{22} \mathrm{Na}$ density in excess of either of the reasured samples, but not more than their sum. Thus, the ${ }^{22} \mathrm{Na}$ density of the hypothetical unshielded keel plate sample would be 23-105\% larger than that of the retainer ring samples, indicating strong evidence for the space/Earth anisotropy.

\section{ACKNOWLEDGEMENTS}

C.D. Ouzts is thanked for counting the LDEF samples and assisting with the development of the detector efficiency calibrations. Confirmation measurements supporting the efficiency model were provided by David Lindstrom, NASA Johnson Space Center, Houston, Texas. Guidance and partial funding for this project were provided through the efforts or G.J. Fishman and B.A. Harmon, NASA Marshall Space Center, Huntsville, Alabama. Also, information contained in this work was developed during the course of work undex Contract No. DE-AC09-89SR18035 with the U.S. Department of Energy. 


\section{REFERENCE8}

1. G.J. Fishman, I.A. Parnell, and B.A. Harmon, "Long Duration Exposure Facility (IDEF) Induced Radioactivity Plan", NASA Marshall space Center Report [Astrophysics Division, Space Science Laboratory] (December, 1989).

2. E.V. Benton and $W$. Heinrich, "Ionizing Radiation Exposure on LDEF", University of San Francisco Report USF-TR-77 (August, 1990).

3. T.W. Armstrong and B.L. Colborn, "Scoping Estimates of the LDEF Satellite Induced Radioactivity", Science Applications International Corp. Report SAIC-90/1462 (September 1990)

4. T.W. Armstrong and B.I. Colborn, "Radiation Calculations and Comparisons with Data", First LDEF Post-Retrieval Symposium, NASA Confe.ence in Kissimmee, Florida (June $2-8,1991$ ) - to be published.

5. W.G. Winn, W.W. Bowman, and A.L. Boni, "Ultra-Clean Underground Counting Facility for Low-Level

Environmental Samples", The science of the Total Environment 69, $107(1988)$. [Also available as USDOE SRI Report DP-1747, 57 pp (1987)].

6. W.G. Winn, "Ultrasensitive Examination of Environmental Samples by SRI Underground counting Facility", Trans. Am. NuC. SOC. 54, 34 (1987).

7. Dave Lindstrom, report letter on LDEF results, NASA Johnson Space Center, Houston, Texas (May 6, 1991).

8. C.E. Moss and R.C. Reedy, "Measurements of Induced Radioactivity in Some LDEF Samples", First LDEF PostRetrieval Symposium, NASA Conference in Kissimmee, Florida (June 2-8, 1991) - to be published.

9. K. Debertin and R.G. Helmer, Gamma- and X-ray Spectrometry with Semiconductor Detectors, North-Holland, Elsevier Science Publisting Co., New York (1988).

10. G.J. Fishman, B.A. Harmon, et'al, "Observation of ${ }^{7} \mathrm{Be}$ on the Surface of LDEF Spacecraft", Nature, 439, 678 (1991).

11. W.G. Winn and R.A. Sigg, "Pre-Operational RadioEnvironmental studies of Plant Vogtle", USDOE SRS Report WSRC-RP-89-161 (May 1, 1989). 
Table 1. Trunnion Disk Results

Decay Correction Date - January 20, 1990

\begin{tabular}{|c|c|c|c|c|c|c|c|c|}
\hline \multirow{2}{*}{ Sample } & \multicolumn{8}{|c|}{ Isotopic Activities in $\mathrm{pCi} / \mathrm{Kg}$ sample } \\
\hline & $\mathrm{Be}-7$ & $\mathrm{Sc}-46$ & $c x-51$ & $M n-54$ & $\mathrm{Co}-56$ & Co-57 & Co-58 & $\underline{\mathrm{C} 0-60}$ \\
\hline LHB & - & $\begin{array}{l}4.31 \\
\pm .59\end{array}$ & - & $\begin{array}{r}120.21 \\
\pm 1.53\end{array}$ & $\begin{array}{l}4.58 \\
\pm .75\end{array}$ & $\begin{array}{r}15.17 \\
\pm .73\end{array}$ & $\begin{array}{r}3.31 \\
\pm 1.15\end{array}$ & $\begin{array}{l}1.96 \\
\pm .18\end{array}$ \\
\hline LHE & - & $\begin{array}{l}4.57 \\
.5 .71\end{array}$ & - & $\begin{array}{l}95.21 \\
\pm 1.75\end{array}$ & $\begin{array}{l}2.92 \\
\pm .77\end{array}$ & $\begin{array}{l}9.60 \\
\pm .66\end{array}$ & $\begin{array}{r}1.33 \\
\pm 2.35\end{array}$ & $\begin{array}{l}1.59 \\
\pm .30\end{array}$ \\
\hline LHF & - & $\begin{array}{l}3.37 \\
\pm .51\end{array}$ & - & $\begin{array}{r}100.50 \\
\pm 1.41\end{array}$ & $\begin{array}{l}4.84 \\
\pm .75\end{array}$ & $\begin{array}{r}10.47 \\
\pm .63\end{array}$ & $\begin{array}{r}4.06 \\
\pm 1.16\end{array}$ & $\begin{array}{l}1.40 \\
\pm .19\end{array}$ \\
\hline LHP & $\begin{array}{r}0.95 \\
\pm 3.29\end{array}$ & $\begin{array}{l}3.53 \\
\pm .20\end{array}$ & $\begin{array}{l}16.38 \\
\pm 7.38\end{array}$ & $\begin{array}{r}79.43 \\
\pm .68\end{array}$ & $\begin{array}{l}2.65 \\
\pm .21\end{array}$ & $\begin{array}{l}7.48 \\
\pm .28\end{array}$ & $\begin{array}{l}4.90 \\
\pm .33\end{array}$ & $\begin{array}{l}1.58 \\
\pm .11\end{array}$ \\
\hline LHR & $\begin{array}{l}-7.48 \\
\pm 3.65\end{array}$ & $\begin{array}{l}3.78 \\
\pm .21\end{array}$ & $\begin{array}{l}34.35 \\
\pm 8.43\end{array}$ & $\begin{array}{r}76.71 \\
\pm .68\end{array}$ & $\begin{array}{l}2.66 \\
\pm .23\end{array}$ & $\begin{array}{l}7.23 \\
\pm .36\end{array}$ & $\begin{array}{l}4.68 \\
\pm .35\end{array}$ & $\begin{array}{l}1.52 \\
\pm .11\end{array}$ \\
\hline LHS & $\begin{array}{r}2.56 \\
\pm 3.28\end{array}$ & $\begin{array}{r}4.34 \\
\pm .19\end{array}$ & $\begin{array}{l}23.14 \\
\pm 8.15\end{array}$ & $\begin{array}{r}75.25 \\
\pm .59\end{array}$ & $\begin{array}{l}2.53 \\
\pm .20\end{array}$ & $\begin{array}{l}6.22 \\
\pm .25\end{array}$ & $\begin{array}{l}4.92 \\
\pm .30\end{array}$ & $\begin{array}{l}1.55 \\
\pm .09\end{array}$ \\
\hline RHB & - & $\begin{array}{r}5.04 \\
\pm 1.00\end{array}$ & - & $\begin{array}{l}82.52 \\
\pm 1.36\end{array}$ & $\begin{array}{l}3.21 \\
\pm .79\end{array}$ & $\begin{array}{l}7.34 \\
\pm .59\end{array}$ & $\begin{array}{r}4.67 \\
\pm 1.27\end{array}$ & $\begin{array}{l}1.39 \\
\pm .25\end{array}$ \\
\hline RHE & - & $\begin{array}{l}1.96 \\
\pm .75\end{array}$ & - & $\begin{array}{r}79.77 \\
\pm 1.57\end{array}$ & $\begin{array}{l}2.15 \\
\pm .95\end{array}$ & $\begin{array}{r}6.63 \\
\pm .57\end{array}$ & $\begin{array}{r}2.35 \\
\pm 1.27\end{array}$ & $\begin{array}{l}1.16 \\
\pm .22\end{array}$ \\
\hline RHF & - & $\begin{array}{l}2.99 \\
\pm .64\end{array}$ & - & $\begin{array}{l}78.98 \\
\pm 1.34\end{array}$ & $\begin{array}{l}3.75 \\
\pm .89\end{array}$ & $\begin{array}{l}7.00 \\
\pm .59\end{array}$ & $\begin{array}{r}2.45 \\
\pm 1.26\end{array}$ & $\begin{array}{l}1.32 \\
\pm .20\end{array}$ \\
\hline RHP & $\begin{array}{r}5.36 \\
\pm 3.53\end{array}$ & $\begin{array}{l}3.46 \\
\pm .21\end{array}$ & $\begin{array}{l}35.22 \\
\pm 8.84\end{array}$ & $\begin{array}{r}72.56 \\
\pm .66\end{array}$ & $\begin{array}{l}2.67 \\
\pm .22\end{array}$ & $\begin{array}{l}7.28 \\
\pm .30\end{array}$ & $\begin{array}{l}4.39 \\
\pm .33\end{array}$ & $\begin{array}{l}1.45 \\
\pm .11\end{array}$ \\
\hline RHR & $\begin{array}{r}8.75 \\
\pm 3.07\end{array}$ & $\begin{array}{l}3.48 \\
\pm .19\end{array}$ & $\begin{array}{l}26.16 \\
\pm 8.13\end{array}$ & $\begin{array}{r}72.75 \\
\pm .60\end{array}$ & $\begin{array}{l}2.41 \\
\pm .19\end{array}$ & $\begin{array}{r}6.20 \\
\pm .24\end{array}$ & $\begin{array}{l}4.29 \\
\pm .30\end{array}$ & $\begin{array}{l} \pm .55 \\
\pm .09\end{array}$ \\
\hline RHS & $\begin{array}{r}2.67 \\
\pm 3.74\end{array}$ & $\begin{array}{l}3.94 \\
\pm .23\end{array}$ & $\begin{array}{r}31.89 \\
\pm 10.08\end{array}$ & $\begin{array}{r}74.66 \\
\pm .71\end{array}$ & $\begin{array}{l}2.73 \\
\pm .25\end{array}$ & $\begin{array}{l}6.01 \\
\pm .32\end{array}$ & $\begin{array}{l}4.32 \\
\pm .41\end{array}$ & $\begin{array}{l}1.44 \\
\pm .12\end{array}$ \\
\hline
\end{tabular}

All errors are $1-\sigma$ counting errors 
Table 2. Trunnion Layer Results

Decay Correction Date: January 20, 1990

\begin{tabular}{|c|c|c|}
\hline \multicolumn{3}{|c|}{ space side } \\
\hline$R H-G-S P-$ & $\mathrm{pCi} / \mathrm{Kg}$ & Sample \\
\hline & $M n-54$ & Co-57 \\
\hline 2 & $\begin{array}{l}95.10 \\
\pm 3.44\end{array}$ & $\begin{array}{l}19.57 \\
\pm 3.17\end{array}$ \\
\hline 3 & $\begin{array}{l}83.24 \\
\pm 2.77\end{array}$ & $\begin{array}{l}14.78 \\
\pm 1.88\end{array}$ \\
\hline 4 & $\begin{array}{r}77.62 \\
\pm 2.25\end{array}$ & $\begin{array}{l}11.98 \\
\pm 1.72\end{array}$ \\
\hline 5 & $\begin{array}{r}70.89 \\
\pm 1.44\end{array}$ & $\begin{array}{r}12.18 \\
\pm 1.27\end{array}$ \\
\hline 6 & $\begin{array}{l}70.26 \\
\pm 1.63\end{array}$ & $\begin{array}{l}12.74 \\
\pm 1.43\end{array}$ \\
\hline
\end{tabular}

\begin{tabular}{|c|c|c|}
\hline \multicolumn{3}{|c|}{ Earth side } \\
\hline RH-G-ER- & $\mathrm{DCi} / \mathrm{Kg}$ & Sample \\
\hline & $M n-54$ & $\mathrm{Co}-57$ \\
\hline 2 & $\begin{array}{l}98.46 \\
\pm 3.60\end{array}$ & $\begin{array}{l}17.50 \\
\pm 2.51\end{array}$ \\
\hline 3 & $\begin{array}{l}93.62 \\
\pm 2.04\end{array}$ & $\begin{array}{l}15.02 \\
\pm 1.69\end{array}$ \\
\hline 4 & $\begin{array}{l}87.82 \\
\pm 2.36\end{array}$ & $\begin{array}{l}17.48 \\
\pm 2.22\end{array}$ \\
\hline 5 & $\begin{array}{l}80.00 \\
\pm 1.47\end{array}$ & $\begin{array}{l}10.92 \\
\pm 1.19\end{array}$ \\
\hline 6 & $\begin{array}{l}76.64 \\
\pm 1.63\end{array}$ & $\begin{array}{l}12.07 \\
\pm 1.22\end{array}$ \\
\hline
\end{tabular}

AIl errors are $1-\sigma$ counting errors 


\section{Table 3. Vanadium and Aluminum sample Results}

$$
\text { Decay Correction Date: January 20, } 1990
$$

\begin{tabular}{|cc|}
\hline \multicolumn{2}{|c|}{ Vanadium } \\
\hline Sample & $\frac{\mathrm{pCi} / \mathrm{Kg} \text { Sample }}{\mathrm{SC}-46}$ \\
& \\
G12-A2-FNV & 16.00 \\
& \pm 1.32 \\
I-C9-V & 20.24 \\
& \pm 1.51 \\
I-F2-V & 21.12 \\
& \pm 2.70 \\
I-H12-VA & 19.82 \\
& \pm 12.84 \\
I-H12-VB & 21.59 \\
& \pm 6.77 \\
\hline
\end{tabular}

\begin{tabular}{|cc|}
\hline \multicolumn{2}{|c|}{ Aluminum } \\
\hline Sample & $\frac{\mathrm{pCi} / \mathrm{Kg} \text { Sample }}{\mathrm{Ni}-22}$ \\
& \\
ESR-1 & 90.60 \\
& \pm 3.31 \\
ESR-5 & 91.70 \\
& \pm 1.94 \\
& 111.47 \\
$\mathrm{KP}-3$ & \pm 1.95 \\
& 75.33 \\
$\mathrm{KP}-10$ & \pm 2.60 \\
& \\
& \\
& \\
& \\
\end{tabular}

All errors are $1-\sigma$ counting errors 
Table 4. Cosmic-Induced Radionuclides in LDEF samples

RADIONUCLIDE PRODUCTION REACTIONS

\begin{tabular}{|c|c|c|c|c|c|c|c|}
\hline \multicolumn{7}{|c|}{ RADIONUCLIDE PRODUCTION REACTIONS } & \\
\hline $\begin{array}{l}\text { Cosmic } \\
\text { Particle }\end{array}$ & & $\begin{array}{c}\text { Target } \\
\text { Nuellide }\end{array}$ & & $\begin{array}{l}\text { Radlo- } \\
\text { Nuclide }\end{array}$ & & $\begin{array}{l}\text { Residual } \\
\text { Partlcles }\end{array}$ & $i$ \\
\hline$\frac{\text { Aluminum }}{\mathrm{p}}$ & + & ${ }^{27} \mathrm{Al}$ & $-\cdots-\cdots$ & ${ }^{22} \mathrm{Na}$ & + & spallation & \\
\hline$\frac{\text { Vanadium }}{\mathrm{p}}$ & + & $\because V$ & $-\cdots-\cdots$ & ${ }^{46} \mathrm{Sc}$ & + & spallation & \\
\hline$\frac{\text { Iunnions }}{\mathrm{p}}$ & + & ${ }^{4} \mathrm{~N}$ & $-\cdots-\cdots$ & 'Be & + & $2 \alpha$ & \\
\hline n & + & ${ }^{40} \mathrm{Ti}$ & $-\cdots-\cdots$ & ${ }^{46 \mathrm{Sc}}$ & + & $p$ & \\
\hline n & + & ${ }^{\mathrm{BA}} \mathrm{Fe}$ & $-\cdots---\cdots$ & ${ }^{51} \mathrm{Cr}$ & + & $\alpha$ & \\
\hline $\mathrm{p}$ & + & ${ }^{56} \mathrm{Fe}$ & $-\cdots-\cdots$ & ${ }^{54} \mathrm{Mn}$ & + & $2 p+n$ & \\
\hline $\mathrm{p}$ & + & ${ }^{58} \mathrm{Ni}$ & $-\cdots-\cdots$ & ${ }^{56} \mathrm{CO}_{0}$ & + & $2 p+n$ & \\
\hline$p$ & + & ${ }^{50} \mathrm{Ni}$ & $-\cdots--\cdots$ & ${ }^{57} \mathrm{Co}_{0}$ & + & $2 p$ & \\
\hline$n$ & + & ${ }^{5 n} \mathrm{Ni}$ & $-\cdots-\cdots$ & ${ }^{58} \mathrm{Co}$ & + & $p$ & \\
\hline$n$ & + & ${ }^{50} \mathrm{Co}$ & $-\cdots---\rightarrow$ & ${ }^{80} \mathrm{Co}$ & & & \\
\hline & & $\because$ & & & & & \\
\hline
\end{tabular}



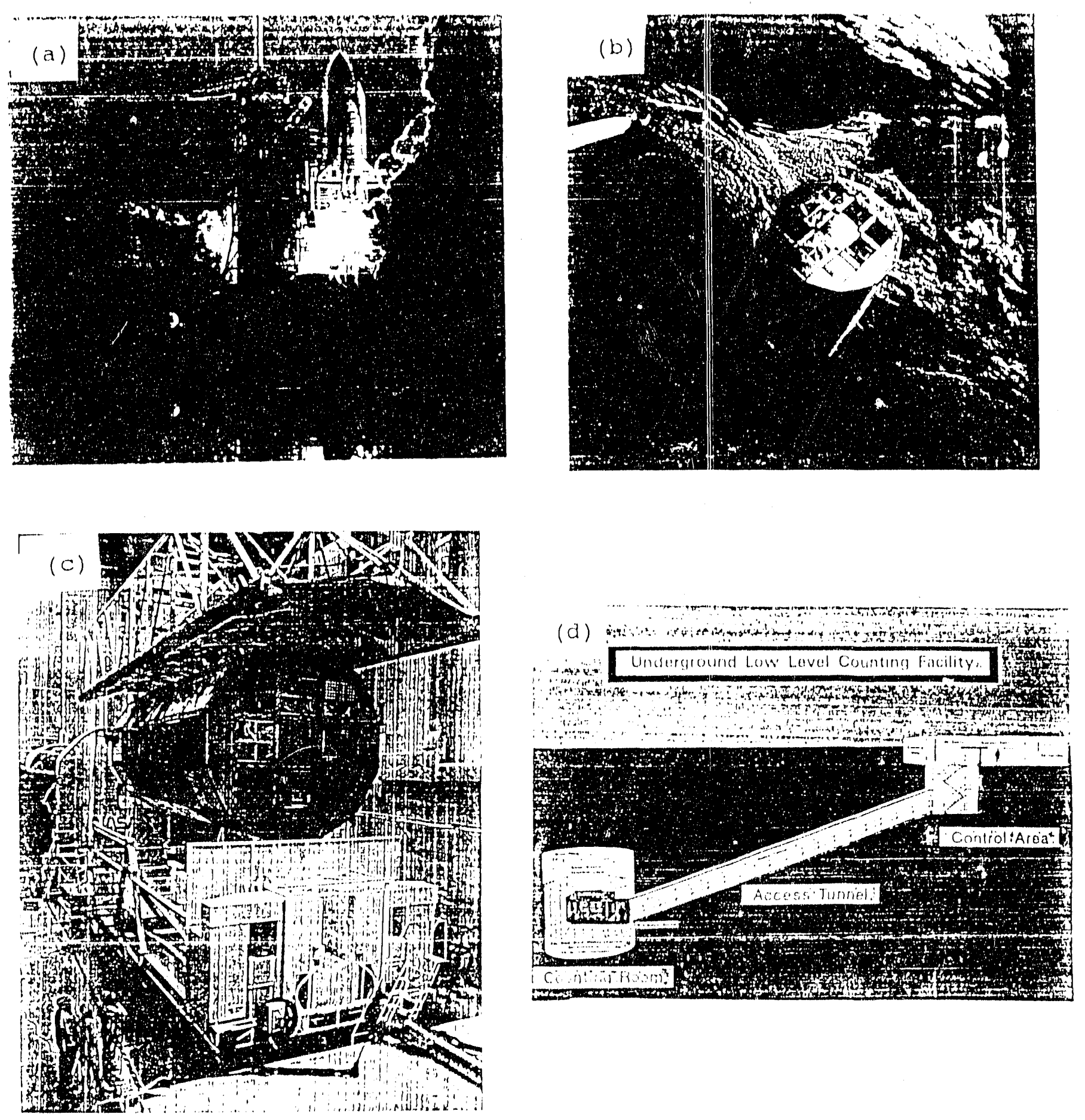

Figure 1. LDEF Historical Events

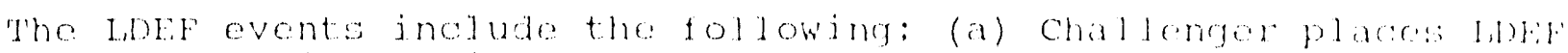
in Earth orbit, April $198 \hat{4}$. (b) Jofr remang in orbit unt il retrieved by columbia in January goso. (o) sample rotriaval

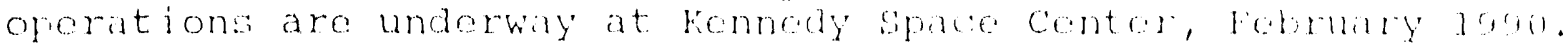
(a) Initial anmles and yad at sks Undergrome count ing Facidity, March 1990 . 


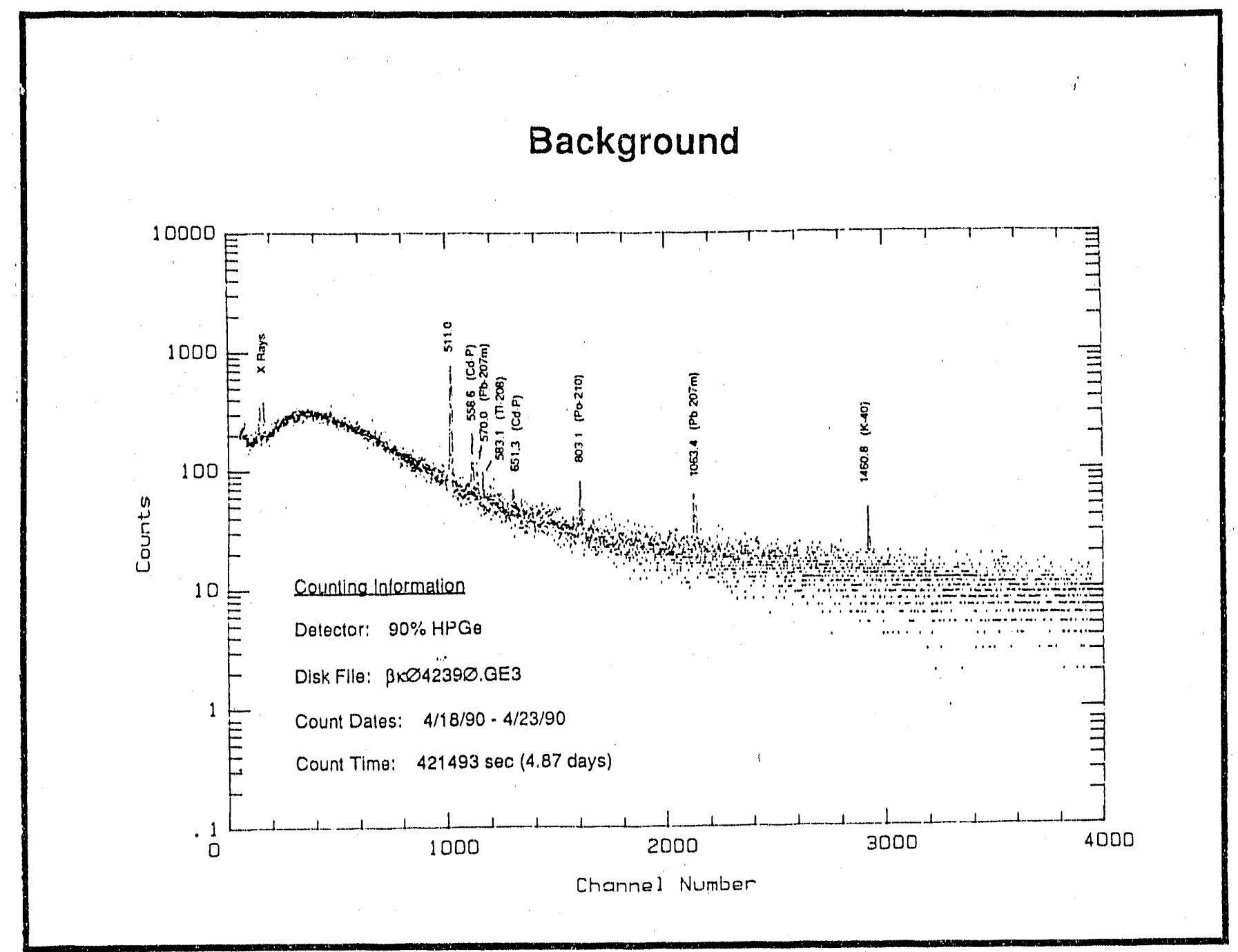

Figure 2. Background spectrum

Typical background of $90 \%$ HPGe During LDEF Analyses. 
(a)

\section{0\% HPGE DETECTOR WITH ACTIVE/PASSIVE SHIELD AND NITROGEN PURGE}

(See pholograph on lett.)

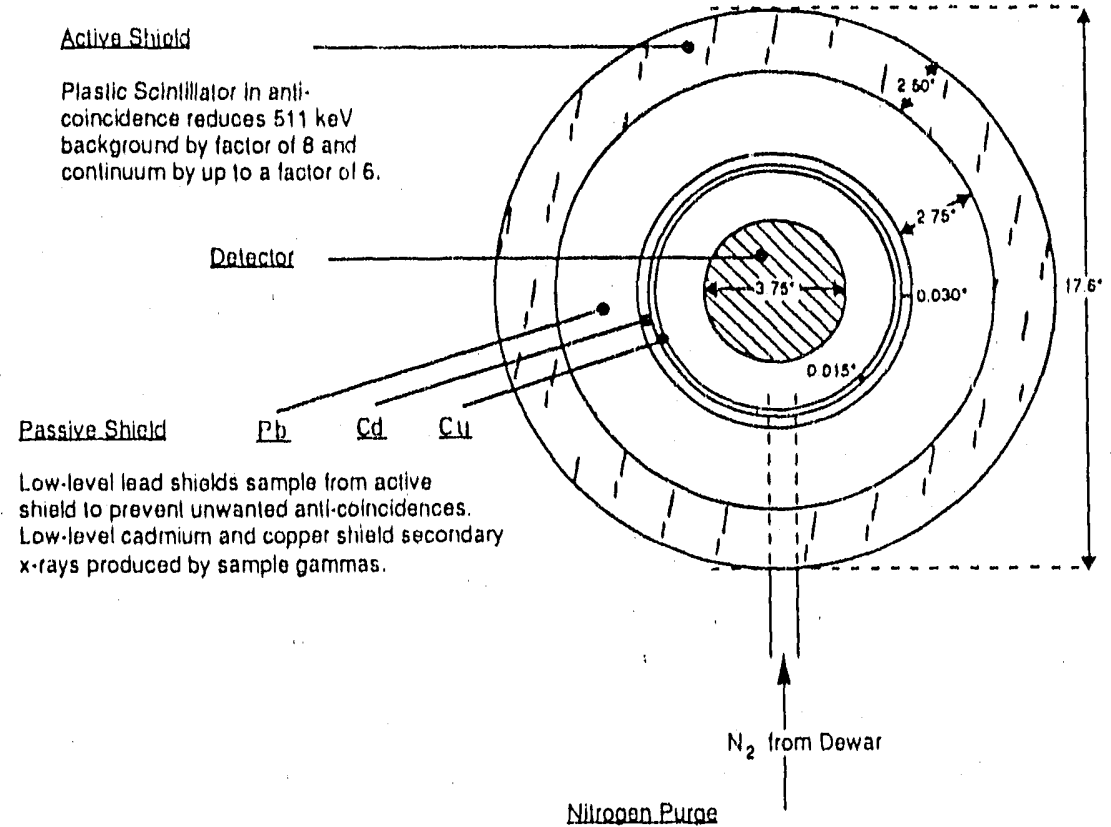

Liquid nitrogen evaporalion purges the

sample counting chamber of nalural radon background.

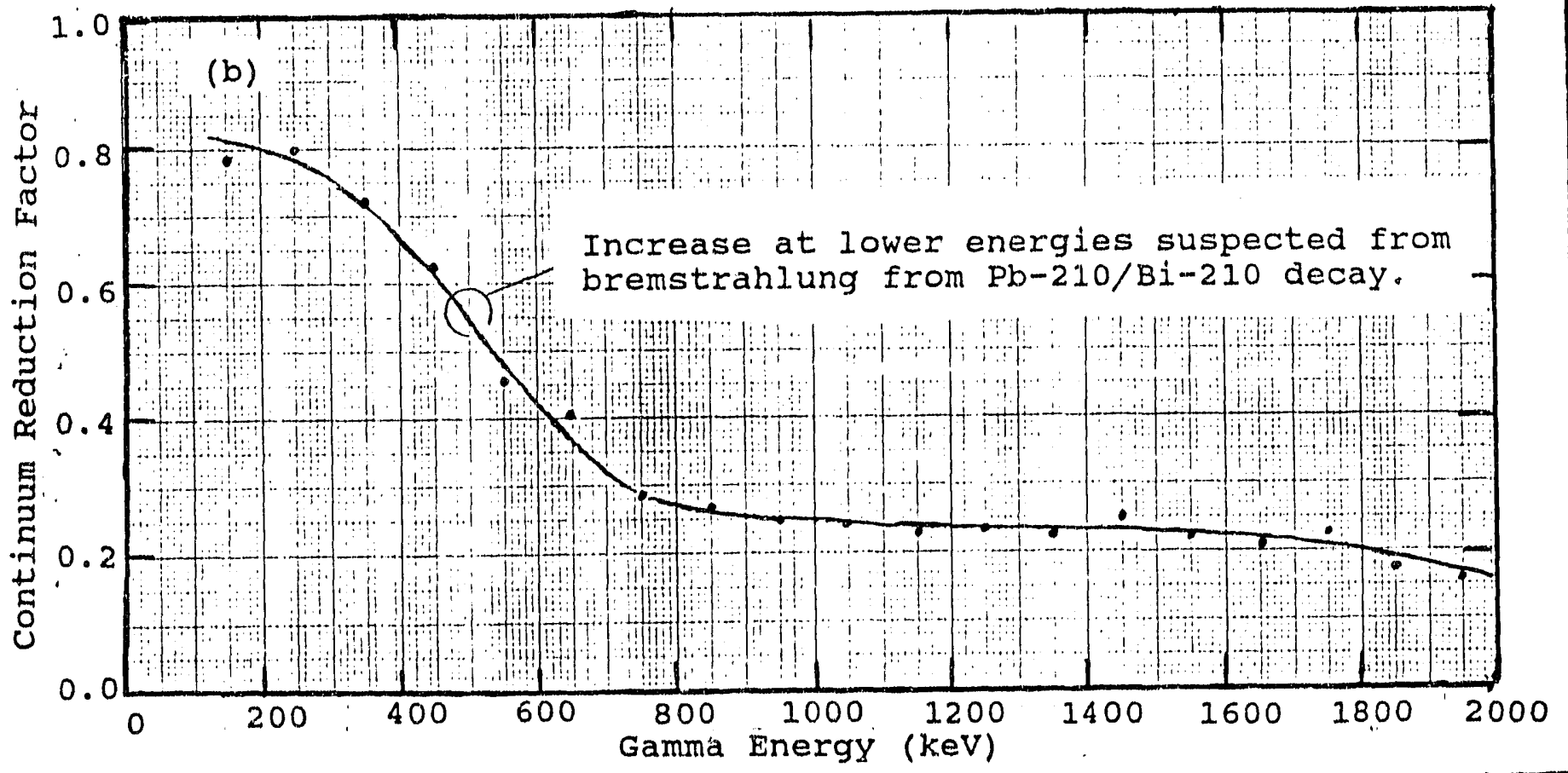

Figure 3. Detector shielding

$90 \%$ HPGe detector (a) shielding configuration and (b) effect of active shield in reducing continuum background. 


\section{Sample LHS}

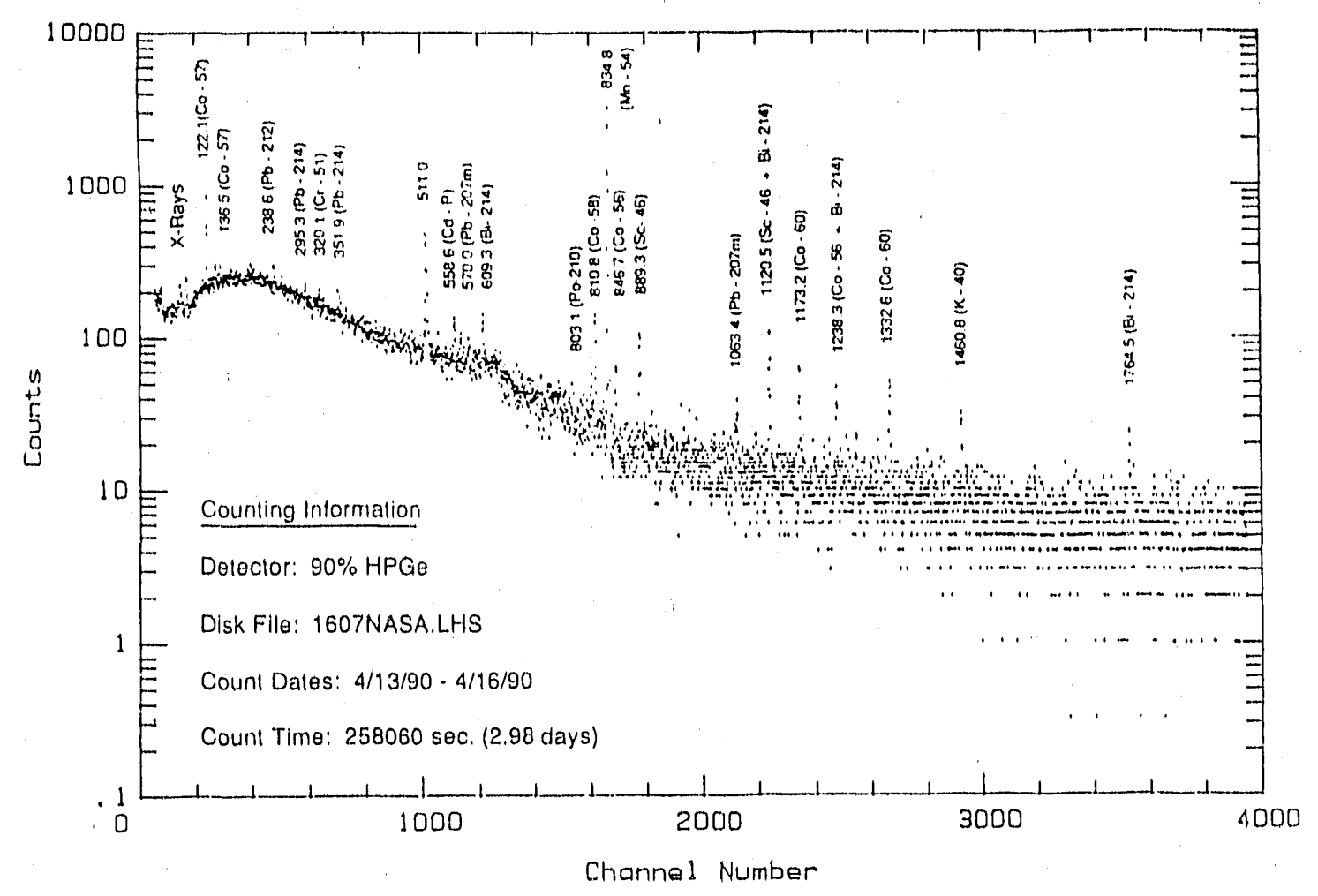

Figure 4. IDEF sample spectrum

Typical trunnion sample spectrum with 90\% HPGe detector. 


\section{EFFICIENOY OALIBRATION}

DATA

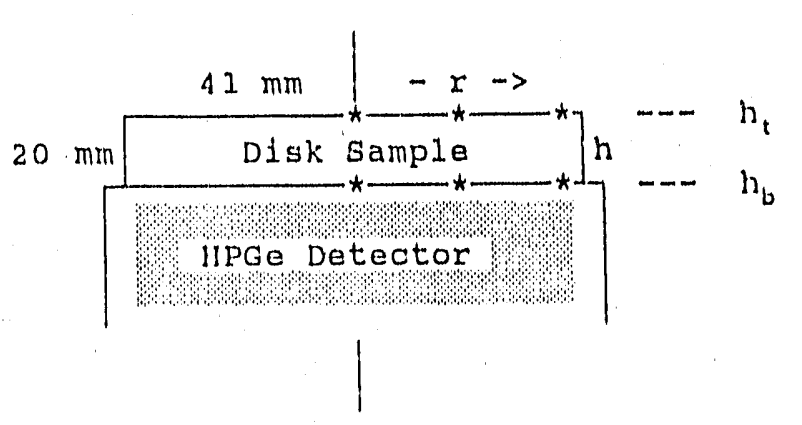

point sourae

Location: *

Data: $\epsilon(r, h)$

ANALYSIS

(1) Average exponentially over sample height

$$
\epsilon(r)=\frac{\epsilon\left(r, h_{t}\right)-\epsilon\left(r, h_{b}\right)}{\ln \left[\epsilon\left(r, h_{t}\right) / \epsilon\left(r, h_{b}\right)\right]}
$$

(2) Fit radial dependence

$$
\epsilon(r)=A-B r^{p}
$$

(3) Average over sample radial areas

$$
\epsilon=A-[2 /(2+p)] B\left[r_{\max }\right]^{p}
$$

Figure 5. Overview of Efficiency Calibration Method 


\section{LDEF Induced Activity Analysis}
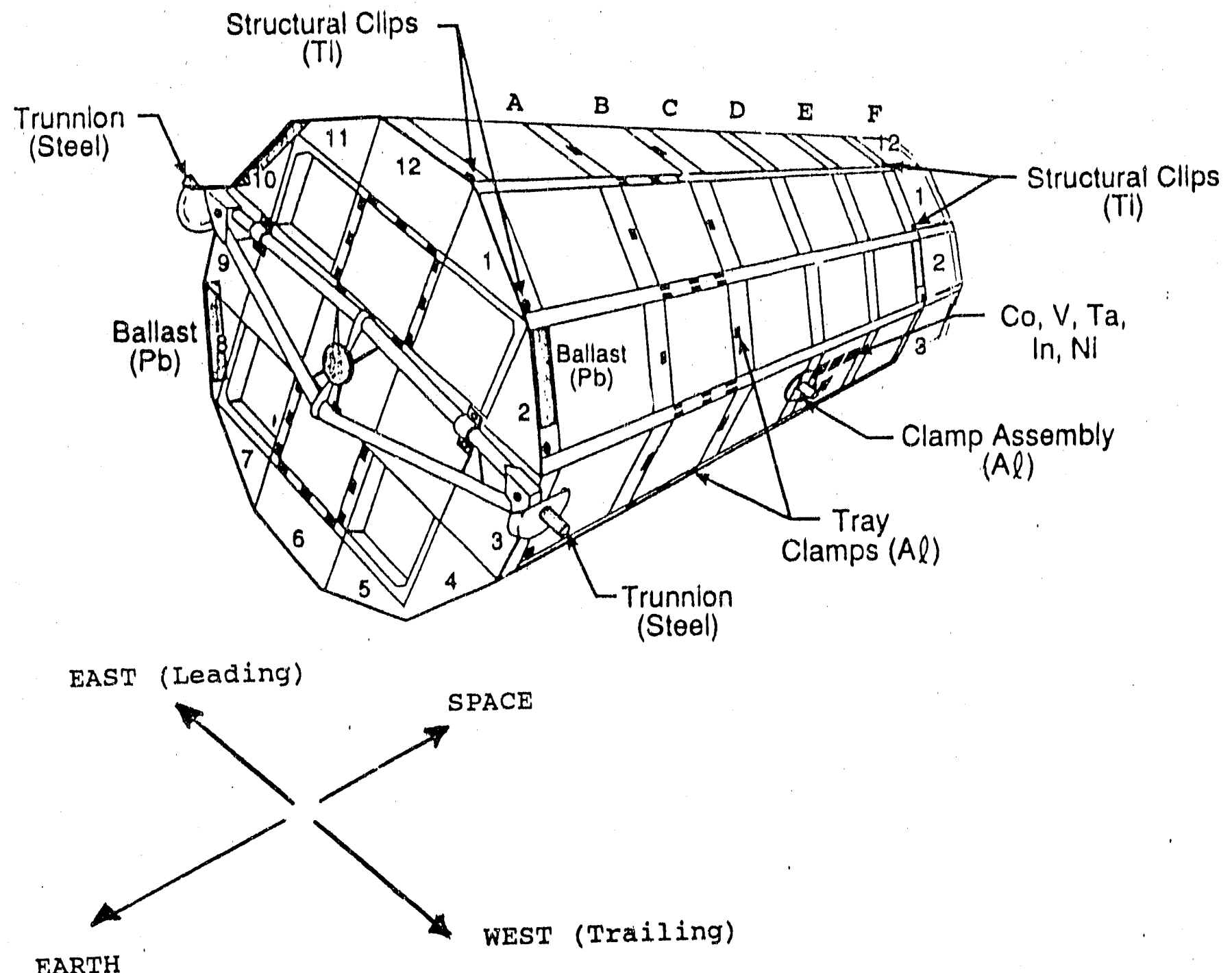

Figure 6. LDEF Location Scheme

Location of Radionuclide Samples taken from LDEF, with radial locations $1-12$ and axial locations $A-F$. 


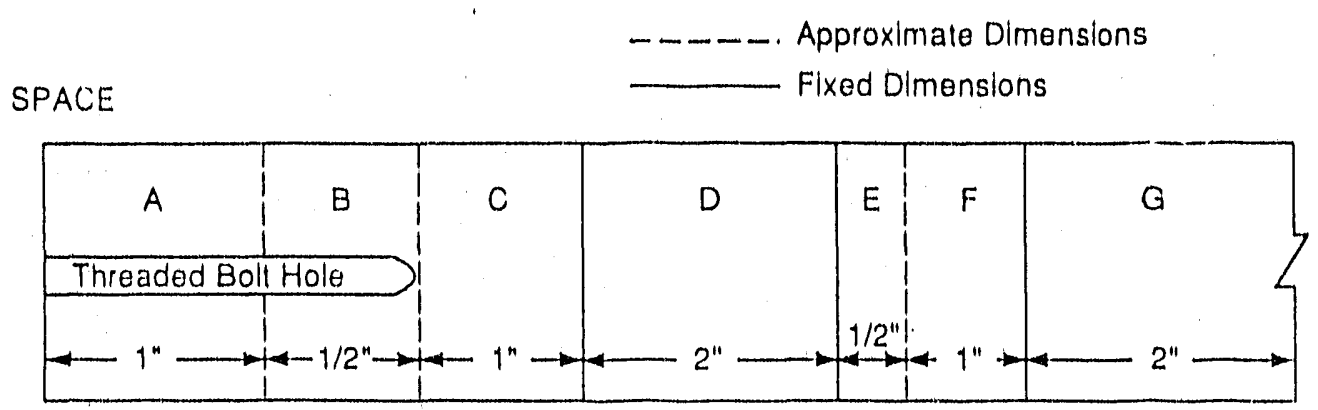

END

TO LDEF INTERIOR $\longrightarrow$

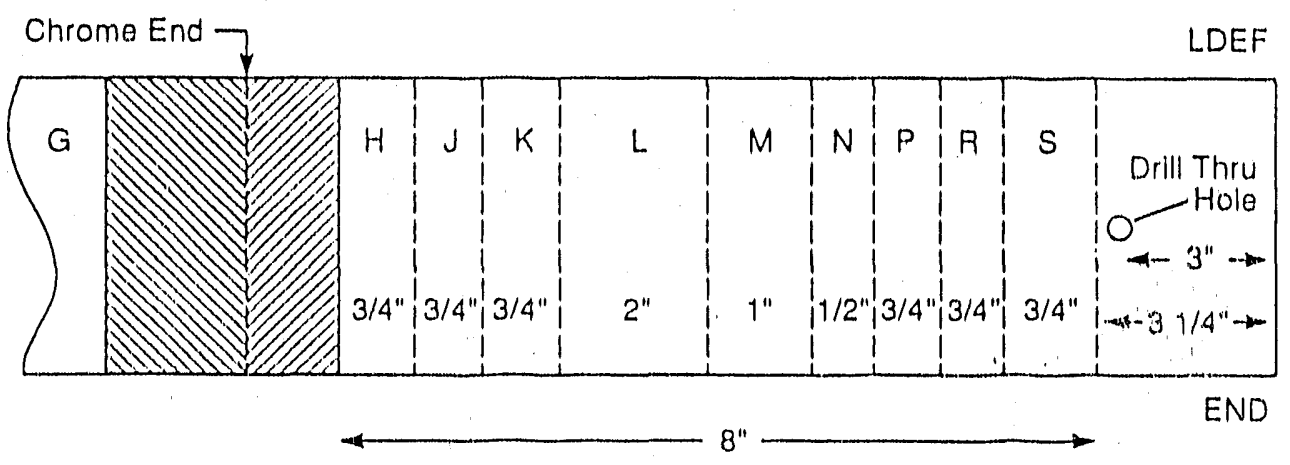

LDEF TRUNNION LABELING CONVENTION

Figure 7. Location scheme for LDEF Trunnion samples 


\section{Trunnion Disk Samples}

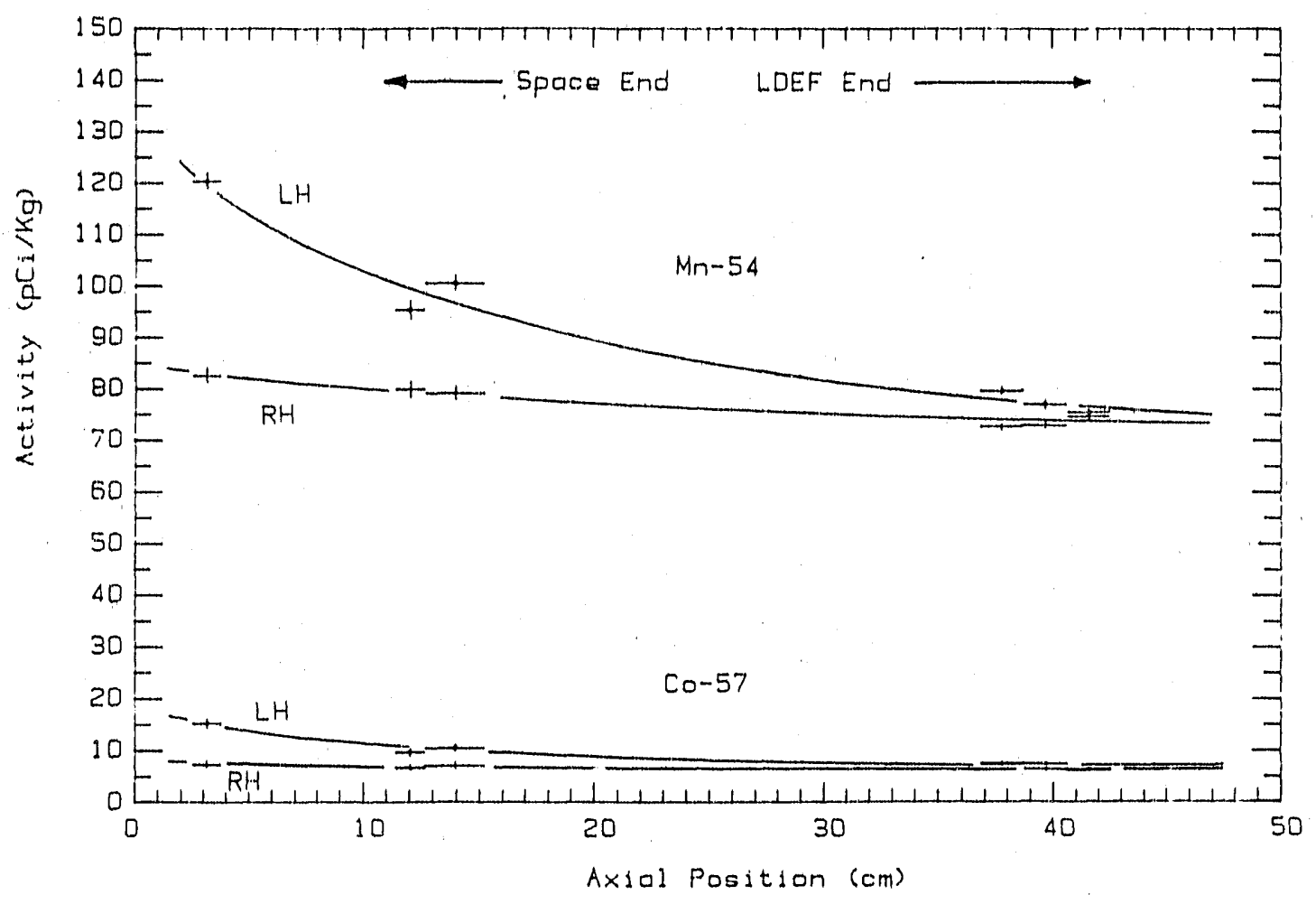

Figure 8. Activity of Trunnion Disk samples

The trunnion activity axial dependence is given for the west ( $L H$ ) and east (RH) trunnions on the Earth end of LDEF. The activity error bars are 1-o counting errors, and position error bars are the widths of the layers. 


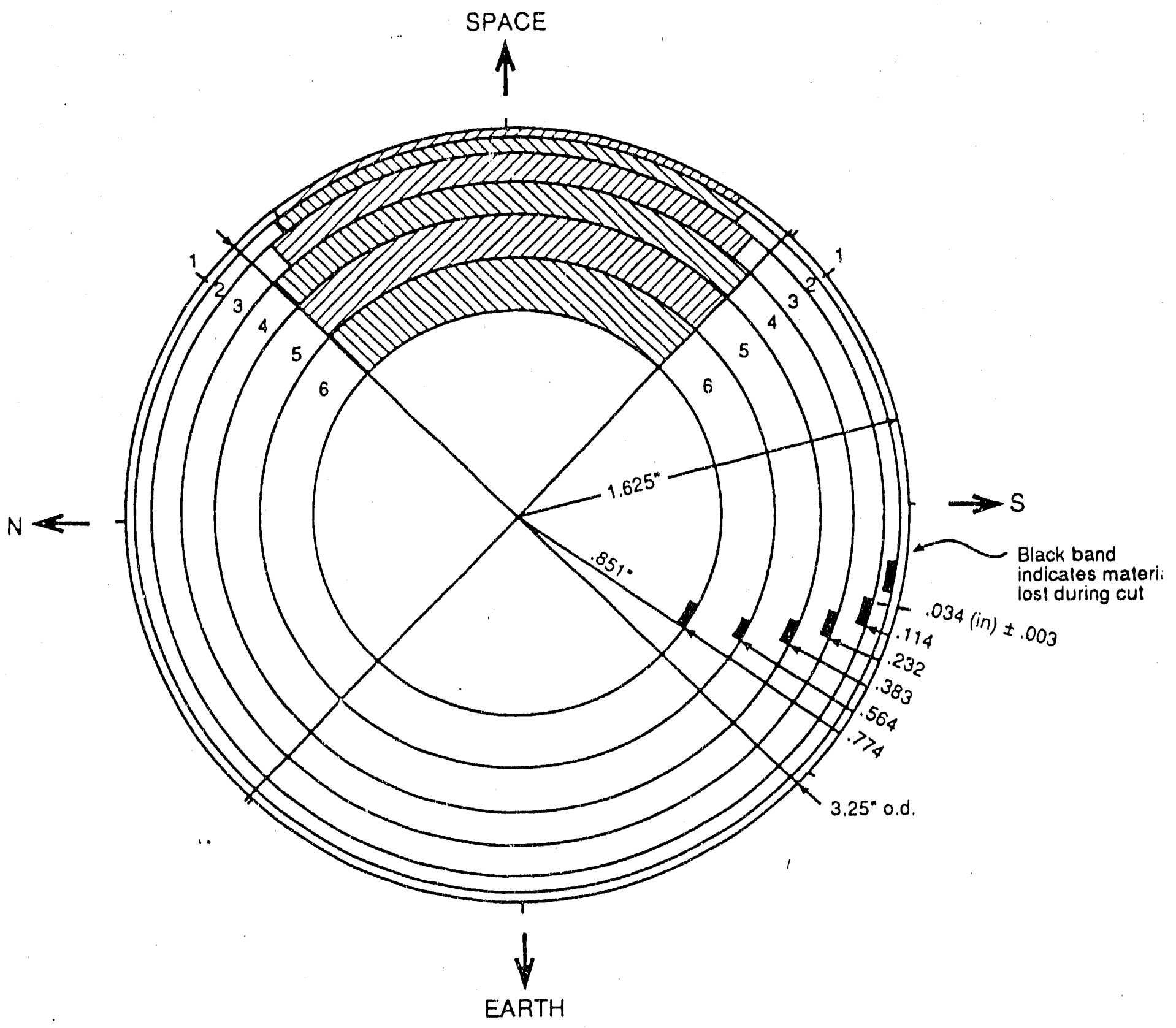

Figure 9. Location scheme for Trunnion Layer Samples 


\section{RH-G Trunnion Layer Samples}

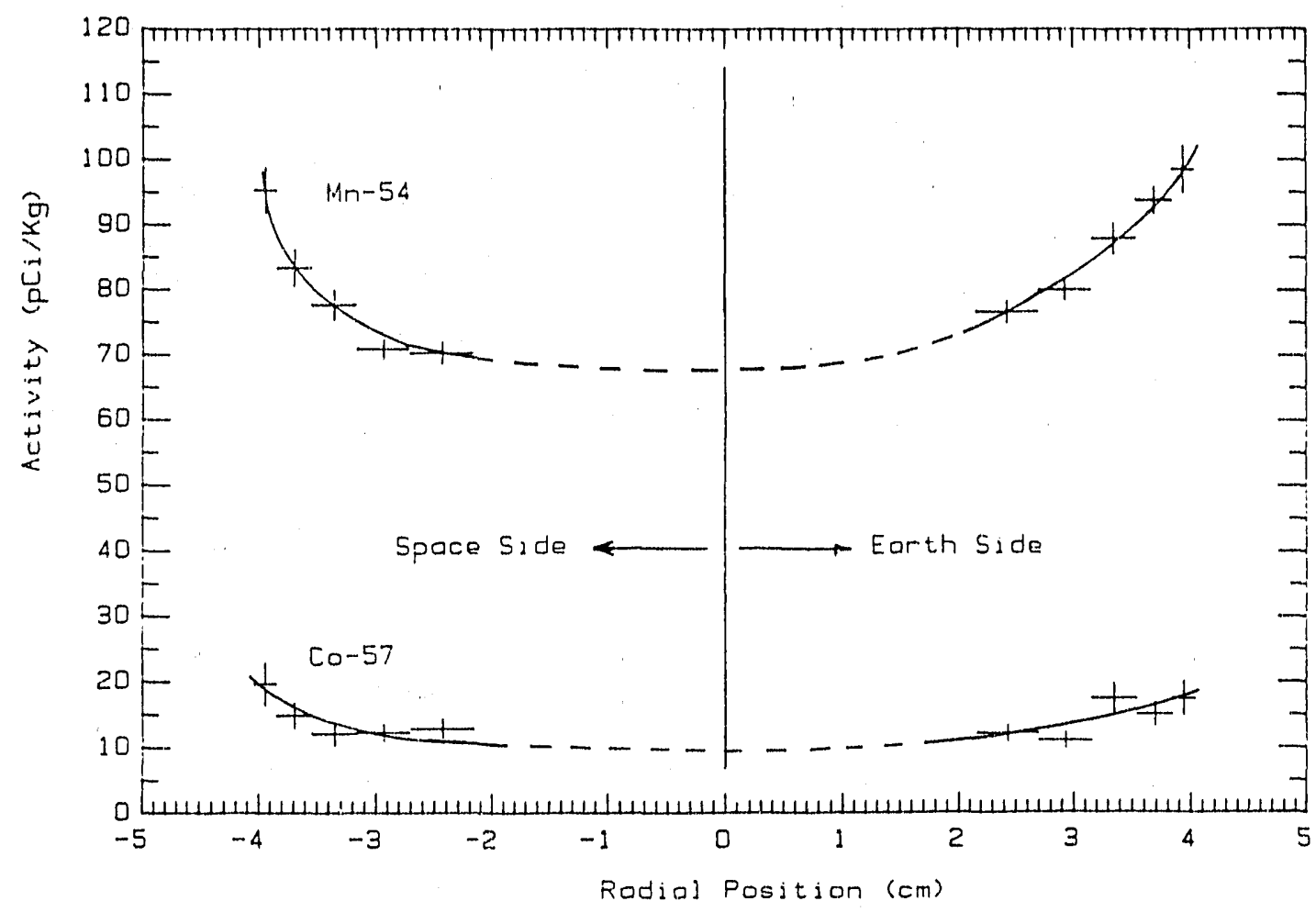

\section{Figure 10. Activity of Trunnion Layer samples}

The $\mathrm{RH}-\mathrm{G}$ trunnion activity radial dependence is given. The activity error bars are $1-\sigma$ counting errors, and position error bars are the widths of the layers. 
(a) Keel Plate

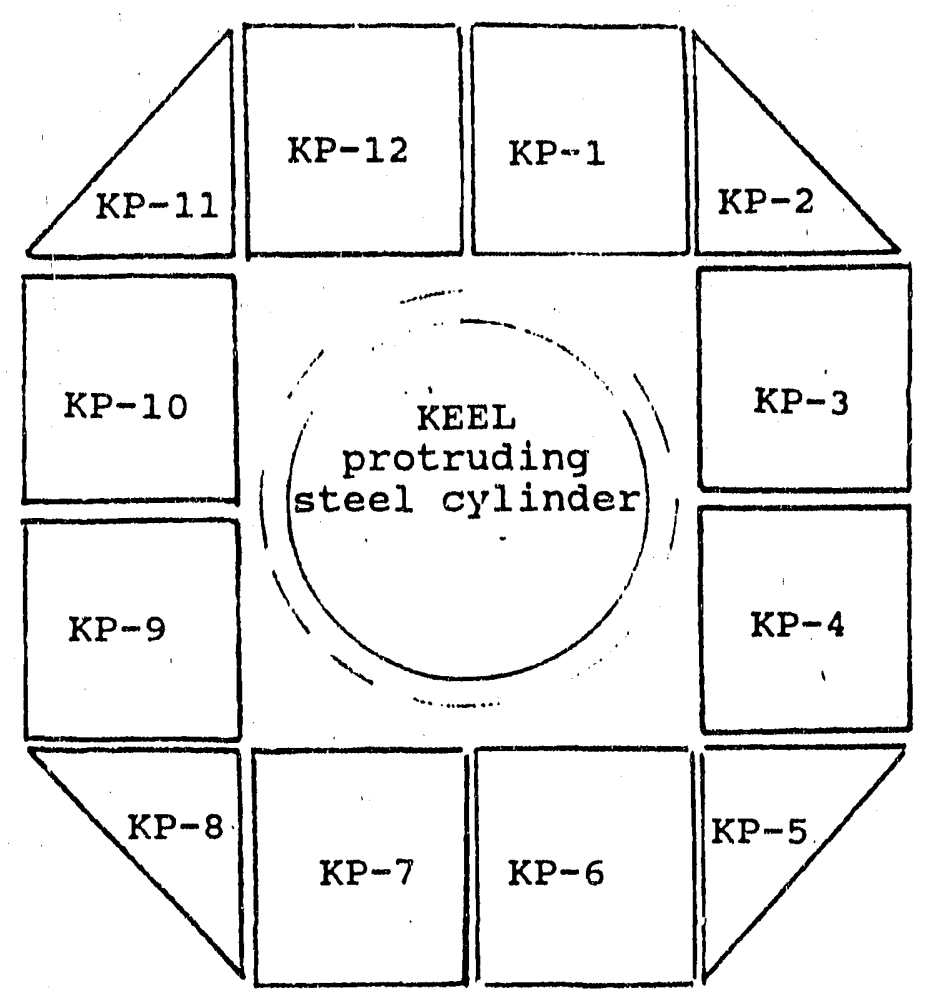

LOCATION

Centered between

$\mathrm{C}-6$ and $\mathrm{c}-6$

$\prod_{21}^{11}$

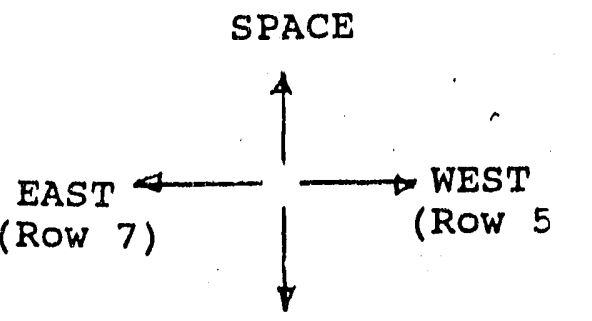

EARTH

(b) End support Retainer Plate

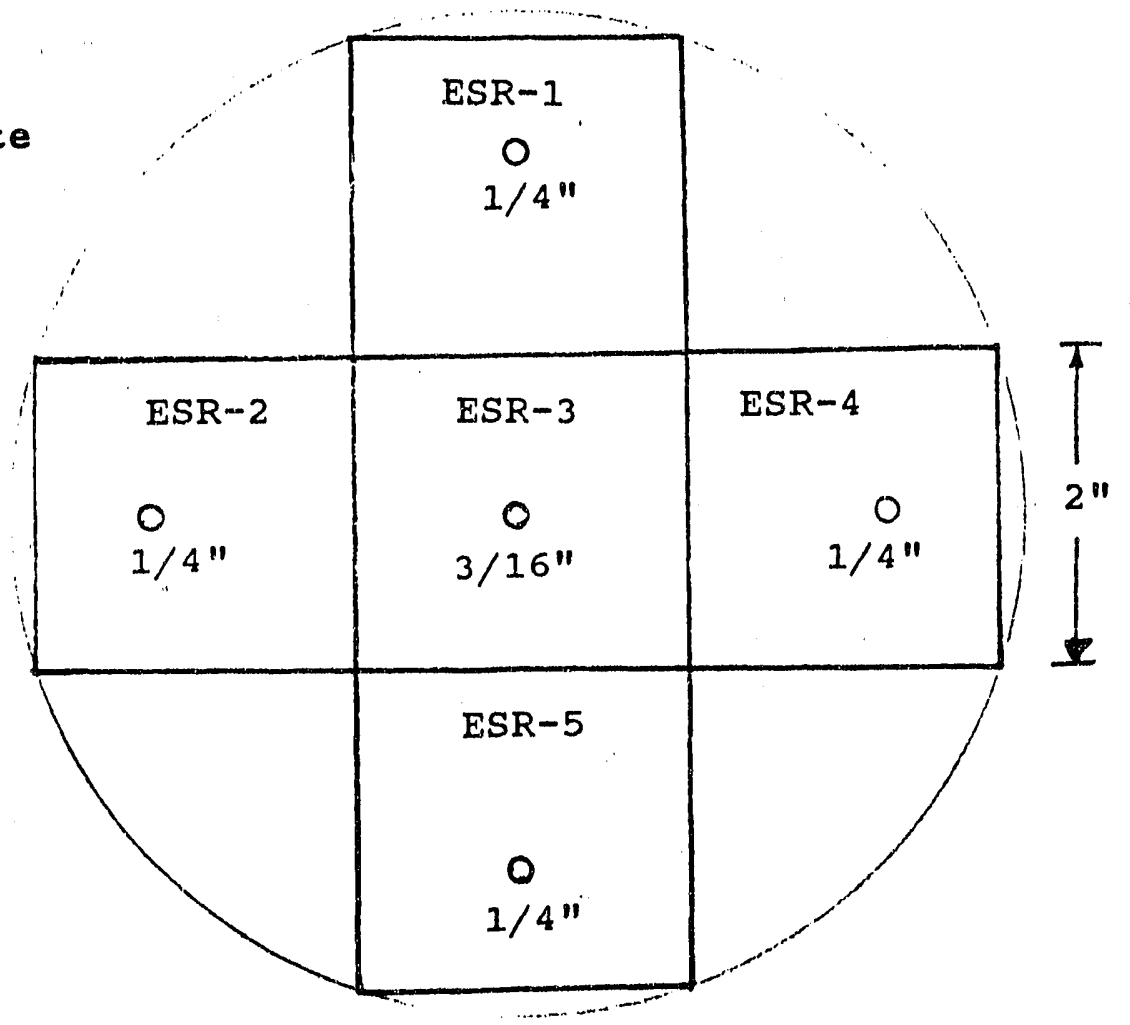

LOCATION

Centered on Earth end

\section{II}

Figure $X$ : Detailed Locations of Aluminum samples

Alumirum samples analyzed at SRS were (a) keel plate samples $\mathrm{KP}-3$ and $\mathrm{KP}-10$ and (b) end-support plate samples ESR-1 and ESR-5. 


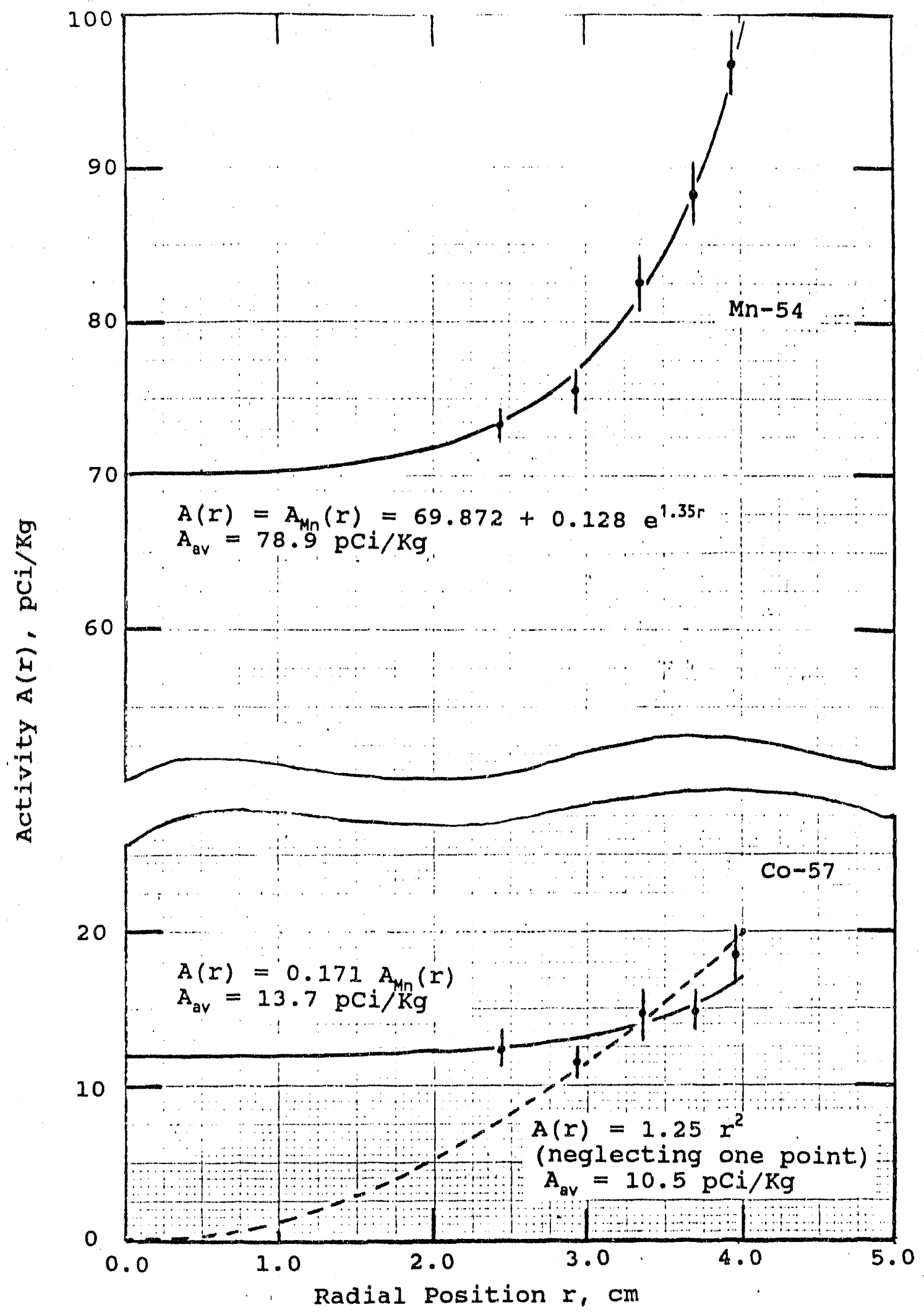

\section{Figure 12. Trunnion Layer Averages}

The trunnion radial profile points are averaged, and smooth curves are developed to predict the average activities $A_{\mathrm{av}}$. 
The table below describes peaks in the background spectrum in Figure 2. These backgrounds are representative of the bulk of the data collected with the $90 \%$ HPGe detector during this work. The active shield became of use later in the study, causing reduction in the continuum background and the $511.0 \mathrm{keV}$ annihilation gamma, as illustrated in Figure 3.

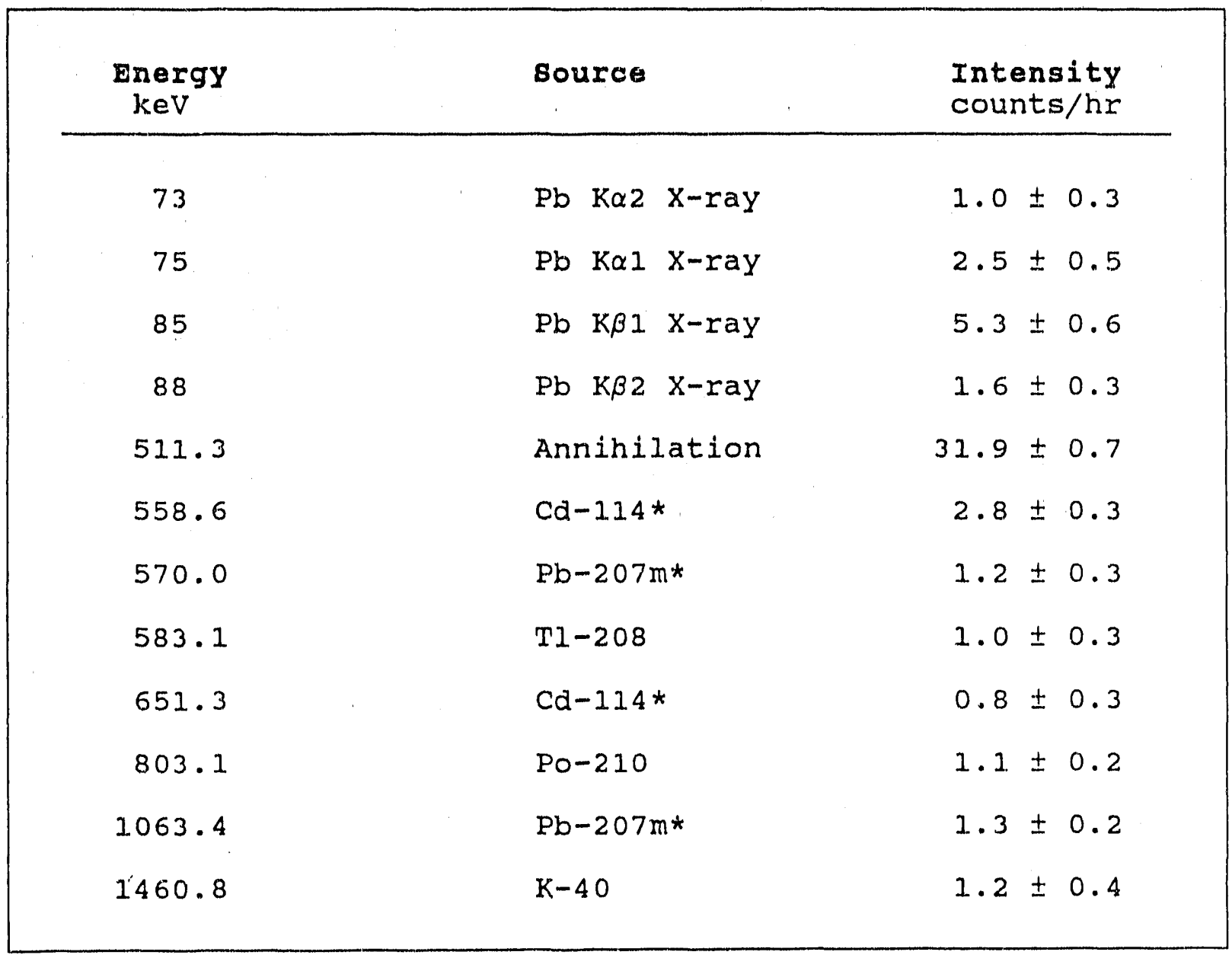

* These isotopes are produced in equillibrium with neutrons from cosmic rays. Prompt reaction gammas for transitions in $\mathrm{Cd}-114$ are produced by $\mathrm{Cd}-113(\mathrm{n}, \tau)$ and $\mathrm{Cd}-114\left(n, n^{\prime}\right)$.

Effectively prompt gammas from $\mathrm{Pb}-207 \mathrm{~m}(0.8 \mathrm{~s})$ are produced by $\mathrm{Pb}-20^{\circ} ;\left(n, n^{\prime}\right)$ and $\mathrm{Pb}-208(n, 2 \mathrm{n})$. 


\section{APPENDIX B. DETECTOR EFFICIENCY CALIBRATIONS}

\section{General Theory}

The basic model for the calibration is given in Equation 2 of the main text as

$$
\epsilon(r, h)=g(r) e^{-U(r) h},
$$

where $r$ and $h$ are the coordinates within the sample; Although experimental support for this model has been cited, ${ }^{7,8}$ it is worthwhile to examine it mathematically.

The basis for the $e^{-U(r) h}$ dependence of $\epsilon(r, h)$ results from the fact that at any point in the sample, the efficiency can be expressed as the product of a $\mathrm{k} / \mathrm{R}^{2}$ geometry factor and a $r-$ attenuation factor $e^{-\mu h \sec \theta}$, where $k$ is a constant, $R$ is the effective source-to-detector distance, $\mu$ is the $\tau$-attenuation coefficient for the sample, and hsece is the portion of $R$ within the sample. Referring to Figure $B-1, \theta=\sin ^{-1}(r / R)$, so that $\sec \theta=f(r)$. Thus,

$$
\epsilon(r, h)=k e^{-\mu h \sec \theta} / \mathrm{R}^{2}=\mathrm{k} \mathrm{e}^{-\mu h f(r)} \mathrm{e}^{-2 \ln (R)}
$$

Using $R=R_{0}+$ hsec $\theta$ yields the approximation,

$$
\ln \left(R / R_{0}\right)=\ln \left(1+h f(r) / R_{0}\right) \approx h f(r) / R_{0}=C(r) h
$$

In the present work. $\left[R / R_{0}\right]^{2} \equiv 1$ at $h=h_{b} \equiv 0$, and the corresponding measured $\left[R / R_{0}\right]^{2}$ are as large as 2.0 at $h=h_{t}$. Thus $R / R_{0}$ ranges from 1.0 to 1.4 , and $\ln \left(R / R_{0}\right)$ is $h$ approximates a straight line with maximum deviations of about 0.005 . Accordingly, $\mathrm{R}^{-2}$ approximates an exponential in $\mathrm{h}$ to within about $1 \%$. Thus, Equation $\mathrm{B}-2$ may be written as

$$
\begin{aligned}
\epsilon(r, h) & =k e^{-\mu h f(r)} e^{-2[\ln (R 0)+\ln (R / R 0)]} \\
& =k e^{-2 \ln (R 0)-2 c(r) h-\mu f(r) h} \\
& =g(r) e^{-U(r) h},
\end{aligned}
$$

where Equation $B-1$ has been reproduced. In terms of this 
derivation, the functions $g(r)$ and $U(r)$ are

$$
\begin{aligned}
& g(r)=k e^{-2 \ln (R o)} \\
& U(r)=2 C(r)+\mu f(r)
\end{aligned}
$$

\section{Trunnion Disk samples}

The text (Equation 4) shows that the above model yields an average radial sample efficiency of

$$
\epsilon(r)=\frac{\epsilon\left(r, h_{t}\right)-\epsilon\left(r, h_{b}\right)}{\ln \left[\epsilon\left(r, h_{t}\right) / \epsilon\left(r, h_{b}\right)\right]}
$$

where $h_{t}$ and $h_{b}$ are point source locations on the top and bottom surfaces of the trunnion disk. Detector measurements of $\epsilon(r, h)$ at both $h_{1}$ and $h_{b}$ for three $r$ locations shown in Figure 5 produced the relative efficiency curves shown in Figure B-2. These curves plot $\epsilon_{\text {rel }}(r, h)$ vs $E_{\tau}$ for the trunnion disks, using the normalization $\epsilon_{\text {rel }}(r, h)=\epsilon(r, h) / \epsilon(0,0)$ for each gamma energy $E_{f}$. The $\epsilon_{\mathrm{rel}}(r, h)$ are useful from an experimental aspect, because they are determined from the ratio of count rates and do not require knowledge of the source strength. Also, Equation B- 6 may be expressed as

$$
\epsilon(r)=\epsilon(0,0) \epsilon_{\text {rel }}(r)=\epsilon(0,0) \frac{\epsilon_{\text {rel }}\left(r, h_{t}\right)-\epsilon_{\text {rel }}\left(r, h_{b}\right)}{\ln \left[\epsilon_{\text {rel }}\left(r, h_{t}\right) / \epsilon_{\text {rel }}\left(r, h_{b}\right)\right]}
$$

A BASIC code GEnLDEFA was developed to calculate $\epsilon_{\text {rel }}(x)$ at the three $r$ locations, using the curves of Figure $B-2$. This code also uses these $\epsilon_{\text {rel }}(r)$ to calculate the three parameters ( $A, B$, and $p$ ) used in calculating $\epsilon$, per modifications of Equations 5 and 6 of the main text, viz.

$$
\begin{aligned}
\epsilon(r) & =\epsilon(0,0) \epsilon_{\mathrm{rel}}(r)=\epsilon(0,0)\left\{A_{\mathrm{rel}}-B_{r e l} r^{p}\right\} \\
\epsilon & =\epsilon(0,0) \epsilon_{\mathrm{rel}}=\epsilon(0,0)\left\{A_{\mathrm{rel}}-[2 /(2+p)] B_{\mathrm{rel}}\left[r_{d}\right]^{p}\right\}
\end{aligned}
$$

Here, $A_{r e l}=A / \epsilon(0,0)$ and $B_{r e l}=B / \epsilon(0,0)$. Thus, GEnLDEFA calculated $\epsilon_{\text {rel }}$ as a function of $E_{\tau}$ for the trunnions. To obtain $\epsilon(0,0)$ as a function of $\mathrm{E}_{\tau}$, earlier calibrations with aqueous vials were used as explained below.

Aqueous vials of $65 \mathrm{~mm}$ diameter had been calibrated earlier 
as a function of height for $E_{\tau}=88-1836 \mathrm{keV}$ using NIST-traceable standards. The $\epsilon$ were calculated for aqueous samples with $h$ equal to that of the calibration trunnions, but the aqueous disk radius $r_{d}$ and attenuation $\mu$ differed from those of the trunnions.

Nevertheless, the $\epsilon(0,0)$ were obtained from the:e earlier aqueous vial calibrations as follows. Measurements were mapped for $\epsilon(r, h)$ $=\epsilon_{0}(r, h)$ at the same locations as earlier, but with no sample (essentially air, using a thin plastic shell "sample"). Dividing the earlier $\epsilon(r, h)$ measurements for the trunnions by these yielded

$$
\epsilon(r, h) / \epsilon_{0}(r, h)=e^{-\left[U(r) \cdot U_{0}(r)\right] h}=e^{-\mu f(r) h}
$$

from Equations $B-4$ and $B-5$, since $U_{0}(r)$ effectively has a $\mu=0$. The $\mu$ for the trunnion was obtained from tabulations, $h$ (actually $h_{t}-h_{b}$ ) was measured, and $\epsilon(r, h) / \epsilon_{0}(r, h)$ were measured, so that the $f(r)$ could be determined. Then, obtaining the $\mu_{A}$ for the aqueous samples from tabulations, the corresponding $\epsilon_{A}(r, h)$ were calculated per rearrangement of Equation B-10 as

$$
\epsilon_{A}(r, h)=\epsilon_{0}(r, h) e^{-\mu A f(r) h}
$$

Thus, replacing $\epsilon(r, h)$ with $\epsilon_{A}(r, h)$ beginning with Equation $B-6$ and proceeding to Equation $B-9$ as before, we obtain

$$
\epsilon_{\mathrm{A}}=\epsilon(0,0) \epsilon_{\mathrm{Arel}}=\epsilon(0,0)\left(\mathrm{A}_{\mathrm{Arel}}-[2 /(2+\mathrm{p})] \mathrm{B}_{\mathrm{Arel}}\left[\mathrm{r}_{\mathrm{Ad}}\right]^{\mathrm{PA}}\right\}
$$

where the GEnLDEFA code only yields $\epsilon_{\text {Arel }}$. However, $\epsilon_{A}$ are known from the earlier aqueous calibrations, so that the $\epsilon(0,0)$ are readily calculated. Subsequently, the final trunnion $\epsilon$ were determined from

$$
\epsilon=\epsilon(0,0) \epsilon_{\text {rel }}=\left[\epsilon_{A} / \epsilon_{\text {Arel }}\right] \epsilon_{\text {rel }}=\left[\epsilon_{\text {rel }} / \epsilon_{\text {Arel }}\right] \epsilon_{A}
$$

where the calculated ratio of the relative efficiencies is multiplied by the known efficiency of the aqueous standards. Figure B-3 shows the curves for $\epsilon_{\text {rel }}$ and $\epsilon_{\text {Arel }}$ generated from the base data of Figure $B-2$, and Figure $B-4$ shows corresponding curves for $\epsilon$ and $\epsilon_{\wedge}$.

Substituting $\epsilon(0,0)$ with the $661.6 \mathrm{keV}$ gamma point-source efficiencies from ${ }^{137} \mathrm{Cs}$ standard atop the $20 \%$ and $25 \%$ HPGe detectors, Equation 12 yielded efficiencies $\epsilon_{A}$ in $5 \%$ agreement with the earlier measured aqueous efficiencies, as shown in Table B-1. Because the NIST-based $\epsilon$ were considered more accurate,

$$
\mathrm{B}-3
$$


these were adopted over the point source values. Trunnion calculations with $\epsilon$ using Equation B-13 differed by a factor of $1.070 \pm 0.020$ for the two detectors, in examining the most intense $834.8 \mathrm{keV}$ gamma of ${ }^{54} \mathrm{Mn}$. Consequently, the efflalencies of these similar detectors were adjusted by factors of $(1.07)^{1 / 2}$ so that their individual results would agree with their average.

The above efficiency deveoplment is favored over other alternatives for several reasons in addition to being NIST-based. Table B-2 shows the results of various obyious alternatives including the adopted one. Note that the ${ }^{54} \mathrm{Mn}$ for the slabdetermined RHG disk and the adjacent RHF disk agree best with the adopted method. Because the efflcienoy corrections for the slab samples of the RHG disk are relatively ininor, the ${ }^{54} \mathrm{Mn}$ estimate for this disk is considered falrly reliable. Thus, the adopted method provides the best overall self-consistency.

The $90 \%$ HPGe was out-of-service during these oalibration studies, but an efficiency curve for it was later "bootstrapped" from the other two detectors by comparing count rates for common trunnion samples; earlier calibration flies for this detector were also used. The $834.8 \mathrm{keV}$ gamma from Mn-54 was the main gamma used to normalize the calibrations in the range where most sample gammas (from 810.8 to $1332.6 \mathrm{keV}$ ) were detected. The shape of the calibration curve in this region is also only weakly affected by sample attenuation and geometry, allowing an earlier unattenuated calibration curve to check the consistency of some of the less intense gammas in this region. The intensity of the previously measured $122.0 \mathrm{keV}$ gamma of ${ }^{57} \mathrm{Co}$ was sufficiently accurate $( \pm 4.7 \%)$ to guide the calibration at lower energies, which included other sample gammas at $136.7 \mathrm{keV}\left({ }^{57} \mathrm{Co}\right)$ and $320.0 \mathrm{keV}$ $\left({ }^{51} \mathrm{Cr}\right)$, which have generally intensity accuarcies above $25 \%$. A gamma at $477.0 \mathrm{keV}\left({ }^{7} \mathrm{Be}\right)$ will have the least accurate efficiency, but it is not positively detected. The $90 \%$ HPGe was primarily incorporated to check whether any smaller activities were missed with the less efficient detectors. Thus, the accuracy of this efficiency curve is more than sufficient to analyze any previously undetected weak gamma peaks, whose counting errors will overshadow the accuracy of the efficiency curve. The efficiency curve is given in Figure $B-5$, and it was crosscalibrated using the RHR trunnion sample.

As implied in Table $B-1$, the above base calibrations applied to specific trunnion pieces. The $h$ for the different trunnions ranged from 10-2. mm, but most were in the neighborhood of $20 \mathrm{~mm}$. For those with $\mathrm{h} \approx 20 \mathrm{~mm}$, a perturbation correction for the small $\delta \mathrm{h}$ differences was applied, whereby the fractional change was estimated with an $\epsilon(r, h)$ of Equation $B-1$ approximated with an average $U(r)=U$. The count rate $c_{s}$ and $c_{x}$ of the standard trunnion $\left(h_{t}-h_{b}=h_{s}\right)$ and a nearly identical one $\left(h_{t}-h_{b}=h_{s}+\delta h\right)$ are ratioed for the correction 


$$
c_{x} / c_{s}=\left(1-e^{-U[h s+\delta h]}\right) /\left(1-e^{-U h s}\right)
$$

which ranged from 0.972 to 1.043 for the trunnions that were corrected for small $\mathrm{\delta} h$, as shown in Table $\mathrm{B}-3$. Dividing the observed countrates by these factors normalized the countrate to that of a standard trunnion. Then the resulting activity was divided by the corresponding mass of the trunnion standard to obtain the speaific activity in $\mathrm{pci} / \mathrm{kg}$.

For trunnions with significant $\delta \mathrm{h}$, a more elaborate correction was developed. The above method caloulates an average radial efficlency $\epsilon(r)$ according to Equation $B-6$, which inoludes a term

$$
\epsilon\left(r, h_{t}\right) / \epsilon\left(r, h_{b}\right)=\exp \left[-U(r)\left(h_{t}-h_{b}\right)\right]
$$

Thus, for a different thickness of sample such that $h_{t}=h_{x}$ we may write

$$
\begin{aligned}
\epsilon\left(r, h_{x}\right) / \epsilon\left(r, h_{b}\right)=\exp \left[-U(r)\left(h_{x}-h_{b}\right)\right]=\exp \left[-U(r)\left(h_{t}-h_{b}\right) X\right]= \\
=\left[\epsilon\left(r, h_{t}\right) / \epsilon\left(r, h_{b}\right)\right]^{x}=F_{t b}(x)
\end{aligned}
$$

The $\epsilon(r)=\epsilon_{X}(r)$ corresponding to $h_{x}$ is then calculated using Equation $B-6$ per substitution from Equation $B-16, v 1 z$.

$$
\epsilon_{x}(r)=\frac{\epsilon\left(r, h_{x}\right)-\epsilon\left(r, h_{b}\right)}{\ln \left[\epsilon\left(r, h_{x}\right) / \epsilon\left(r, h_{b}\right)\right]}=\frac{\epsilon\left(r, h_{b}\right)\left[F_{t b}(x)-1\right]}{x \ln \left[\epsilon\left(r, h_{t}\right) / \epsilon\left(r, h_{b}\right)\right]}(B-17)
$$

Thus, this efficiency was used, where $x$ is the thickness of the sample in units of $h=h_{t}-h_{b}$ for the reference standard. The GEnLDEFC code, developed from the GEnLDEFA code, calculated the corresponding efficiency $\epsilon_{x}$ along with the $\epsilon$ of the standard trunnion, so that the efficiency corrections $\epsilon_{\mathrm{x}} / \epsilon$ could be applied to these samples.

\section{Small Layer and slab samples}

All layer and slab samples were counted on the 90\% HPGe. For these samples $\epsilon(r, h)$ was found to be sufficiently modeled as

$$
\epsilon(r, h)=\epsilon\left(r, h_{b}\right) e^{-U(h-h b)}
$$


whioh is Equation 7 of the main text. Source mappings across the top of the deteotor produced $\epsilon\left(r, h_{b}\right)$ that could be fitted with the function

$$
\epsilon\left(r, h_{b}\right)=\epsilon(r, 0)=\epsilon(0,0)\left(1+a r^{3}\right)^{\cdot 1 / 2},
$$

where $h_{b}=0$ has been defined for convenience and a is a constant. Figure $B-5$ gives $\epsilon(0,0)$, which is the point source efficiency curve for this detector. Experimental plots for the $\left(1+a r^{3}\right)^{-1 / 2}$ dependence are given in Figure $B-6$. The average of $\epsilon(r, h)$ over the surface or $r$, depends only on $\epsilon(r, 0)$, and thus the area average over the sample is

$$
\epsilon(h)=\langle\epsilon(r, 0)\rangle e^{-U h}=\epsilon(0,0) e^{-U h}\left\langle\left(1+a r^{3}\right)^{-1 / 2}\right\rangle \quad(B-20)
$$

A BASIC code PLATEFF3 was written to numericaliy perform the average over the rectangular areas.

To average over the helght of the sample for different energles, $U$ must be caloulated from

$$
\mathrm{U}=\mathrm{C}+\mu \mathrm{f}
$$

This is the same as Equation 9 of the main text, where it was discussed that 661 and $1332 \mathrm{keV}$ point sources measured two different $U$, which are associated with corresponding tabulated $\mu$, and thus provide two equations for solving the two unknowns $c$ and $f$. The resulting $\mu \mathrm{f}$ term dominated over the c term of $U$. With $U$ known, the average over h ylelds

$$
\epsilon=\epsilon(0,0)\left\langle\left(1+a r^{3}\right)^{-1 / 2}\right\rangle \frac{2-e^{-U(h t-h b)}}{U\left(h_{t}-h_{b}\right)}
$$

The layer efficiencles were directly calculated with this equation.

The method for the exponential average factor was checked experimentally with ${ }^{54} \mathrm{Mn}$ and ${ }^{57} \mathrm{Co}$ sources and a trunnion slab. The $835 \mathrm{keV}$ gamma of ${ }^{54} \mathrm{Mn}$ yielded 0.833 for this factor, which is in excellent agreement with that of 0.827 for the method. The 122 $\mathrm{keV}$ gamma yielded a factor of 0.649 , whtch agreed poorly with the 0.500 predicted by the method; thus, the experimental. factors were applied for ${ }^{57} \mathrm{Co}$. Note that the ${ }^{54} \mathrm{Mn}$ predictions were by interpolation, while the ${ }^{57} \mathrm{Co}$ was an extrapolation. Except for ${ }^{57} \mathrm{Co}$, all slab-sample radionuclides were determined by the more reliable interpolation. 
The $\epsilon$ for steel trunnion layers were calculated for the 835 $\mathrm{keV}$ gamma of ${ }^{54} \mathrm{Mn}$ and the $122 \mathrm{keV}$ of ${ }^{57} \mathrm{Co}$. Only ${ }^{46} \mathrm{Sc}$ was detected in the vanadium samples and its low level $889 \mathrm{keV}$ and $1.20 \mathrm{keV}$ gammas were corrected assuming an average energy of $1000 \mathrm{keV}$. only ${ }^{22} \mathrm{Na}$ was detected in the aluminum sauple, and $1 \mathrm{ts} 1274 \mathrm{keV}$ gamma was used; however, a significant suming correction needed to be addressed as disoussed next below.

In ${ }^{22} \mathrm{Na}$ decay, the $1274 \mathrm{keV}$ gamma is coincident with a positron emission about $90 \%$ of the time, so that an average of 1.81 annihilation $511 \mathrm{keV}$ gammas cascade with each $1274 \mathrm{keV}$ gamma. Simultaneous detection (or summing) of $51 \mathrm{l} \mathrm{keV}$ and 1274 keV gammas does not register a count in the $1274 \mathrm{keV}$ spectral peak, so that the resulting peak area is abnormally low. Given that a $1274 \mathrm{keV}$ gamma is detected, the probability that it sums with a $511 \mathrm{keV}$ gamma is $1.811 \epsilon_{T}(511)$, where $\epsilon_{\mathrm{T}}(511)$ is the total detection efficiency (not just peak efficiency) of tho $511 \mathrm{keV}$ gamma. Thus,

$$
{ }^{22} \mathrm{Na} \text { summing correction }=\frac{1}{1-1.811 \epsilon_{\top}(511)}
$$

This work calculated a summing correction for a point source atop the 90\% HPGe detector. A sizeable summing correction of 1.97 resulted, which incorporated an $\epsilon_{T}(511)=0.272$ from detector model calculations. The summing was also examined with point source measurements, yielding a correction of $1.87 \pm 0.07$. The BASIC code DETOTEFF was developed for the calculation, which also predicted a peak ratio $(511 \mathrm{keV} / 1274 \mathrm{keV})$ of 4.76 that agrees well with the average measured ratio of $4.62 \pm 0.12$. From the above, a correction of 1.90 was adopted for the point source correction or $\epsilon_{T}(511)=0.262$; the actual source is extended,
resulting in calculated relative efficiency reductions by 0.84 , pr $U$. and 0.73 for surface distribution and sample attenuation. Thus, for the actual sample, $\epsilon_{T}(511)=(0.84)(0.73)(0.262)=0.161$, and the corresponding summing correction is 1.41 .

\section{Mathematical Aspects of Exponential Average}

Because the exponential average is frequently used in this study, its functional behavior is worth examining. Figure $B-7$ plots the most relevant aspects, where exponential average of 1 and $x$ is given as $y=(x-1) / \ln (x)$,... which is appropriate for comparing relative efficiencies in the present work. In the figure, the straight average $(x+1) / 2$ is also plotted for comparison to emphasize the difference; use of a straight average in the present work will overestimate the efficiencies and accordingly underestimate the sample activities. Finally the percent deviations in $y$ that result from yercent deviations in $x$

$$
\text { B-7 }
$$


are examined. Fortunately, the $x$-deviations produce relatively smaller $y$-deviations, allowing some leniency in the experimental measurements of $x$. Thus, the accuracy of the average relative efficlency from plots like that of Figur: $B-2$ produce exponentional averages that are considerably more accurate.

\section{Further Information}

The present appendix provides essential data for comparison with other LDEF results. Further information such data files, calculation codes, detailed detector dimensions, and individual geometry and attenuation correction factors can be provided upon special request. 


\section{Test of Model with standard Vial}

For the $20 \%$ and $25 \%$ HPGe detectors, calibrations based on NIST standards were also avallable for soll and aqueous standards [ref 6]. The largest vial for these standards had diameter of 65 $\mathrm{mm}$, whioh is somewhat smaller than the diameter of $82 \mathrm{~mm}$ for the trunnion samples. The model given by Equation B-12 was tested as summarized below:

Detector

$\frac{\text { Sample }}{\text { diam } x h t}$

$20 \%$ HPGe

$65 \mathrm{~mm} \times 19.6 \mathrm{~mm}$

$25 \%$ HPGe

$65 \mathrm{~mm} \times 18.1 \mathrm{~mm}$

$\begin{array}{llr}\frac{661.6}{\text { NIST }} & \frac{\text { MeV EIficlency }}{\text { Model }} & \frac{\text { gater }}{\text { g-diff }} \\ 0.0132 & 0.0139 & 5.3 \% \\ 0.0171 & 0.0179 & 4.7 \%\end{array}$

The agreement is quite good, but suggests a systematic error of about $5 \%$ for the model.

\section{Model Normalization to NIST Standards}

To address the above 5\% bias, the trunnion effloiency curves were developed as

$$
\epsilon_{T}=\epsilon \text { (Water Vial|NIST) } \frac{\epsilon \text { (Trunnion Sample|Model) }}{\epsilon \text { (Water Vial|Model) }}
$$

where any bias in the model of tends to be cancelled in the ratio.

\section{Normalization to Trunnion Average for $20 \%$ and $25 \%$ HPGe}

The model for $\epsilon_{1}$ above yielded activities that differed by a factor of $1.070 \pm 0.020$ for the two detectors. Thus, the geometric average of the results would be $(1.07)^{1 / 2}$ larger for one detector and $(1.07)^{-1 / 2}$ smallex for the other. Accordingly, correcting each detector to agree with the average yielded

$$
\begin{aligned}
& \epsilon(20 \% \mathrm{HPGe})=(1.07)^{1 / 2} \epsilon_{T}(20 \% \mathrm{HPGe})=1.034 \epsilon_{T}(20 \% \mathrm{HPGe}) \\
& \epsilon(25 \% \mathrm{HPGe})=(1.07)^{-1 / 2} \epsilon_{T}(25 \% \mathrm{HPGe})=0.967 \epsilon_{\mathrm{T}}(25 \% \mathrm{HPGe})
\end{aligned}
$$


Table B-2. Alternative Efficiency Development

Efficiency Method

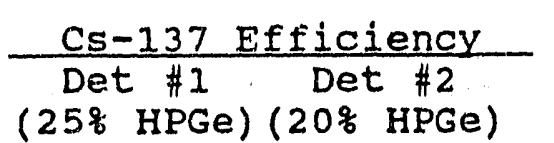
(25\% HPGe) (20\% HPGe) $\frac{\text { Trunnion } \mathrm{Mn}-54}{\text { RHGslabs RHFdisk }}$

Measurements
$\epsilon(N I S T)=\epsilon_{n}$
0.0171
0.0131
$\epsilon($ Pt std $)=\epsilon_{\mathrm{s}}$
0.0179
0.0139

Adopted
$\epsilon_{n}(1.07)^{ \pm 1 / 2}$
0.0165
0.0135
79.8
$78.98 \pm 1.34$

Alternatives

$\begin{array}{lllll}\epsilon_{n}(\# 1) 1.07 \times \epsilon_{n}(\# 2) & 0.0171 & 0.0137 & 79.8 & 76.35 \pm 1.30 \\ \operatorname{Avg}\left(\epsilon_{n}, \epsilon_{s}\right)(1.07)^{ \pm 1 / 2} & 0.0169 & 0.0140 & 79.8 & 76.69 \pm 1.30 \\ \epsilon_{g}(1.07)^{ \pm 1 / 2} & 0.0173 & 0.0142 & 79.8 & 75.22 \pm 1.28\end{array}$

$B-10$ 
Table B-3. Corrections for count Rate

$c_{x} / c_{s}=\begin{gathered}\text { count rate ratio of unknown/standard samples with same } \\ \text { uniform activity density }\end{gathered}$

\begin{tabular}{|c|c|c|c|c|c|c|c|}
\hline \multirow[b]{2}{*}{ Detector/Energy } & \multirow[b]{2}{*}{$\begin{array}{c}I D \\
h(m m)\end{array}$} & \multicolumn{6}{|c|}{ Sample } \\
\hline & & $\begin{array}{l}\text { LHP } \\
18.1\end{array}$ & $\begin{array}{l}\text { RHP } \\
18.5\end{array}$ & $\begin{array}{l}\text { RHR } \\
18.5\end{array}$ & $\begin{array}{l}\text { RHS } \\
18.8\end{array}$ & $\begin{array}{l}\text { LHS } \\
19.6\end{array}$ & $\begin{array}{l}\text { LHR } \\
20.6\end{array}$ \\
\hline $\begin{aligned} \# 1(25 \% \text { HPGe }) & / 122 \\
& / 661- \\
& / 1332\end{aligned}$ & & $\begin{array}{l}=1.000 \\
=1.000\end{array}$ & $\begin{array}{l}1.000 \\
1.008\end{array}$ & $\begin{array}{l}1.000 \\
1.008\end{array}$ & $\begin{array}{l}1.000 \\
1.013\end{array}$ & $\begin{array}{l}1.000 \\
1.028\end{array}$ & $\begin{array}{l}1.000 \\
1.043\end{array}$ \\
\hline $\begin{aligned} & \# 2(20 \% H P G e) / 122 \\
& / 661- \\
& 1332\end{aligned}$ & & $\begin{array}{l}1.000 \\
0.972\end{array}$ & $\begin{array}{l}1.000 \\
0.980\end{array}$ & $\begin{array}{l}1.000 \\
0.980\end{array}$ & $\begin{array}{l}1.000 \\
0.986\end{array}$ & $\begin{array}{l}=1.000 \\
=1.000\end{array}$ & $\begin{array}{l}1.000 \\
1.015\end{array}$ \\
\hline $\begin{array}{r}\# 3(90 \% \mathrm{HPGe}) / \\
/ 122 \\
/ 661- \\
1332\end{array}$ & & $\begin{array}{l}1.000 \\
0.992\end{array}$ & $\begin{array}{l}1.000 \\
1.000\end{array}$ & $\begin{array}{l}=1.000 \\
=1.000\end{array}$ & $\begin{array}{l}1.000 \\
1.006\end{array}$ & $\begin{array}{l}1.000 \\
1.020\end{array}$ & $\begin{array}{l}1.000 \\
1.035\end{array}$ \\
\hline
\end{tabular}




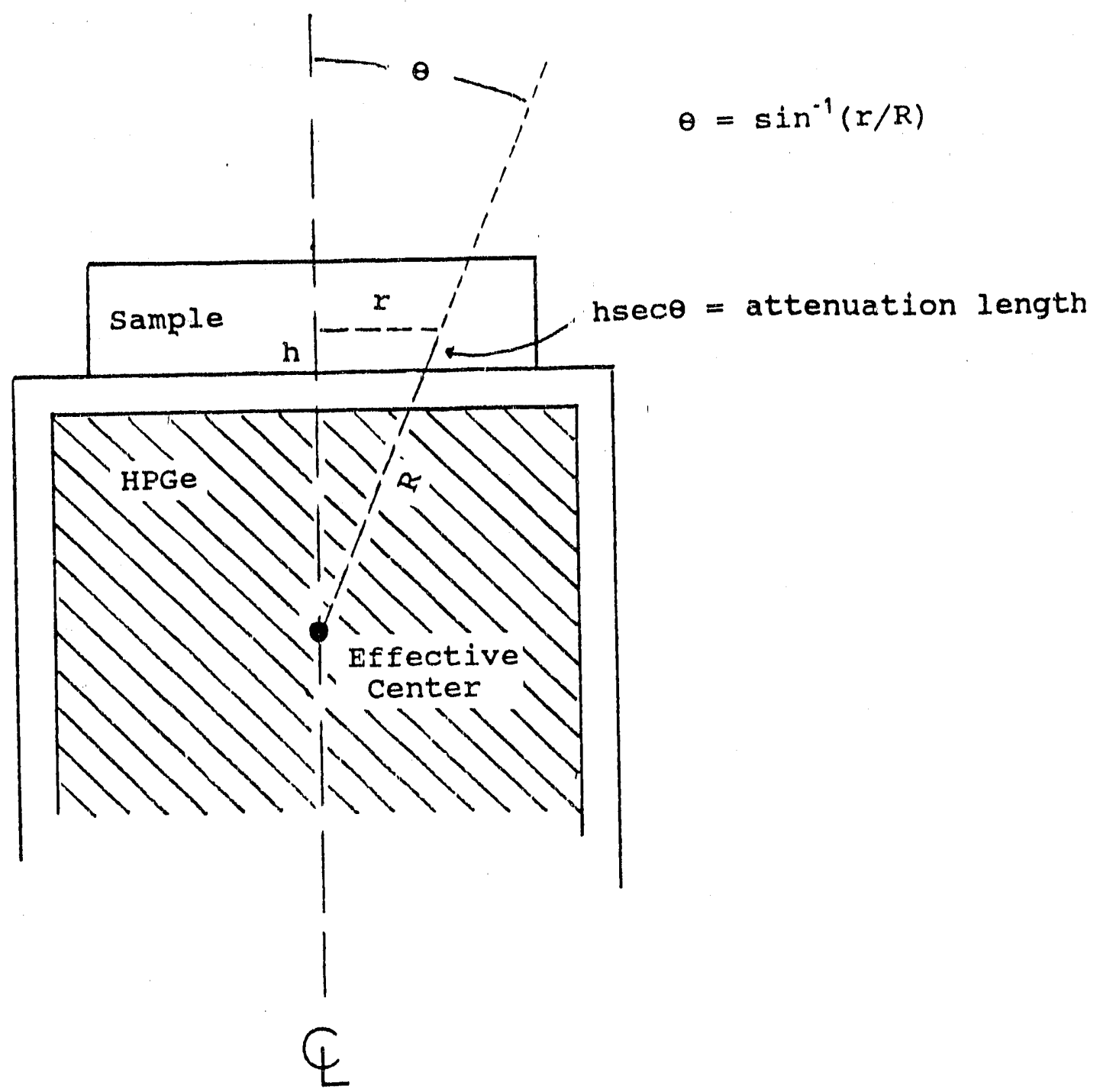

Figure B-1. Geometrical Relations for sample Attenuation

B-1 2 


\section{DETECTOR \# 1}

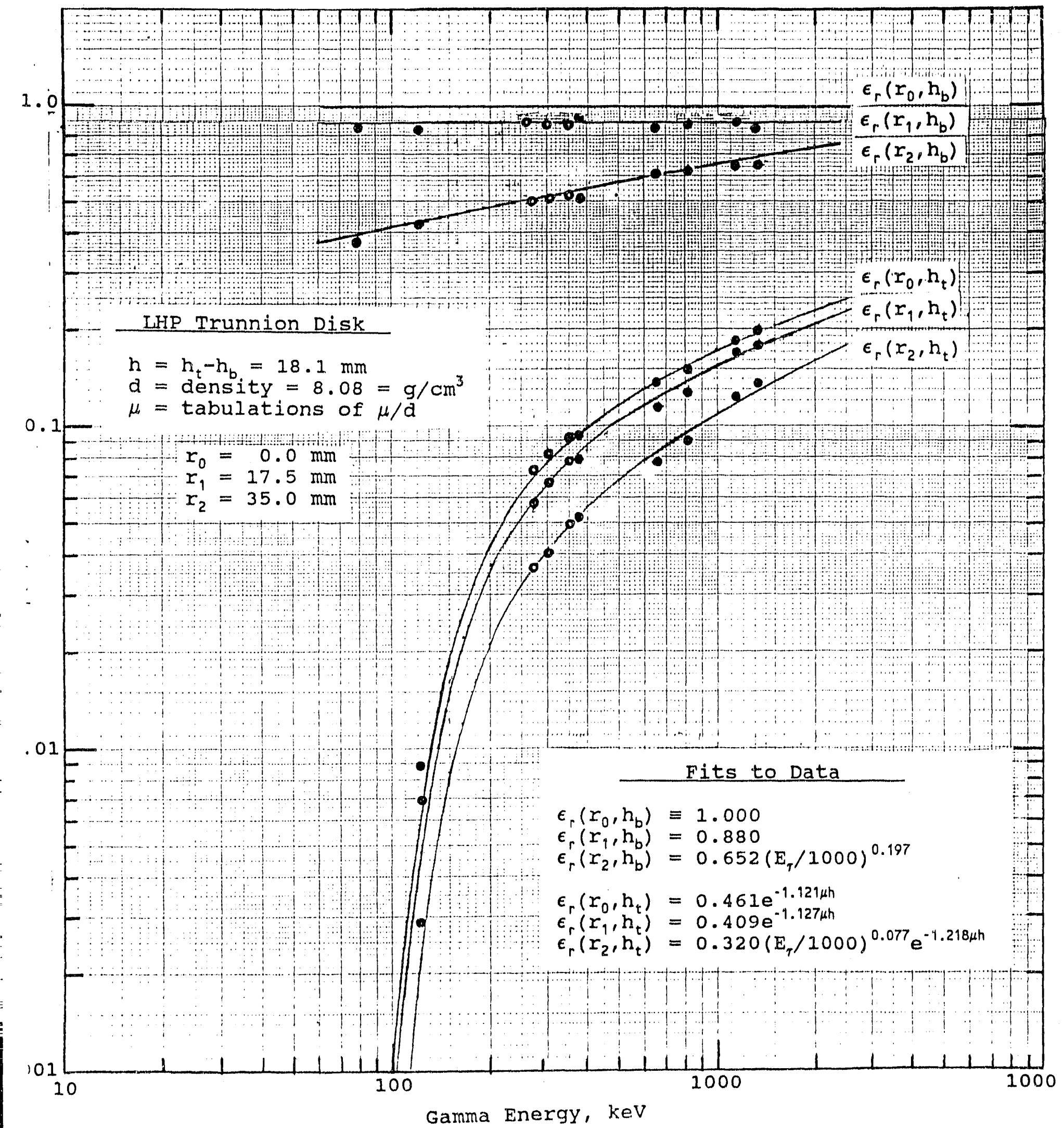

Figure B-2a. $\epsilon_{r e l}(r, h)=\bar{\epsilon}_{r}(I, h)$ Rlots for $25 \%$ HPGe 


\section{DETECTOR \#2}

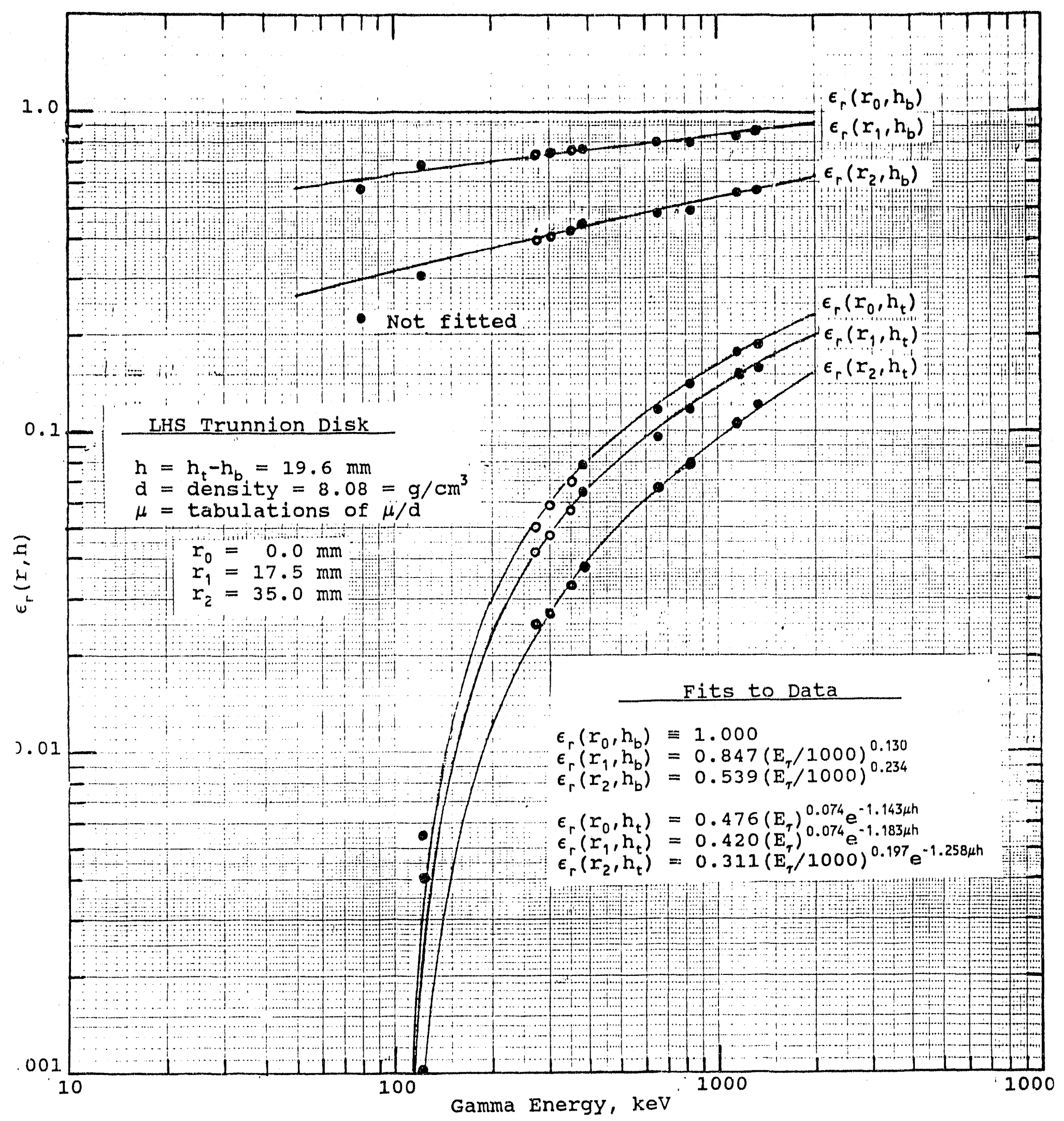

Figure B-2b. $\epsilon_{\text {rel }}(r, h)=\epsilon_{r}(r, h)$ Flots for $20 \%$ HPGe. 
DETECTOR \# 1

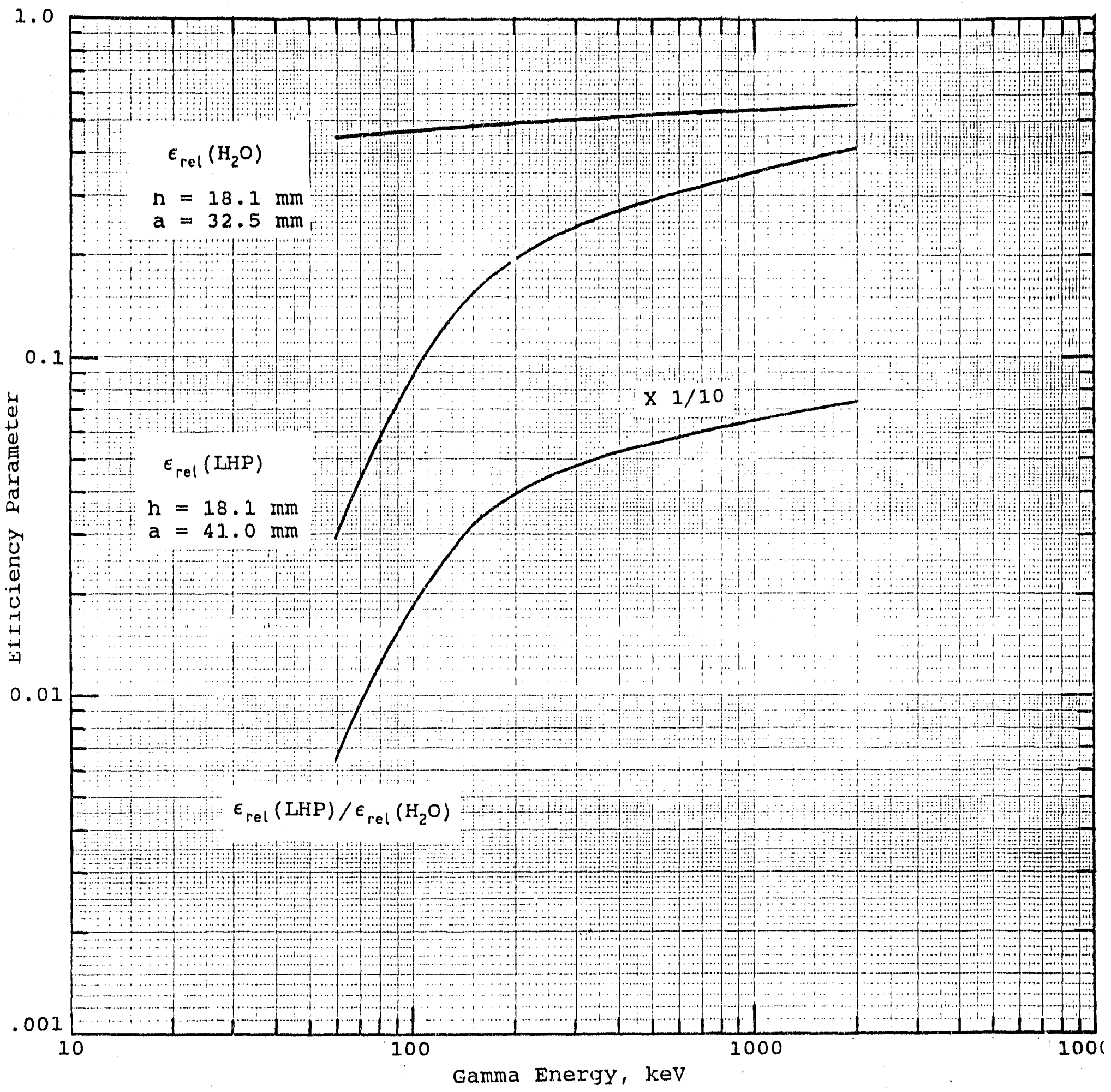

i.st

Figure B-3a. $\epsilon_{\text {rel }}\left(\mathrm{H}_{2} \mathrm{O}\right)$ and $\epsilon_{\text {rel }}(\mathrm{LHP})$ Rlots for $25 \%$ HPGe. 
120

DETECTOR \#2

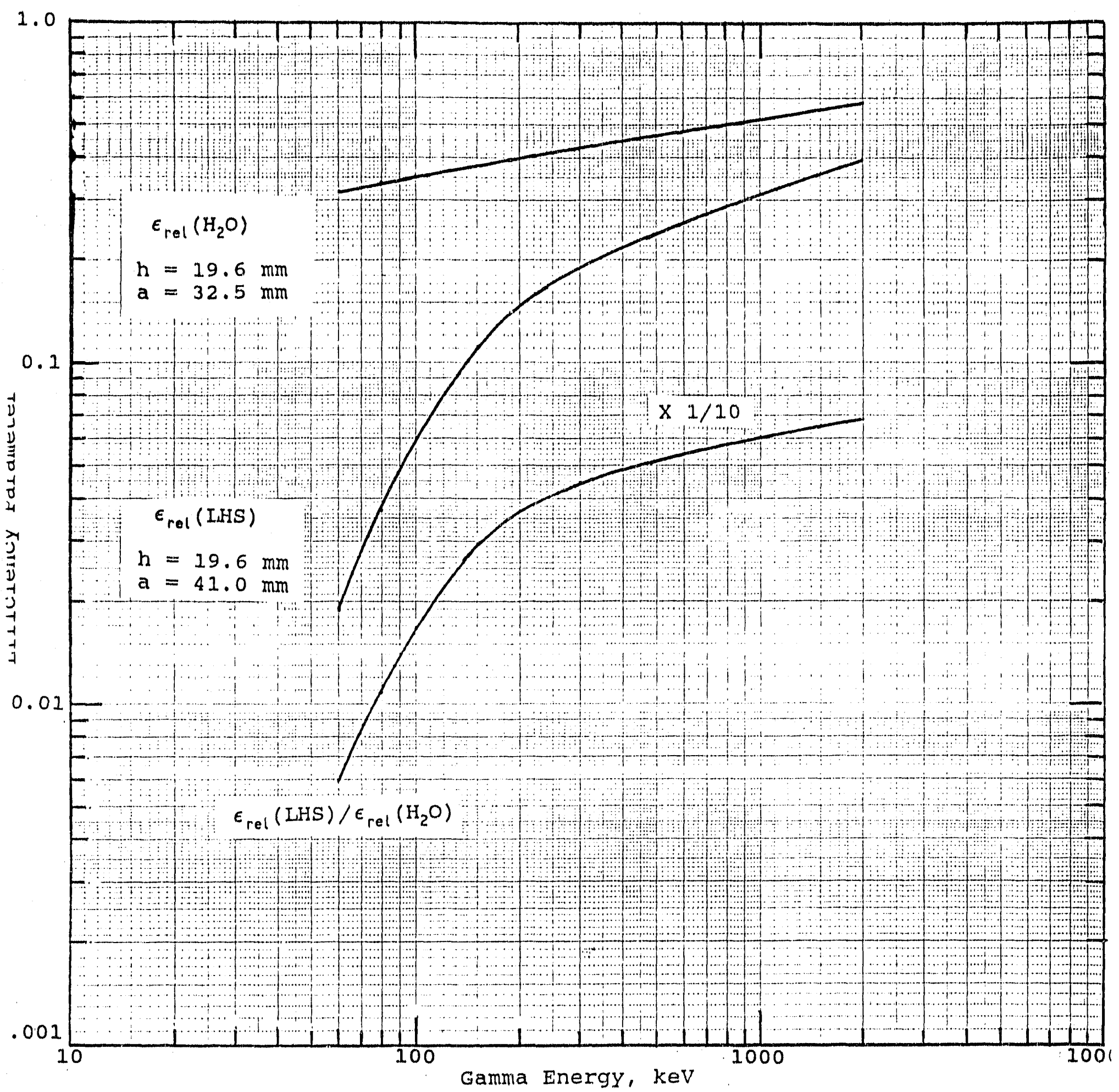

Figure $\mathrm{B}-3 \mathrm{~b} . \epsilon_{\text {rel }}\left(\mathrm{H}_{2} \mathrm{O}\right)$ and $\epsilon_{\text {rel }}$ (LHS) Plots for $20 \%$ HPGe. 
DETECTOR \# 1

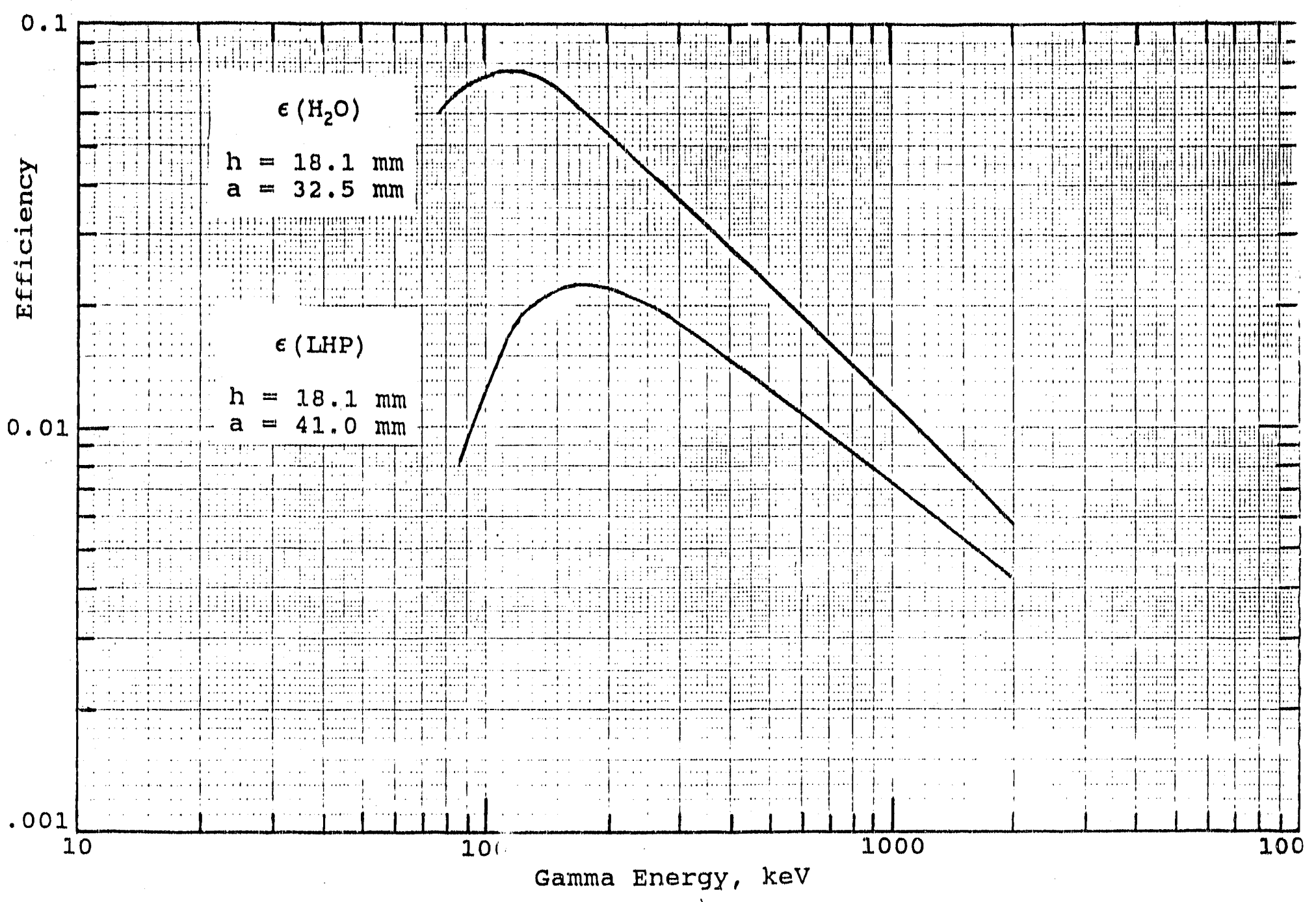

Figure $\mathrm{B}-4 \mathrm{a} \cdot \epsilon\left(\mathrm{H}_{2} \mathrm{O}\right)$ and $\epsilon(\mathrm{LHP})$ plots for $25 \%$ HPGe. 


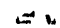

DETECTOR \#2

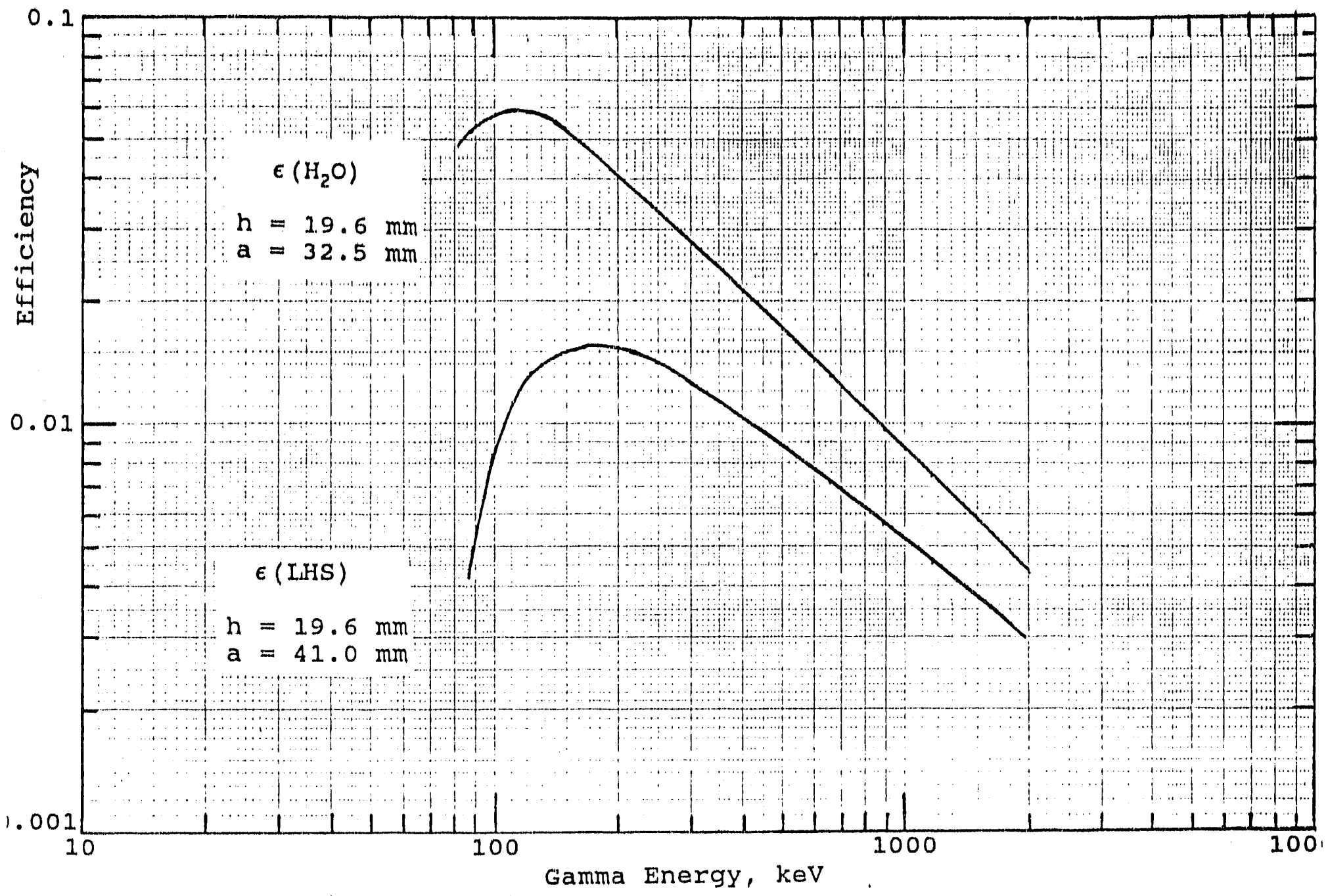

Figure. B-4b. $\epsilon\left(\mathrm{H}_{2} \mathrm{O}\right)$ and $\epsilon$ (LHS) Plots for $20 \%$ HPGe.

$B-18$ 


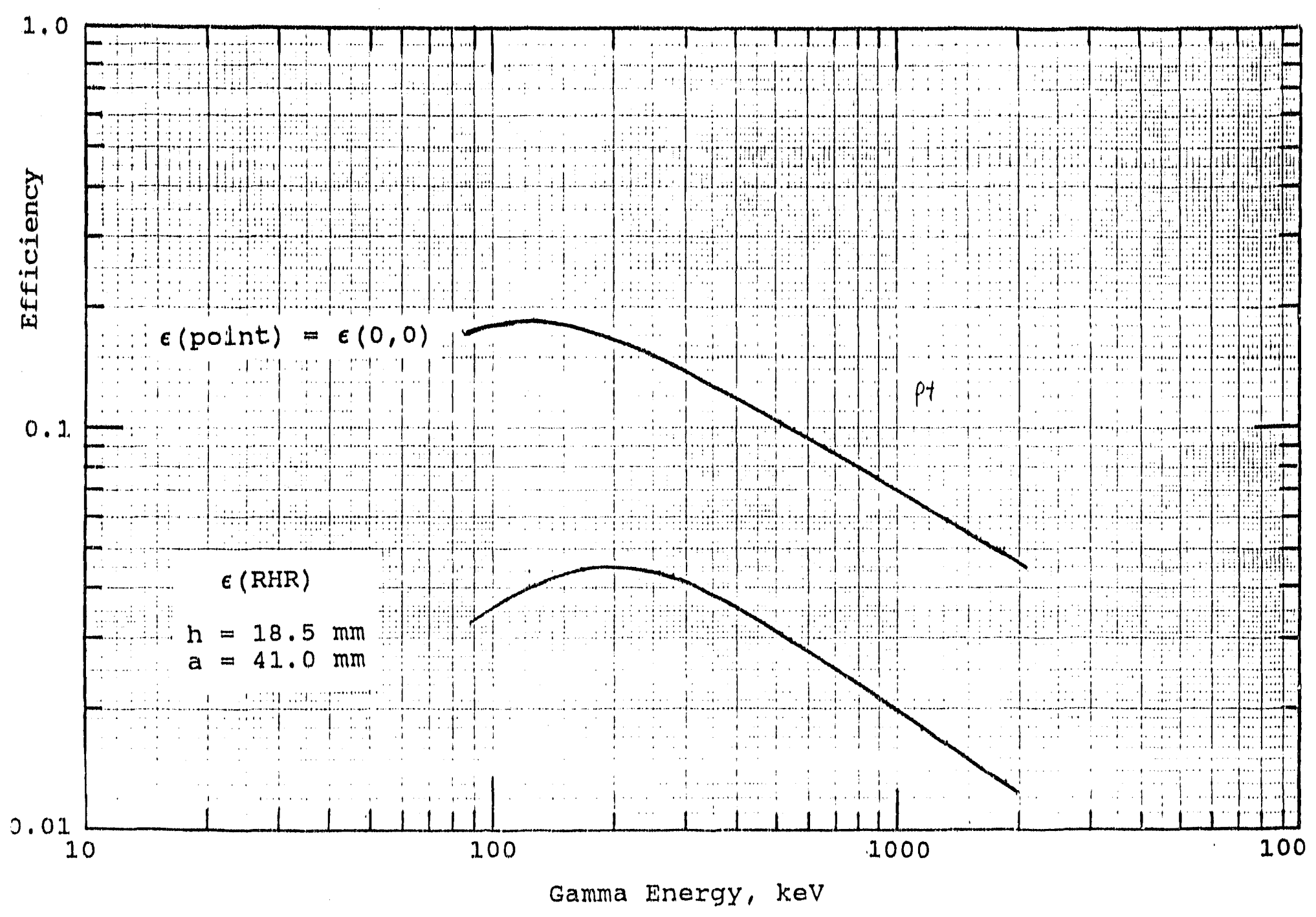

Figure B-5. Efficienoy Curves for $90 \%$ HPGe 


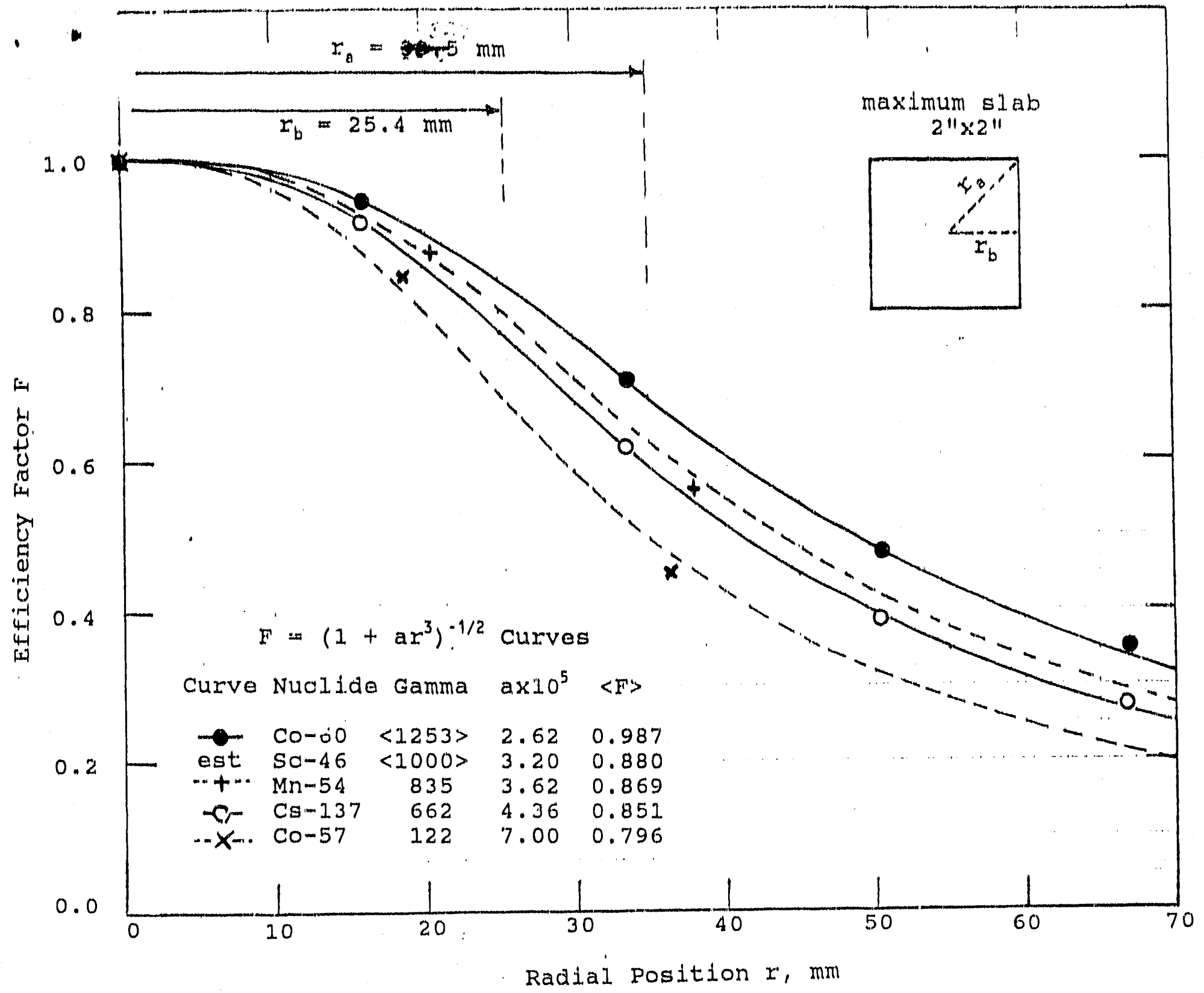

Figure B-6. Relative Effioiency on surface of $90 \%$ HPGe

The efflciency radial dependence $1 \mathrm{~s}$ examined tn terms of the empirical efficiency factor $\mathrm{F}=(1+\mathrm{ar})^{-1 / 2}$. Calculations for the average $F=\langle F\rangle$ for the maximum 2 "x2" slabs of this study are given, along with the fitted values of a. 


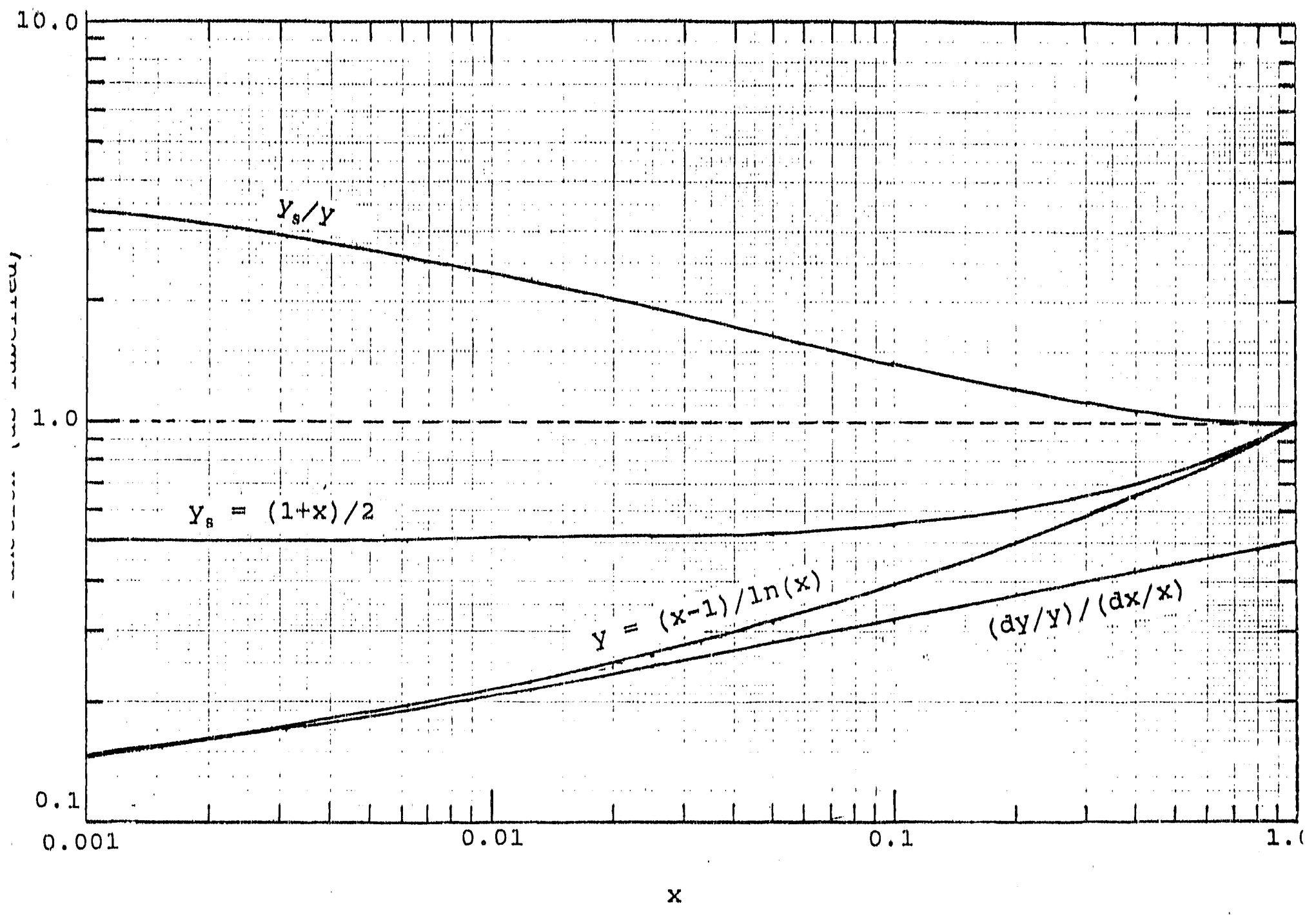

Figure B-7. Exponential Average Comparisons

The the average of 1 and $x$ are examined as an exponential average $y$ and straight average $y_{s}$. Also, the relative error sensitivity for the exponential average are examined as $(d y / y) /(d x / x)$. 


\section{Appendix o. Sample Detalis}

The tables of this appendix give details concerning the LDEF samples examined at SRS. Table $\mathrm{C}-1$ gtves the sample labels, archival files, dimensions, mass, counting dates, and lab institutions from which the samples were recelved. Table $\mathrm{C}-2$ summarlizes the sample results and averages obtained. Each table is subdivider for (A) trunnion samples, (B) trunnion layers, and (C) vanadium and aluminum pieces. The order in the Tables parallels that of Tables $1-3$ of the main text, to allow efficient cross referencing, as summartzed below:

\section{Appendix C Tables}

C-1.A Trunnion Counting Information

C-1.B Trunnion Layer counting Information

C-1.C Vanadium and Aluminum Counting information

C-2.A Detalled Trunnion Results - 20\% and 25\% HPGe Detectors

C-2.A' Detalied Trunnion Results - 90\% HPGe Detector

C-2.B Trunnion Layer Samples - 90\% HPGe Detector

$\mathrm{C}-2$.C Vanadium and Aluminum Samples - $90 \%$ Detector 
Table c-1.A. Trunnion counting Information ${ }^{a}$

\begin{tabular}{|c|c|c|c|c|c|c|}
\hline $\begin{array}{l}\text { Sample/ } \\
\text { Geo/Det }\end{array}$ & $\frac{\text { Speotrum }}{\text { File }}$ & $\frac{\text { Mass }}{q}$ & $\frac{\text { Thiok }}{\mathrm{mm}}$ & $\frac{\text { Counting }}{1990}$ & $\frac{\text { SRS }}{\text { Recpt }}$ & $\frac{\text { Prevlous }}{\text { Laboratory }}$ \\
\hline $\begin{array}{r}\mathrm{LHB} / \mathrm{A} / 1 \\
/ \mathrm{B} / 1\end{array}$ & $\begin{array}{l}1657 \mathrm{NASA} \cdot \mathrm{DAT} \\
166.9 \mathrm{NASA} \cdot \mathrm{DAT}\end{array}$ & $760.8^{b}$ & 18.6 & $\begin{array}{l}6 / 15-6 / 18 \\
6 / 29-7 / 2\end{array}$ & $5 / 25$ & $\begin{array}{c}\text { NASA, Houston } \\
\text { TX }\end{array}$ \\
\hline $\begin{array}{r}\mathrm{LHE} / \mathrm{A} / 2 \\
\mathrm{~B} / 1\end{array}$ & $\begin{array}{l}1652 \mathrm{NASA} . \text { DAT } \\
1673 \mathrm{NASA} . \mathrm{DAT}\end{array}$ & 430.0 & 10.1 & $\begin{array}{c}6 / 11-6 / 13 \\
7 / 3-7 / 6\end{array}$ & $6 / 7$ & $\begin{array}{l}\text { TVA/Muscle } \\
\text { Shoals AL }\end{array}$ \\
\hline $\begin{array}{r}L H F / A / 1 \\
\qquad / B / 1\end{array}$ & $\begin{array}{l}1654 \text { NASA.DAT } \\
1675 \text { NASA.DAT }\end{array}$ & 715.4 & 17.0 & $\begin{array}{c}6 / 13-6 / 15 \\
7 / 6-7 / 9\end{array}$ & $6 / 11$ & $\begin{array}{c}\text { LBL/ Berkeley } \\
C A\end{array}$ \\
\hline $\begin{array}{r}\mathrm{LHP} / \mathrm{A} / \mathrm{I} \\
/ \mathrm{B} / \mathrm{I} \\
\mathrm{B} / 3\end{array}$ & $\begin{array}{l}1589 \mathrm{NASA} . \text { LHP } \\
1591 \mathrm{NASA} . \text { LHP } \\
1605 \mathrm{NASA} \text {. LHP }\end{array}$ & 773 & 18.1 & $\begin{array}{r}3 / 9-3 / 12 \\
3 / 12-3 / 15 \\
4 / 9-4 / 11\end{array}$ & $3 / 7$ & $\begin{array}{l}\text { NASA/Hunts- } \\
\text { vilie AL }\end{array}$ \\
\hline $\begin{array}{r}\mathrm{LHR} / \mathrm{A} / 2 \\
/ \mathrm{B} / 1 \\
/ \mathrm{B} / 3\end{array}$ & $\begin{array}{l}1590 \mathrm{NASA} . \text { LHR } \\
1593 \mathrm{NASA} . \mathrm{LHR} \\
1606 \mathrm{NASA} . \mathrm{IHR}\end{array}$ & 878 & 20.6 & $\begin{array}{r}3 / 9-3 / 12 \\
3 / 16-3 / 19 \\
4 / 11-4 / 13\end{array}$ & $3 / 7$ & $\begin{array}{l}\text { NASA/Hunts- } \\
\text { vilie AL }\end{array}$ \\
\hline $\begin{array}{r}\mathrm{LHS} / \mathrm{A} / 2 \\
/ \mathrm{B} / 2 \\
/ \mathrm{B} / 3\end{array}$ & $\begin{array}{l}1592 \text { NASA. IHS } \\
1594 \text { NASA. LHS } \\
1607 \text { NASA. LHS }\end{array}$ & 838 & 19.6 & $\begin{array}{l}3 / 12-3 / 15 \\
3 / 16-3 / 19 \\
4 / 13-4 / 16\end{array}$ & $3 / 7$ & $\begin{array}{l}\text { NASA/Hunts- } \\
\text { ville AL }\end{array}$ \\
\hline $\begin{array}{r}\mathrm{RHB} / \mathrm{A} / 2 \\
/ \mathrm{B} / 2\end{array}$ & $\begin{array}{l}\text { 1658NASA.DAT } \\
1670 N A S A . D A T\end{array}$ & $696.2^{c}$ & 1.7 .0 & $\begin{array}{l}6 / 18-6 / 20 \\
6 / 29-7 / 2\end{array}$ & $5 / 25$ & $\begin{array}{l}\text { NASA/Houston } \\
\text { TX }\end{array}$ \\
\hline $\begin{array}{r}\mathrm{RHE} / \mathrm{A} / \mathrm{I} \\
/ \mathrm{B} / 2\end{array}$ & $\begin{array}{l}1651 \text { NASA.DAT } \\
1674 \text { NASA.DAT }\end{array}$ & 459.7 & 10.8 & $\begin{array}{c}6 / 11-6 / 13 \\
7 / 3-7 / 6\end{array}$ & $6 / 7$ & $\begin{array}{l}\text { TVA/Muscle } \\
\text { Shoals AL }\end{array}$ \\
\hline $\begin{array}{r}\mathrm{RHF} / \mathrm{A} / 2 \\
/ \mathrm{B} / 2\end{array}$ & $\begin{array}{l}1655 \mathrm{NASA} . \mathrm{DAT} \\
1676 \mathrm{NASA} . \mathrm{DAT}\end{array}$ & 648.2 & 15.2 & $\begin{array}{c}6 / 13-6 / 15 \\
7 / 6-7 / 9\end{array}$ & $6 / 11$ & $\begin{array}{c}\text { LBL/Berkeley } \\
\text { CA }\end{array}$ \\
\hline $\begin{array}{r}\mathrm{RHP} / \mathrm{A} / \mathrm{I} \\
/ \mathrm{B} / \mathrm{I} \\
/ \mathrm{B} / 3\end{array}$ & $\begin{array}{l}1595 \mathrm{NASA} \cdot \text { RHP } \\
1599 \mathrm{NASA} \cdot \mathrm{RHP} \\
1603 \mathrm{NASA} \cdot \mathrm{RHP}\end{array}$ & 790.8 & 18.5 & $\begin{array}{c}3 / 22-3 / 26 \\
3 / 30-4 / 2 \\
4 / 4-4 / 6\end{array}$ & $3 / 21$ & $\begin{array}{l}\text { NASA/Hunts- } \\
\text { vilie AL }\end{array}$ \\
\hline $\begin{array}{r}\mathrm{RHR} / \mathrm{A} / 2 \\
/ \mathrm{B} / 2 \\
/ \mathrm{B} / 3\end{array}$ & $\begin{array}{l}1596 \text { NASA.RHR } \\
1598 \text { NASA.RHR } \\
1601 \text { NASA.RHR }\end{array}$ & 788.8 & 18.5 & $\begin{array}{l}3 / 22-3 / 26 \\
3 / 26-3 / 28 \\
3 / 30-4 / 2\end{array}$ & $3 / 21$ & $\begin{array}{l}\text { NASA/Hunts- } \\
\text { vilie AI }\end{array}$ \\
\hline $\begin{array}{r}\mathrm{RHS} / \mathrm{A} / 1 \\
/ \mathrm{B} / 2 \\
/ \mathrm{B} / 3\end{array}$ & $\begin{array}{l}1597 \mathrm{NASA} . \text { RHS } \\
1600 \mathrm{NASA} . \text { RHS } \\
1602 \mathrm{NASA} . \text { RHS }\end{array}$ & 801.5 & 18.8 & $\begin{array}{c}3 / 26-3 / 28 \\
3 / 30-4 / 2 \\
4 / 2-4 / 4\end{array}$ & $3 / 21$ & $\begin{array}{l}\text { NASA/Hunts- } \\
\text { ville AL }\end{array}$ \\
\hline
\end{tabular}

Table Notes -next page 
Table Co-1.A. (Continued)

\section{Table Notes}

a) Abbreviated table headings are detailed as

Sample/ Sample label/ Geometry label facing (A) away from Geo/Det or (B) toward detector/ Detector is (I) 25\%, (2) $20 \%$, or (3) $90 \%$ HPGe.

Spectrum File label of ADCAM spectrum sent on floppy disk File to NASA for permanent archive of LDEF studies.

Mass Measured mass of sample at SRS. q

Thick Disk thicknesses calcujated using direct

$\mathrm{mm}$ measurements and masses of samples, with all samples assumed to have identical diameters.

counting

Counting interval dates - detailed live counting 1990 times are available from the disk files.

$\frac{\text { SRS }}{\text { Recpt }}$ Date in 1990 that sample was received.

Previous Laboratory from which sample was received. Laboratory

b) Sample LHB had $17 \mathrm{~mm}$ hole in center, and would have mass of $795 \mathrm{~g}$ if sample were solid.

c) Sample RHB had $17 \mathrm{~mm}$ hole in center, and would have mass of $727.5 \mathrm{~g}$ if sample were solid. 
Table C-1.B. Trunnion Layer counting Information ${ }^{a}$

All these samples were received from NASA, Huntsville AL, on May 5, 1990. All samples were counted on 90\% HPGe (Detector \#3). Archival files are referenced in sub-table at bottom of page.

Space side of Trunnion

Sample/ Mass Area Geo/Dt3 g inxin

counting 1990

$\mathrm{RH}-\mathrm{G}-\mathrm{SP}-$

$\begin{array}{lll}2 / \mathrm{A} & 32.9 & 2 \times 2 \\ / \mathrm{B} & \end{array}$

$3 / \mathrm{A}$ $/ B$

$51.12 \times 2$

$4 / \mathrm{A}$

$/ B$

$68.42 \times 2$

$5 / A$

$/ B$

$74.5 \cdot 2 \times 2$

$6 / A$

$/ \mathrm{B}$

$72.5 \quad 2 \times 1.5$
$5 / 21-5 / 23$ $9 / 18-9 / 19$

$6 / 18-6 / 20$

$9 / 12-9 / 13$

$6 / 22-6 / 25$

$9 / 17-9 / 18$

$6 / 20-6 / 22$

$7 / 16-7 / 18$
$6 / 6-6 / 8$

$8 / 6-8 / 8$
Earth side of Trunnion

Sample/ Mass Area

Geo/Dt3 $\mathrm{g}$ inxin

Counting

RH-G-ER-

$\begin{array}{llll}2 / A & 32.7 & 2 \times 2 & 5 / 23-5 / 25 \\ / B & & 9 / 11-9 / 12\end{array}$

$\begin{array}{llll}3 / \mathrm{A} & 51.7 \quad 2 \times 2 & 6 / 25-6 / 27 \\ \text { / B } & & 8 / 1-8 / 3\end{array}$

$4 / A \quad 68.3 \quad 2 \times 1.756 / 27-6 / 29$

/B $9 / 10-9 / 11$

$5 / \mathrm{A} \quad 76.0 \quad 2 \times 1.75 \quad 6 / 29-7 / 2$

/B $7 / 18-7 / 20$

$6 / A \quad 72.2 \quad 2 \times 1.5 \quad 6 / 8-6 / 11$

$/ \mathrm{B}$

$7 / 30-8 / 1$

Note - The sample thicknesses were calculated in $\mathrm{g} / \mathrm{cm}^{2}$ using the above data. These thicknesses were converted to $\mathrm{cm}$ as needed, using the trunnion density.

Sub-Table C-1.B Archival Data Files

Sample/Geometry spectrum File

$\begin{array}{rr}\text { RH-G-SP-2/A } & 1621 \mathrm{NASA} \cdot \mathrm{DAT} \\ / \mathrm{B} & 1727 \mathrm{NASA} \cdot \mathrm{DAT} \\ 3 / \mathrm{A} & 1660 \mathrm{NASA} \cdot \mathrm{DAT} \\ / \mathrm{B} & 1721 \mathrm{NASA} \cdot \mathrm{DAT} \\ & \\ 4 / \mathrm{A} & 1666 \mathrm{NASA} \cdot \mathrm{DAT} \\ / \mathrm{B} & 1726 \mathrm{NASA} \cdot \mathrm{DAT} \\ 5 / \mathrm{A} & 1661 \mathrm{NASA} \cdot \mathrm{DAT} \\ / \mathrm{B} & 1679 \mathrm{NASA} \cdot \mathrm{DAT} \\ & \\ 6 / \mathrm{A} & 1641 \mathrm{NASA} \cdot \mathrm{DAT} \\ / \mathrm{B} & 1683 \mathrm{NASA} \cdot \mathrm{DAT}\end{array}$

Sample/Geometry spectrum File

$\begin{array}{rr}\text { RH-G-ER-2/A } & 1624 \mathrm{NASA} \cdot \mathrm{DAT} \\ / \mathrm{B} & 1720 \mathrm{NASA} \cdot \mathrm{DAT} \\ 3 / \mathrm{A} & 1677 \mathrm{NASA} \cdot \mathrm{DAT} \\ / \mathrm{B} & 1686 \mathrm{NASA} \cdot \mathrm{DAT} \\ & \\ 4 / \mathrm{A} & 1668 \mathrm{NASA} \cdot \mathrm{DAT} \\ / \mathrm{B} & 1719 \mathrm{NASA} \cdot \mathrm{DAT} \\ \text { 5/A } & 1671 \mathrm{NASA} \cdot \mathrm{DAT} \\ / \mathrm{B} & 1680 \mathrm{NASA} \cdot \mathrm{DAT} \\ & \\ \text { 6/A } & 1650 \mathrm{NASA} \cdot \mathrm{DAT} \\ / \mathrm{B} & 1685 \mathrm{NASA} \cdot \mathrm{DAT}\end{array}$

a) Abbreviated table headings described in Table C-1.A notes.

$$
\mathrm{C}-4
$$


Table C-1.C. Vanadium and Aluminum Counting Information"

\begin{tabular}{|c|c|c|c|c|c|c|}
\hline$\frac{\text { Sample/ }}{\text { Geo/Dt } 3}$ & $\frac{\text { spectrum }}{\text { Fjle }}$ & $\frac{\text { Mass }}{q}$ & $\frac{\text { Area }}{\text { inxin }}$ & $\frac{\text { Counting }}{1990 / 1991}$ & \multicolumn{2}{|c|}{$\frac{\text { SRS }}{\text { Recpt }} \frac{\text { Previous }}{\text { Laboratory }}$} \\
\hline \multicolumn{7}{|l|}{ Vanadium } \\
\hline $\begin{array}{r}\text { G12-A2FNV } / A \\
B\end{array}$ & $\begin{array}{l}1630 \mathrm{NASA} . \mathrm{DAT} \\
1636 \mathrm{NASA} . \mathrm{DAT}\end{array}$ & 52.4 & $2 \times 2$ & $\begin{array}{l}5 / 29-5 / 31 \\
5 / 31-6 / 4\end{array}$ & $5 / 24$ & $\begin{array}{c}\text { LLL/Livermore } \\
\text { CA }\end{array}$ \\
\hline $\begin{array}{r}I-C 9-V / A \\
/ B\end{array}$ & $\begin{array}{l}\text { 1653NASA.DAT } \\
1678 \text { NASA. DAT }\end{array}$ & 53.0 & $2 \times 2$ & $\begin{array}{l}6 / 11-6 / 13 \\
7 / 12-7 / 16\end{array}$ & $5 / 25$ & $\begin{array}{c}\text { NASA/Houston } \\
\text { TX }\end{array}$ \\
\hline $\begin{array}{r}I-F 2-V / A \\
/ B\end{array}$ & $\begin{array}{l}1656 \mathrm{NASA} . \mathrm{DAT} \\
1741 \mathrm{NASA} . \mathrm{DAT}\end{array}$ & 53.6 & $2 \times 2$ & $\begin{array}{c}6 / 16-6 / 18 \\
10 / 19-10 / 22\end{array}$ & $6 / 11$ I & $\begin{array}{l}\text { LBL/Berkeley } \\
\text { CA }\end{array}$ \\
\hline $\begin{array}{r}I-H 12-V A / A \\
/ B\end{array}$ & $\begin{array}{l}1682 \text { NASA. DAT } \\
1731 \text { NASA. DAT }\end{array}$ & 19.4 & $2 \times 3 / 4$ & $\begin{array}{l}7 / 23-7 / 25 \\
9 / 24-9 / 25\end{array}$ & $7 / 18$ & $\begin{array}{c}\text { PNL/Richland } \\
\text { WA }\end{array}$ \\
\hline $\begin{array}{r}\mathrm{I}-\mathrm{H} 12-\mathrm{VB} / \mathrm{A} \\
/ \mathrm{B}\end{array}$ & $\begin{array}{l}1683 \text { NASA. DAT } \\
1730 \text { NASA. DAT }\end{array}$ & 19.8 & $2 \times 3 / 4$ & $\begin{array}{l}7 / 25-7 / 27 \\
9 / 21-9 / 24\end{array}$ & $7 / 18$ & $\begin{array}{c}\text { PNL/Richland } \\
\text { WA }\end{array}$ \\
\hline \multicolumn{7}{|l|}{ Aluminum } \\
\hline $\begin{array}{r}\mathrm{ESR}-1 / \mathrm{A} \\
/ \mathrm{B}\end{array}$ & $\begin{array}{l}1672 \text { NASA. DAT } \\
1729 \text { NASA. DAT }\end{array}$ & 63.4 & $2 \times 2$ & $\begin{array}{c}7 / 5-7 / 6 \\
9 / 20-9 / 21\end{array}$ & $5 / 17$ & $\begin{array}{l}\text { NASA/Hunts- } \\
\text { ville AL }\end{array}$ \\
\hline $\begin{array}{r}E S R-5 / A \\
/ B\end{array}$ & $\begin{array}{l}1677 \text { NASA. DAT } \\
1687 \text { NASA. DAT }\end{array}$ & 63.5 & $2 \times 2$ & $\begin{array}{l}7 / 6-7 / 9 \\
8 / 3-8 / 6\end{array}$ & $5 / 17$ & $\begin{array}{l}\text { NASA/Hunts- } \\
\text { ville AL }\end{array}$ \\
\hline $\begin{array}{r}\mathrm{KP}-3 / \mathrm{A} \\
/ \mathrm{B}\end{array}$ & $\begin{array}{l}1789 \text { NASA. DAT } \\
1790 \text { NASA. DAT }\end{array}$ & 65.25 & $2 \times 2$ & $\begin{array}{l}1 / 15-1 / 17 \\
1 / 17-1 / 18\end{array}$ & $1 / 14$ & $\begin{array}{l}\text { NASA/Hunts- } \\
\text { ville AL }\end{array}$ \\
\hline $\mathrm{KP}-10 / \mathrm{A}$ & $\begin{array}{l}1791 \text { NASA.DAT } \\
1792 \text { NASA. DAT }\end{array}$ & 65.42 & $2 \times 2$ & $\begin{array}{l}1 / 18-1 / 21 \\
1 / 21-1 / 22\end{array}$ & $1 / 14$ & $\begin{array}{l}\text { NASA/Hunts- } \\
\text { ville AL }\end{array}$ \\
\hline \multicolumn{7}{|c|}{$\begin{array}{l}\text { Note - The sample thicknesses were calculated in } \mathrm{g} / \mathrm{cm}^{2} \text { using the } \\
\text { above data. These thicknesses were converted to } \mathrm{cm} \text { as needed, } \\
\text { using the sample densities. }\end{array}$} \\
\hline
\end{tabular}

a) Abbreviated table headings described in Table C-1. A notes. 
Table C-2.A. Detailed Trunnion Results - $20 \%$ and $25 \%$ HPGe Detectors

Sample orientations:

A. Label facing away from detector

B. Label facing detector

C. Average of above - $\left(1 / \sigma^{2}\right)$-weighted

Decay Correction Date: January 20, 1990

Sample Isotopic Activities in $\mathrm{pci} / \mathrm{Kg}$ Sample

$\underline{B e-7} \underline{\mathrm{SC}-46} \underline{\mathrm{Cr}-51} \underline{\mathrm{Mn}-54} \underline{\mathrm{Co}-56} \underline{\mathrm{Co}-57} \underline{\mathrm{Co}-58} \mathrm{Co-60}$

\begin{tabular}{|c|c|c|c|c|c|c|c|c|}
\hline$L H B / A$ & $\begin{array}{r}8.68 \\
+23.87\end{array}$ & $\begin{array}{r}4.46 \\
\pm 0.89\end{array}$ & $\begin{array}{r}73.99 \\
\pm 149.08\end{array}$ & $\begin{array}{r}124.54 \\
\pm 2.17\end{array}$ & $\begin{array}{r}4.54 \\
\pm 0.95\end{array}$ & $\begin{array}{l}16.02 \\
\pm 1.10\end{array}$ & $\begin{array}{r}4.48 \\
\pm 1.66\end{array}$ & $\begin{array}{r}2.58 \\
\pm 0.28\end{array}$ \\
\hline $\mathrm{LHB} / \mathrm{B}$ & $\begin{array}{r}-2.17 \\
\pm 26.04\end{array}$ & $\begin{array}{r}4.20 \\
\pm 0.79\end{array}$ & $\begin{array}{r}72.91 \\
\pm 181.72\end{array}$ & $\begin{array}{r}115.88 \\
\pm 2.17\end{array}$ & $\begin{array}{r}4.64 \\
\pm 1.20\end{array}$ & $\begin{array}{l}14.49 \\
\pm 0.99\end{array}$ & $\begin{array}{r}2.22 \\
\pm 1.59\end{array}$ & $\begin{array}{r}1.52 \\
\pm 0.24\end{array}$ \\
\hline $\begin{array}{l}\text { LHB / C } \\
\text { (AVG) }\end{array}$ & $\begin{array}{r}3.73 \\
\pm 17.60\end{array}$ & $\begin{array}{r}4.31 \\
\pm 0.59\end{array}$ & $\begin{array}{r}73.56 \\
\pm 115.26\end{array}$ & $\begin{array}{r}120.21 \\
\pm 1.53\end{array}$ & $\begin{array}{r}4.58 \\
\pm 0.75\end{array}$ & $\begin{array}{l}15.17 \\
\pm 0.73\end{array}$ & $\begin{array}{r}3.31 \\
\pm 1.15\end{array}$ & $\begin{array}{r}1.96 \\
\pm 0.18\end{array}$ \\
\hline $\mathrm{HE} / \mathrm{A}$ & $\begin{array}{r}33.45 \\
\pm 30.83\end{array}$ & $\begin{array}{r}3.65 \\
\pm 1.07\end{array}$ & $\begin{array}{l}-168.39 \\
\pm 168.39\end{array}$ & $\begin{array}{l}94.74 \\
\pm 2.73\end{array}$ & $\begin{array}{r}3.95 \\
\pm 1.34\end{array}$ & $\begin{array}{r}8.17 \\
\pm 0.95\end{array}$ & $\begin{array}{r}0.21 \\
\pm 2.09\end{array}$ & $\begin{array}{r}1.53 \\
\pm 0.42\end{array}$ \\
\hline LHE / B & $\begin{array}{r}23.55 \\
\pm 29.43\end{array}$ & $\begin{array}{r}5.31 \\
\pm 0.95\end{array}$ & $\begin{array}{r}-99.64 \\
\pm 199.99\end{array}$ & $\begin{array}{l}95.53 \\
\pm 2.27\end{array}$ & $\begin{array}{r}2.41 \\
\pm 0.94\end{array}$ & $\begin{array}{l}10.93 \\
\pm 0.92\end{array}$ & $\begin{array}{r}2.12 \\
\pm 1.77\end{array}$ & $\begin{array}{r}1.65 \\
\pm 0.44\end{array}$ \\
\hline $\begin{array}{l}\mathrm{LHE} / \mathrm{C} \\
(\mathrm{AVG})\end{array}$ & $\begin{array}{r}28.27 \\
\pm 21.29\end{array}$ & $\begin{array}{r}4.57 \\
\pm 0.71\end{array}$ & $\begin{array}{l}-139.87 \\
\pm 128.81\end{array}$ & $\begin{array}{l}95.21 \\
\pm 1.75\end{array}$ & $\begin{array}{r}2.92 \\
\pm 0.77\end{array}$ & $\begin{array}{r}9.60 \\
\pm 0.66\end{array}$ & $\begin{array}{r}1.33 \\
\pm 1.35\end{array}$ & $\begin{array}{r}1.5 \\
\pm 0.3\end{array}$ \\
\hline $\mathrm{LHF} / \mathrm{A}$ & $\begin{array}{r}-2.98 \\
\pm 26.78\end{array}$ & $\begin{array}{r}2.88 \\
\pm 0.67\end{array}$ & $\begin{array}{r}105.68 \\
+151.12\end{array}$ & $\begin{array}{r}100.50 \\
\pm 1.99\end{array}$ & $\begin{array}{r}4.86 \\
\pm 1.20\end{array}$ & $\begin{array}{r}9.75 \\
\pm 1.08\end{array}$ & $\begin{array}{r}5.39 \\
\pm 1.72\end{array}$ & $\begin{array}{r}1.2 \\
\pm 0.3\end{array}$ \\
\hline$L H F / B$ & $\begin{array}{l}-24.80 \\
\pm 24.80\end{array}$ & $\begin{array}{r}4.04 \\
\pm 0.78\end{array}$ & $\begin{array}{r}-74.08 \\
\pm 184.70\end{array}$ & $\begin{array}{r}100.50 \\
\pm 1.99\end{array}$ & $\begin{array}{r}4.83 \\
\pm 0.97\end{array}$ & $\begin{array}{l}10.84 \\
\pm 0.78\end{array}$ & $\begin{array}{r}2.97 \\
\pm 1.56\end{array}$ & $\begin{array}{r}1.4 \\
\pm 0.2\end{array}$ \\
\hline $\begin{array}{l}A F / C \\
A \vee G)\end{array}$ & $\begin{array}{l}-14.72 \\
\pm 18.19\end{array}$ & $\begin{array}{r}3.37 \\
\pm 0.51\end{array}$ & $\begin{array}{r}33.60 \\
\pm 116.96\end{array}$ & $\begin{array}{r}100.50 \\
\pm 1.41\end{array}$ & $\begin{array}{r}4.84 \\
\pm 0.75\end{array}$ & $\begin{array}{l}10.47 \\
\pm 0.63\end{array}$ & $\begin{array}{r}4.06 \\
\pm 1.16\end{array}$ & $\begin{array}{r}1.4 \\
\pm 0.1\end{array}$ \\
\hline
\end{tabular}

$$
c-6
$$


Table C-2.A. (Continued)

Sample orientations:
A. Label facing away from detector
B. Label facing detector
C. Average of above - $\left(1 / \sigma^{2}\right)$-weighted

Decay Correction Date: January 20, 1990

Sample Isotopic Activities in $\mathrm{pCi} / \mathrm{Kg}$ Sample

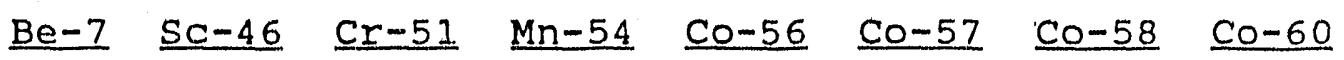

$\begin{array}{lrrrrrrrr}\text { LHP/A } & -5.79 & 3.37 & 26.00 & 79.93 & 2.44 & 8.36 & 5.06 & 1.25 \\ & \pm 5.67 & \pm .36 & \pm 1.32 & \pm 1.31 & \pm .39 & \pm .60 & \pm .61 & \pm .21 \\ \text { LHP/B } & 2.41 & 3.27 & 12.05 & 79.14 & 2.96 & 9.20 & 4.00 & 1.75 \\ & \pm 6.03 & \pm .39 & \pm 12.05 & \pm 1.31 & \pm .42 & \pm .63 & \pm .64 & \pm .23 \\ \text { LHP/C } & -1.94 & 3.32 & 19.46 & 79.53 & 2.68 & 8.77 & 4.56 & 1.51 \\ \text { (AVG) } & \pm 4.13 & \pm .27 & \pm 8.25 & \pm .93 & \pm .29 & \pm .44 & \pm .44 & \pm .16\end{array}$

$\begin{array}{lllrrrrrr}\text { LHR/A } & -6.97 & 3.70 & 53.13 & 77.27 & 2.85 & 6.41 & 4.75 & 1.61 \\ & \pm 6.15 & \pm .38 & \pm 13.03 & \pm 1.45 & \pm .41 & \pm .60 & \pm .66 & \pm .24 \\ \text { LHR/B } & -8.79 & 3.70 & 15.65 & 78.27 & 2.75 & 8.47 & 4.40 & 1.45 \\ & \pm 6.13 & \pm .40 & \pm 12.92 & \pm 1.26 & \pm .43 & \pm .64 & \pm .63 & \pm .22 \\ \text { LHR/C } & -7.88 & 3.70 & 34.23 & 77.84 & 2.80 & 7.37 & 4.57 & 1.52 \\ \text { (AVG) } & \pm 4.34 & \pm .28 & \pm 9.17 & \pm .95 & \pm .30 & \pm .44 & \pm .46 & \pm .16\end{array}$

$\begin{array}{lrrrrrrrr}\text { LHS/A } & 7.59 & 4.16 & 24.44 & 76.16 & 2.67 & 6.17 & 4.73 & 1.88 \\ & \pm 6.55 & \pm .44 & \pm 13.22 & \pm 1.47 & \pm .45 & \pm .59 & \pm .69 & \pm .25 \\ \text { LHS/B } & -0.83 & 4.74 & 23.93 & 75.03 & 3.28 & 5.54 & 5.80 & 1.45 \\ & \pm 6.97 & \pm .45 & \pm 14.80 & \pm 1.36 & \pm .47 & \pm .86 & \pm .71 & \pm .25 \\ & & & & & & & & \\ \text { LHS/C } & 3.64 & 4.44 & 24.21 & 75.55 & 2.96 & 5.97 & 5.25 & 1.66 \\ \text { (AVG) } & \pm 4.77 & \pm .32 & \pm 9.86 & \pm 1.00 & \pm .33 & \pm .49 & \pm .50 & \pm .18\end{array}$


Table C-2.A. (Continued)

Sample orientations:

A. Label facing away from detector

B. Label facing detector

C. Average of above $-\left(1 / \sigma^{2}\right)$-weighted

Decay Correction Date: January 20, 1990

Sample

Isotopic Activities in $\mathrm{pCi} / \mathrm{Kg}$ Sample

\section{$\underline{\mathrm{Be}-7} \underline{\mathrm{Sc}-46} \mathrm{Cr}-51 \quad \mathrm{Mn}-54 \quad \mathrm{Co}-56$ Co-57 $\mathrm{Co}-58$ Co-60}

$\begin{array}{rrrrrrrrr}\mathrm{RHB} / \mathrm{A} & 18.18 & 5.10 & 170.11 & 83.59 & 3.40 & 8.16 & 4.76 & 1.20 \\ & \pm 29.99 & \pm 1.06 \pm 189.02 & \pm 2.20 \pm 1.12 & \pm 0.91 & \pm 1.99 & \pm 0.33 \\ & & & & & & & \\ \mathrm{RHB} / \mathrm{B} & 56.34 & 4.53 & 117.01 & 81.85 & 3.03 & 6.76 & 4.61 & 1.63 \\ & \pm 25.45 & \pm 3.02 & \pm 195.32 & \pm 1.74 & \pm 1.11 & \pm 0.77 & \pm 1.65 & \pm 0.38 \\ & & & & & & & \\ \mathrm{RHB} / \mathrm{C} & 40.37 & 5.04 & 144.43 & 82.52 & 3.21 & 7.34 & 4.67 & 1.39 \\ (\mathrm{AVG}) \pm 19.40 & \pm 1.00 \pm 135.83 & \pm 1.36 \pm 0.79 & \pm 0.59 & \pm 1.27 & \pm 0.25\end{array}$

\begin{tabular}{|c|c|c|c|c|c|c|c|c|}
\hline $\mathrm{HE} / \mathrm{A}$ & $\begin{array}{r}2.28 \\
\pm 25.11\end{array}$ & $\begin{array}{r}2.06 \\
\pm 0.89\end{array}$ & $\begin{array}{r}205.54 \\
\pm 146.82\end{array}$ & $\begin{array}{l}81.26 \\
\pm 2.34\end{array}$ & $\begin{array}{r}2.02 \\
\pm 1.19\end{array}$ & $\begin{array}{r}9.82 \\
\pm 0.98\end{array}$ & $\begin{array}{r}1.19 \\
\pm 1.70\end{array}$ & $\begin{array}{r}0.75 \\
\pm 0.29\end{array}$ \\
\hline & $\begin{array}{r}14 . \\
\pm 29 .\end{array}$ & $\begin{array}{r}1.71 \\
\pm 1.37\end{array}$ & $\begin{array}{l}-317 . \\
\pm 211 .\end{array}$ & & $\begin{array}{r}2 . \\
\pm 1 .\end{array}$ & & $\begin{array}{r}3 \\
\pm 1\end{array}$ & \\
\hline & $\begin{array}{r}7.66 \\
+19.02\end{array}$ & $\begin{array}{r}1.96 \\
\pm 0.75\end{array}$ & $\begin{array}{r}35.78 \\
\pm 120.65\end{array}$ & & $\begin{array}{r}2.15 \\
\pm 0.95\end{array}$ & $\begin{array}{r}6.63 \\
\pm 0.57\end{array}$ & $\begin{array}{r}2.35 \\
\pm 1.27\end{array}$ & \\
\hline
\end{tabular}

$\begin{array}{lrrrrrrrr}\mathrm{RHF} / \mathrm{A} & 45.21 & 2.47 & -88.77 & 77.42 & 3.23 & 6.63 & 3.15 & 1.15 \\ & \pm 30.42 & \pm 0.97 & \pm 177.53 & \pm 2.25 & \pm 1.32 & \pm 0.91 & \pm 1.98 & \pm 0.32 \\ \mathrm{RHF} / \mathrm{B} & 49.32 & 3.50 & 199.32 & 79.84 & 4.19 & 7.26 & 1.97 & 1.43 \\ & \pm 27.13 & \pm 0.91 & \pm 199.32 & \pm 1.67 & \pm 1.20 & \pm 0.78 & \pm 1.64 & \pm 0.26 \\ & & & & & & & & \\ \mathrm{RHF} / \mathrm{C} & 47.50 & 2.99 & 38.68 & 78.98 & 3.75 & 7.00 & 2.45 & 1.32 \\ (\mathrm{AVG}) & \pm 20.25 & \pm 0.64 & \pm 132.57 & \pm 1.34 & \pm 0.89 & \pm 0.59 & \pm 1.26 & \pm 0.20\end{array}$


Table C-2.A. (Continued)

Sample orientations:
A. Label facing away from detector
B. Label facing detector
C. Average of above - $\left(1 / \sigma^{2}\right)$-weighted

Decay Correction Date: January 20, 1990

Sample Isotopio Activities in $\mathrm{pCi} / \mathrm{Kg}$ Sample

$\underline{B e-7} \underline{\mathrm{SC}-46} \quad \underline{\mathrm{Cr}-51} \underline{\mathrm{Mn}-54} \underline{\mathrm{Co}-56}$ Co-57 Co-58 Co-60

$\begin{array}{rrrrrrrrr}\text { RHP/A } & 0.24 & 2.88 & 29.14 & 72.12 & 2.93 & 8.35 & 4.92 & 1.64 \\ & \pm 5.98 & \pm .35 & \pm 13.40 & \pm 1.17 & \pm .38 & \pm .55 & \pm .59 & \pm .20 \\ \text { RHP/B } & -2.27 & 3.84 & 17.47 & 74.08 & 2.31 & 8.36 & 2.82 & 1.55 \\ & \pm 7.54 & \pm .45 & \pm 18.47 & \pm 1.30 & \pm .48 & \pm .69 & \pm .71 & \pm .23 \\ & & & & & & & & \\ \text { RHP/C } & -0.73 & 3.24 & 25.12 & 72.99 & 2.69 & 8.36 & 4.07 & 1.60 \\ (\text { AVG }) & \pm 4.69 & \pm .27 \pm 10.85 & \pm .87 & \pm .30 & \pm .43 & \pm .45 & \pm .15\end{array}$

$\begin{array}{lrrrrrrrr}\text { RHR/A } & 10.29 & 3.72 & 46.55 & 72.86 & 1.89 & 5.76 & 3.88 & 1.46 \\ & \pm 6.37 & \pm .37 & \pm 16.09 & \pm 1.27 & \pm .39 & \pm .52 & \pm .65 & \pm .22 \\ \text { RHR/B } & -3.82 & 3.79 & 27.66 & 72.63 & 2.93 & 6.24 & 4.93 & 1.17 \\ & \pm 9.55 & \pm .56 \pm 22.45 & \pm 1.73 & \pm .57 & \pm .71 & \pm .94 & \pm .27 \\ \text { RHR/C } & 5.95 & 3.74 & 40.14 & 72.78 & 2.22 & 5.93 & 4.22 & 1.34 \\ \text { (AVG) } & \pm 5.30 & \pm .31 \pm 13.08 & \pm 1.03 & \pm .32 & \pm .42 & \pm .54 & \pm .17\end{array}$

$\begin{array}{rrrrrrrrr}\text { RHS/A } & 3.45 & 3.89 & 32.76 & 73.19 & 3.36 & 7.67 & 4.17 & 1.61 \\ & \pm 8.33 & \pm .47 & \pm 19.14 & \pm 1.56 & \pm .54 & \pm .77 & \pm .78 & \pm .28 \\ \text { RHS/B } & -1.37 & 3.88 & 48.42 & 74.14 & 2.27 & 5.00 & 4.91 & 1.19 \\ & \pm 8.12 & \pm .47 & \pm 20.76 & \pm 1.38 & \pm .50 & \pm .60 & \pm .79 & \pm .23 \\ & & & & & & & \\ \text { RHS/C } & 0.98 & 3.89 & 39.96 & 73.72 & 2.77 & 6.00 & 4.54 & 1.36 \\ \text { (AVG) } & \pm 5.82 & \pm .33 \pm 14.07 & \pm 1.03 & \pm .37 & \pm .47 & \pm .56 & \pm .18\end{array}$


Table C-2.A'. Detailed Trunnion Results - 90\% Hpge Detector

Sample orientation - Label facing toward detector. Decay Correction Date - January 20, 1990

Sample Isotopic Activities in $\mathrm{pCl} / \mathrm{Kg}$ Sample

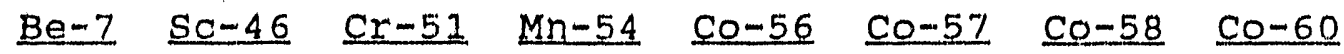

\begin{tabular}{|c|c|c|c|c|c|c|c|c|}
\hline L.HP & $\begin{array}{r}6.01 \\
\pm 5.46\end{array}$ & $\begin{array}{r}3.78 \\
\pm .29\end{array}$ & $\begin{array}{r}3.94 \\
\pm 16.55\end{array}$ & $\begin{array}{l}79.32 \\
\pm 1.01\end{array}$ & $\begin{array}{l}2.61 \\
\pm .31\end{array}$ & $\begin{array}{l}6.53 \\
\pm .37\end{array}$ & $\begin{array}{l}5.35 \\
\pm .50\end{array}$ & $\begin{array}{l}1.64 \\
\pm .15\end{array}$ \\
\hline LHR & $\begin{array}{l}-6.51 \\
\pm 6.74\end{array}$ & $\begin{array}{l}3.91 \\
\pm .34\end{array}$ & $\begin{array}{r}35.00 \\
\pm 21.44\end{array}$ & $\begin{array}{r}75.54 \\
\pm .97\end{array}$ & $\begin{array}{l}2.47 \\
\pm .35\end{array}$ & $\begin{array}{l}6.93 \\
\pm .65\end{array}$ & $\begin{array}{l}4.84 \\
\pm .53\end{array}$ & $\begin{array}{l}1.53 \\
\pm .15\end{array}$ \\
\hline LHS & $\begin{array}{r}1.58 \\
\pm 4.52\end{array}$ & $\begin{array}{l}4.28 \\
\pm .25\end{array}$ & $\begin{array}{r}20.82 \\
\pm 14.50\end{array}$ & $\begin{array}{r}75.09 \\
\pm .73\end{array}$ & $\begin{array}{l}2.28 \\
\pm .24\end{array}$ & $\begin{array}{l}6.32 \\
\pm .30\end{array}$ & $\begin{array}{l}4.73 \\
\pm .37\end{array}$ & $\begin{array}{l}1.50 \\
\pm .11\end{array}$ \\
\hline RHP & $\begin{array}{r}13.37 \\
\pm 5.37\end{array}$ & $\begin{array}{r}3.79 \\
\pm .33\end{array}$ & $\begin{array}{r}55.21 \\
\pm 15.26\end{array}$ & $\begin{array}{r}71.99 \\
\pm 1.00\end{array}$ & $\begin{array}{l}2.63 \\
\pm .33\end{array}$ & $\begin{array}{l}6.25 \\
\pm .42\end{array}$ & $\begin{array}{r}4.77 \\
\pm .49\end{array}$ & $\begin{array}{l}1.26 \\
\pm .16\end{array}$ \\
\hline RHR & $\begin{array}{r}10.17 \\
\pm 3.77\end{array}$ & $\begin{array}{l}3.32 \\
\pm .24\end{array}$ & $\begin{array}{r}17.36 \\
\pm 10.38\end{array}$ & $\begin{array}{r}72.73 \\
\pm .75\end{array}$ & $\begin{array}{l}2.50 \\
\pm .24\end{array}$ & $\begin{array}{l}6.33 \\
\pm .30\end{array}$ & $\begin{array}{l}4.33 \\
\pm .36\end{array}$ & $\begin{array}{l}1.64 \\
\pm .11 .\end{array}$ \\
\hline RHS & $\begin{array}{r}3.86 \\
+4.88\end{array}$ & $\begin{array}{l}4.00 \\
\pm .32\end{array}$ & $\begin{array}{r}23.39 \\
\pm 14.44\end{array}$ & $\begin{array}{r}75.52 \\
\pm .99\end{array}$ & $\begin{array}{l}2.69 \\
\pm .33\end{array}$ & $\begin{array}{r}6.02 \\
\pm .42\end{array}$ & $\begin{array}{l}4.06 \\
\pm .62\end{array}$ & $\begin{array}{r}1.51 \\
\pm .16\end{array}$ \\
\hline
\end{tabular}




\section{Table C-2.B. Trunnion Iayer Bamples - $90 \%$ HPGe Detector}

Sample Measurements:
A. Label facing away from detector
B. Label faoling detector
C. Weighted Average of $(A, B)-\left(1 / \sigma^{2}\right)$-welghted
$D$. Direct Average of $(A, B)$ - even-wedighted

Decay Correction Date: January 20, 1990

Space side of Trunnion

\begin{tabular}{|c|c|c|}
\hline Sample & \multicolumn{2}{|c|}{$\mathrm{pCI} / \mathrm{Kg}$ sample } \\
\hline $\mathrm{RH}-\mathrm{G}-\mathrm{SP}=$ & $M n-54$ & Co- 57 \\
\hline $2 / A$ & $\begin{array}{l}92.29 \\
\pm 3.65\end{array}$ & $\begin{array}{l}17.17 \\
\pm 2.55\end{array}$ \\
\hline $2 / B$ & $\begin{array}{l}94.92 \\
\pm 5.84\end{array}$ & $\begin{array}{l}21.96 \\
\pm 5.80\end{array}$ \\
\hline $2 / C$ & $\begin{array}{l}95.18 \\
\pm 3.10\end{array}$ & $\begin{array}{r}17.95 \\
\pm 2.33\end{array}$ \\
\hline $2 / D$ & $\begin{array}{l}95.10 \\
\pm 3.44\end{array}$ & $\begin{array}{l}19.57 \\
\pm 3.17\end{array}$ \\
\hline $3 / A$ & $\begin{array}{r}89.38 \\
\pm 3.07\end{array}$ & $\begin{array}{l}14.52 \\
\pm 2.05\end{array}$ \\
\hline $3 / B$ & $\begin{array}{l}77.10 \\
\pm 4.60\end{array}$ & $\begin{array}{r}15.05 \\
\pm 3.15\end{array}$ \\
\hline $3 / C$ & $\begin{array}{l}85.60 \\
\pm 2.55\end{array}$ & $\begin{array}{l}14.68 \\
\pm 1.72\end{array}$ \\
\hline $3 / D$ & $\begin{array}{l}83.24 \\
\pm 2.77\end{array}$ & $\begin{array}{r}14.78 \\
\pm 1.88\end{array}$ \\
\hline
\end{tabular}

Earth side of Trunnion

$\frac{\text { Sample }}{\underline{\mathrm{RH}-\mathrm{G}-\mathrm{ER}-}} \frac{\mathrm{pCI} / \mathrm{Kg} \text { Sample }}{\mathrm{Mn}-54 \quad \underline{\mathrm{CO}-57}}$

$\begin{array}{lrr}2 / A & 105.39 & 21.19 \\ & \pm 3.65 & \pm 2.98 \\ 2 / B & 91.53 & 13.81 \\ & \pm 6.20 & \pm 4.03 \\ 2 / C & 101.83 & 18.58 \\ & \pm 3.14 & \pm 2.40 \\ & & \\ 2 / D & 98.46 & 17.50 \\ & \pm 3.60 & \pm 2.51\end{array}$

$\begin{array}{lll}3 / A & 98.05 & 15.40 \\ & \pm 2.69 & \pm 2.25 \\ 3 / B & & \\ & 89.20 & 14.63 \\ & \pm 3.08 & \pm 2.52 \\ 3 / C & & \\ & 94.21 & 15.06 \\ & \pm 2.03 & \pm 1.68 \\ 3 / D & & \\ & 93.62 & 15.02 \\ & \pm 2.04 & \pm 1.69\end{array}$


Table C-2.B. (continued)

(See notes on preceding page)

Space Side of Trunnion

sample pct/Kg sample

$\underline{R H-G-S P}=\quad \mathrm{Mn}-54 \quad \mathrm{CO}-57$

$\begin{array}{lll}4 / \mathrm{A} & 79.63 & 12.82 \\ & \pm 2.10 & \pm 1.39 \\ 4 / \mathrm{B} & 75.61 & 11.14 \\ & \pm 4.02 & \pm 3.15 \\ 4 / \mathrm{C} & 78.82 & 12.55 \\ & \pm 1.80 & \pm 1.27 \\ 4 / D & 77.62 & 11.98 \\ & \pm 2.25 & \pm 1.72\end{array}$

$5 / \AA$

$73.95 \quad 11.16$

$\pm 2.04 \pm 1.61$

$5 / B$

$67.82 \quad 13.21$

$\pm 2.04 \quad \pm 1.96$

$5 / C$

$70.89 \quad 11.99$

$\pm 1.44 \pm 1.25$

$5 / D$

$\begin{array}{ll}70.89 & 12.18 \\ \pm 1.44 & \pm 1.27\end{array}$

$6 / A$

$\begin{array}{ll}72.35 & 11.27 \\ +2.09 & \pm 1.78\end{array}$

$6 / B$

$68.17 \quad 14.21$

$\pm 2.51 \pm 2.24$

$6 / C$

$70.64 \quad 12.40$

$\pm 1.61 \pm 1.39$

$6 / D$

$70.26 \quad 12.74$

$\pm 1.63 \pm 1.43$
Earth Stde of Trunnton

sample $\mathrm{pCl} / \mathrm{Ka}$ sample

RH-G-ER- $\quad M n-54 \quad$ CO-57

$\begin{array}{lll}4 / A & 91.87 & 16.79 \\ & \pm 2.43 & \pm 1.86 \\ 4 / B & & \\ & & \\ & \pm 4.78 & 18.17 \\ 4 / C & & \pm 4.02 \\ & 89.73 & 17.03 \\ & \pm 2.08 & \pm 1.69 \\ 4 / D & & \\ & 87.82 & 17.48 \\ & \pm 2.36 & \pm 2.22\end{array}$

$5 / A$

$83.31 \quad 12.17$

$\pm 2.07 \pm 1.36$

$5 / B$

$\begin{array}{ll}76.68 & 9.67\end{array}$

$\pm 2.07 \pm 1.95$

$5 / C$

$80.00 \quad 11.35$

$\pm 1.47 \pm 1.12$

$5 / D$

$80.00 \quad 10.92$

$\pm 1.47 \pm 1.19$

$6 / \mathrm{A}$

$79.36 \quad 13.05$

$\pm 2.09 \pm 1.44$

$6 / B$

$73.93 \quad 11.09$

$\pm 2.51 \pm 1.96$

$6 / C$

$77.13 \quad 12.36$

$\pm 1.60 \quad \pm 1.16$

$6 / D$

$\begin{array}{ll}76.64 & 12.07\end{array}$

$\pm 1.63 \pm 1.22$ 
Table c-2.c. Vanadium and Aluminum Bamples - 90\% HPGe Detector

Sample Measurements:
A. Label faolng away from detector
B. Label faoing detector
C. Welghted Average of $(A, B)-\left(1 / a^{2}\right)$-weighted
D. Direat Average of $(A, B)$ - even-welghted

Decay Correction Date: January 20, 1990

\begin{tabular}{ll}
\hline & Vanadium Samples \\
Sample $\frac{\text { pCI/Kg Sample }}{\text { SC-46 }}$ & \\
& \\
G12-A2-FNV/A & 16.44 \\
& \pm 1.34 \\
G12-A2-FNV/B & 15.55 \\
& \pm 2.27 \\
G12-A2-FNV/C & 16.21 \\
& \pm 1.16 \\
G12-A2-FNV/D & 16.00 \\
& \pm 1.32 \\
& \\
I-C9-V/A & 18.58 \\
& \pm 2.24 \\
I-C9-V/B & 21.90 \\
& \pm 2.02 \\
$I-C 9-V / C$ & 20.41 \\
& \pm 1.50 \\
& 20.24 \\
& \pm 1.51 \\
&
\end{tabular}

Aluminum samples

Sample pCitKq Sample

$\underline{N a-22}$
ESR-1/A $\quad 88.40$
$\pm 4.94$

ESR $-1 / B \quad 92.79$

$\pm 4.39$

ESR-1/C $\quad 90.85$

$\pm 3.28$

$E S R-1 / D \quad 90.60$

$\pm 3.31$

ESR-5/A $\quad 93.34$

$\pm 2.75$

$\mathrm{ESR}-5 / \mathrm{B} \quad 90.05$

$\pm 2.75$

ESR-5/C $\quad 91.70$

$\pm 1.94$

$E S R-5 / D \quad 91.70$

$\pm 1.94$ 
rable c-2.c. (continued)

(See notes on preceding page)

Vanadium samples

Sample $\mathrm{pCl} / \mathrm{Kg}$ sample

$50-46$

$I-F 2-V / A$

18.19

$\pm 2.54$

$I-F 2-V / B$

24.06

$\pm 4.75$

$I-F 2-V / C$

19.49

$\pm 2.24$

$I-F 2-V / D$

21.12

$\pm 2.70$

$I-H 12-V A / A$

24.07

$\pm 7.73$

$I-H 12-V A / B$

15.57

$\pm 24.49$

$\mathrm{I}-\mathrm{H} 12-\mathrm{VA} / \mathrm{C}$

23.30

$\pm 7.37$

$I-H 12-V A / D$

19.82

$+12.84$

$I-H 12-V B / A$

27.59

$\pm 7.13$

$I-H 12-V B / B$

15.58

$\pm 11.51$

$I-H 12-V B / C$

24.26

$\pm 6.06$

$I-H 12-V B / D$

2.2 .59

$\pm 6.77$

Aluminum samples

Sample $\mathrm{pCl} / \mathrm{Ka}$ sample

$\mathrm{Na}-22$

$\begin{array}{lr}\mathrm{KP}-3 / \mathrm{A} & 113.13 \\ & \pm 2.76 \\ \mathrm{KP}-3 / \mathrm{B} & 109.82 \\ & \pm 2.76 \\ \mathrm{KP}-3 / \mathrm{C} & 111.47 \\ & \pm 1.95 \\ \mathrm{KP}-3 / \mathrm{D} & 111.47 \\ & \pm 1.95\end{array}$

$\mathrm{KP}-1.0 / \mathrm{A}$

80.57

$\pm 2.76$

$K P-10 / B$

70.08

$\pm 4.41$

$K P-10 / C$

77.62

$\pm 2.34$

$K P-10 / D$

75.33

$\pm 2.60$

$$
C-14
$$


DATE

FILMED

$5104 / 92$ 
